\title{
Deep inferior epigastric artery perforator flap breast reconstruction: optimization of technique, perioperative measures, and outcomes
}

Citation for published version (APA):

Enajat, M. (2014). Deep inferior epigastric artery perforator flap breast reconstruction: optimization of technique, perioperative measures, and outcomes. [Doctoral Thesis, Maastricht University]. Maastricht University. https://doi.org/10.26481/dis.20141215me

Document status and date:

Published: 01/01/2014

DOI:

10.26481/dis.20141215me

Document Version:

Publisher's PDF, also known as Version of record

Please check the document version of this publication:

- A submitted manuscript is the version of the article upon submission and before peer-review. There can be important differences between the submitted version and the official published version of record.

People interested in the research are advised to contact the author for the final version of the publication, or visit the DOI to the publisher's website.

- The final author version and the galley proof are versions of the publication after peer review.

- The final published version features the final layout of the paper including the volume, issue and page numbers.

Link to publication

\footnotetext{
General rights rights.

- You may freely distribute the URL identifying the publication in the public portal. please follow below link for the End User Agreement:

www.umlib.nl/taverne-license

Take down policy

If you believe that this document breaches copyright please contact us at:

repository@maastrichtuniversity.nl

providing details and we will investigate your claim.
}

Copyright and moral rights for the publications made accessible in the public portal are retained by the authors and/or other copyright owners and it is a condition of accessing publications that users recognise and abide by the legal requirements associated with these

- Users may download and print one copy of any publication from the public portal for the purpose of private study or research.

- You may not further distribute the material or use it for any profit-making activity or commercial gain

If the publication is distributed under the terms of Article 25fa of the Dutch Copyright Act, indicated by the "Taverne" license above, 
The cover illustration portrayes a sculpture from ancient Mesopotamia in the Chalcolithic Period, ca. $6^{\text {th }}$ Millennium BC. Like many of the earliest female figurines, this woman is shown with large breasts, hips, and thighs. Whether images like these represented real, ideal, or divine women, their main purpose was certainly symbolic, for throughout history, even before the onset of civilization, breasts have been a symbol of femininity, fertility and nurturance. 
Deep Inferior Epigastric Artery Perforator Flap Breast Reconstruction:

Optimization of Technique, Perioperative Measures, and Outcomes

Deep Inferior Epigastric Artery Perforator Lap Borstreconstructie:

Optimalisering van Techniek, Perioperatieve Maatregelen en Postoperatieve Resultaten

\section{PROEFSCHRIFT}

Ter verkriiging van de graad van doctor aan de Universiteit Maastricht

op gezag van de Rector Magnificus

Prof.dr. L.L.G. Soete

volgens het besluit van het College van Decanen

in het openbaar te verdedigen

op maandag 15 december 2014 om 16.00 uur

$$
\text { door }
$$

\section{Morteza Enajat}

Geboren te Teheran, Iran

ISBN: 978-90-822614-3-1 


\section{Co-promotor}

Dr. M.A.M. Mureau,

Erasmus MC, Rotterdam

\section{Beoordelingscommissie}

Prof.dr. G.L. Beets, voorzitter,

AZM, Maastricht

Prof.dr. W.F.F.A. Buhre ,

Dr. E.M. Heuts,

Dr. H.A.H. Winters,

AZM, Maastricht

VUMC, Amsterdam

Prof.dr. D.J.O. Ulrich,

Radboud UMC, Nijmegen

\section{Publication of this thesis was financially supported by:}

Afdeling Plastische en Reconstructieve Chirurgie, Academisch Ziekenhuis Maastricht, NVPC, Allergan

JVPC, QuaMedical, SURE medical, BAP Medical, BlooMedical, Zeiss, Dalton Medical, Van Wijngaarden Medical, ERBE.
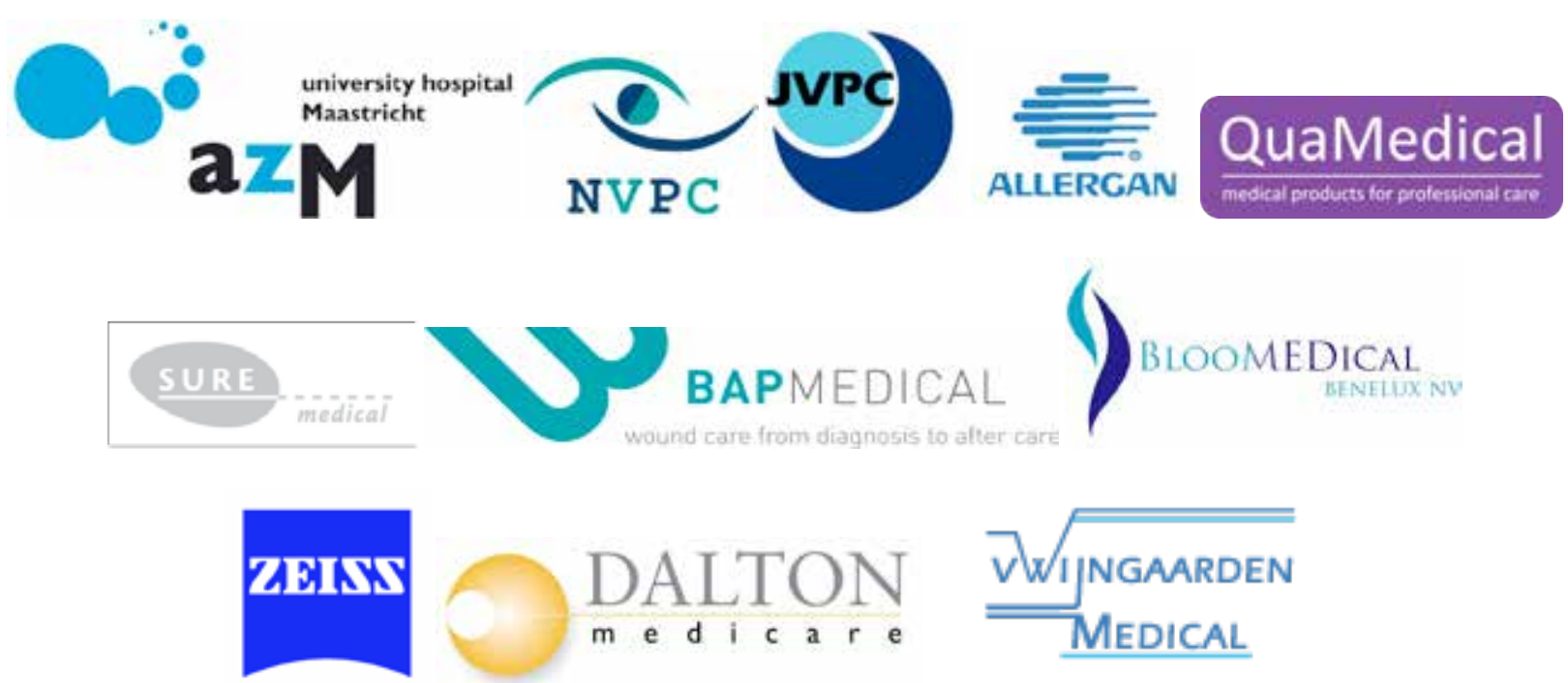

\section{ERBE}

Chapter 1

Part I: Optimization of technique

and perioperative measures

Chapter 2

Chapter 3

Chapter 4

Chapter 5

\section{Chapter 6}

Part II: optimization of surgical and aesthetic outcomes

Chapter 7

Chapter 8

Chapter 9

Chapter 10

Chapter 11

Chapter 12

Chapter 13
A single center comparison of one versus two venous anastomoses in 564 consecutive DIEP flaps: investigating the effect on venous congestion and flap survival.

Performing two DIEP flaps in a working day: an achievable and 39 reproducible practice.

The unilateral deep inferior epigastric perforator flap: comparing university to community hospital.

The effect of acetylsalicylic acid on microvascular thrombosis in $\mathbf{6 7}$ autologous breast reconstruction.

Pulmonary embolism after abdominal flap breast

reconstruction: prediction and prevention. .

Aesthetic refinements and reoperative procedures following

370 consecutive DIEP and SIEA flap breast reconstructions: important considerations for patient consent.

Self-esteem and patients' satisfaction after deep inferio epigastric perforator flap breast reconstruction.

General discussion

English summary

Nederlandse samenvattin

Appendices:

Acknowledgements

List of publications 
Breast cancer (BC) is the most common malignancy in women and is one of the leading causes of cancerrelated mortality. In the Netherlands more than 13,000 new cases of BC are diagnosed annually and 1 in 8 women is estimated to develop $B C$ during their lifetime. ${ }^{1}$ While breast conservation therapy is being applied more increasingly, mastectomy rates remain significant. About $46 \%$ of all women diagnosed with breast cancer still undergo mastectomy. ${ }^{2}$ In addition, about $33 \%$ of women with a genetic predisposition for $\mathrm{BC}$ (BRCA 1 or 2 positive) opt for prophylactic mastectomy. ${ }^{3}$

A wide range of lasting psychological disturbances have been described after mastectomy. ${ }^{4-6}$ The loss of a body part that symbolizes womanliness, sexuality, and nurturance can have a significant impact on a woman's body image and self-identity, including feelings of abnormality, depressive symptoms, loss of wholeness, and mourning for the lost breast. ' Ideally, the possibility of breast reconstruction should be offered to all women with breast cancer and those opting for prophylactic mastectomy in case of high risk for developing breast cancer. Breast reconstruction aims to diminish the negative psychological impact of mastectomy and to improve patients' quality of life. Postmastectomy breast reconstruction can significantly improve patient satisfaction, self-esteem and quality of life. ${ }^{8-12}$

Currently, the methods of reconstructive surgery comprise flap reconstruction, implant reconstruction and a combination of these procedures. Autologous breast reconstruction often provides a more pleasing aesthetic outcome than other options for breast reconstruction, because breast volume and shape can be modified based on individual needs, the texture of the reconstructed breast is a closer match to the native breast, and complications such as capsular contracture are avoided. ${ }^{8,13}$ The most commonly used flaps are taken from the abdomen: the Transverse Rectus Abdominis Myocutaneous (TRAM) and Deep Inferior Epigastric artery Perforator (DIEP) flap.

Abdominal flap breast reconstruction has evolved from TRAM flap breast reconstruction to DIEP flap breast reconstruction; it was first described in 1979 by both Robbins ${ }^{14}$ and Holmström. ${ }^{15}$ The TRAM flap involves sacrifice of an entire rectus abdominis muscle. The free muscle sparing TRAM flap which was developed in the 1980's involves sacrifice of a smaller piece of rectus abdominis muscle. ${ }^{16}$

Koshima and Soeda ${ }^{17}$ were the first to describe the possibility and harvest of a DIEP flap. Without sacrificing the rectus abdominis muscle, they isolated abdominal skin and subcutaneous tissue vascularized by the perforating vessels originating from the deep inferior epigastric artery and veins. Koshima and Soeda, however, did not use the DIEP flap for breast reconstruction. It was in 1994, that Allen and Reece described the use of the DIEP flap for breast reconstruction. ${ }^{18}$ Since that time this procedure has gained increasing popularity and has become an important option in autologous breast reconstruction. ${ }^{19-22}$ However, microsurgical breast reconstruction is a lengthy operation with significant recovery time and has the risk of major complications, including total flap loss. ${ }^{23}$ In experienced hands, free tissue transfer can be performed with success rates as high as 97 percent as defined by flap survival, but postoperative complications rates can approach 20 to 50 percent. ${ }^{24,25}$ Complications can have a negative impact on recovery time, psychological distress, and patient satisfaction. ${ }^{26-28}$

The reconstructive process consists of the preoperative planning, the reconstructive procedure itself and the postoperative phase. All stages are of importance and improvements at each stage of the reconstructive process will contribute to better postoperative outcomes.

In the planning phase, better patient selection and more thorough patient information can contribute to better postoperative results and higher patient satisfaction. Improvements in preoperative planning of the surgical procedure and better understanding of the individual anatomy of the perforators such as size, location, intramuscular and subcutaneous course are all factors that can significantly affect operative technique, length of operation, and postoperative outcomes.

During the surgical procedure itself, improvements in surgical technique and the use of technical adjuncts can improve postoperative results and reduce the risk of complications. By addressing inefficiencies at each step of the operation, operative time can be reduced significantly, thereby reducing risks of postoperative complications and also allowing more reconstructive procedures to be performed in an equal time frame. In the postoperative phase, adequate regimens of anticoagulation and thromboprophylaxis may reduce the risks of microvascular thromboembolic complications as well as deep venous thrombosis and pulmonary embolism. Finally, improvements in flap monitoring can contribute to faster identification of a compromised flap and improve flap salvage rates.

This thesis reviews a decade of efforts made to improve all of the above mentioned stages of the DIEP flap breast reconstruction procedure, and how these efforts have influenced postoperative outcomes. 


\section{Outline of this thesis}

Improvements in surgical technique and the use of technical adjuncts and innovations in DIEP flap breast reconstruction have been developed to reduce postoperative complications and to improve efficient implementation of the surgical procedure as well as patient satisfaction. The aim of this thesis was to investigate technical and perioperative improvements during the last decade, and how these improvements affect surgical as well as aesthetic outcomes after DIEP flap breast reconstruction.

Our studies were all retrospective in nature and our study groups consisted of patients who had been operated between January 2000 and January 2011 in Uppsala, Sweden as well as in Maastricht and Rotterdam, The Netherlands.

\section{PART I: Optimization of technique and perioperative measures}

\section{CHAPTER 2}

Venous complications, such as venous congestion have been reported as rather frequently encountered vascular complications seen after the transfer of DIEP flaps, possibly compromising flap viability and leading to flap failure. In an effort to minimize venous complications, the use of secondary alternate pathways in addition to the deep inferior epigastric vein for venous drainage have been described. These options, include additional venae comitantes of the ipsilateral deep inferior epigastric artery (DIEA), venae comitantes of the contralateral DIEA, the ipsilateral superficial inferior epigastric vein (SIEV) and the contralateral SIEV. All these reports comprised case reports or series of relatively low numbers, and given the low incidence of venous congestion, this has limited the formal evaluation of contributory factors for venous congestion. Therefore, we retrospectively compared the use of one venous anastomosis to two anastomoses in DIEP flap breast reconstructions and assessed the clinical outcomes, in particular rates of venous congestion and flap survival rates.

\section{CHAPTER 3}

While the DIEP flap is a reliable technique for autologous breast reconstruction, the meticulous dissection of perforators may require lengthy operative times, which limits the number of breast reconstructions that can be performed in a single working day.
In general, a surgical team performs no more than one unilateral or bilateral DIEP flap procedure during the hours of one working day. The relatively low number of autologous breast reconstructions compared to the number of mastectomies means that patients often must wait a substantial period of time before they can undergo a DIEP flap breast reconstruction. We sought to assess the feasibility of performing two DIEP flaps within the working hours of a single day. Being able to do more DIEP flaps in a single working day could eventually reduce the waiting list for patients opting for DIEP flap breast reconstruction. More efficient implementation of this procedure could reduce operation time, reduce costs and also contribute to a lower risk of postoperative complications.

\section{CHAPTER 4}

The DIEP flap breast reconstruction is a complex procedure which requires extensive experience by both the surgeon and the surgical team. After its introduction in the Netherlands this procedure was performed in the academic setting only. Gradually, DIEP flap breast reconstruction was also introduced in the community hospital setting. We evaluated and compared different outcome parameters and complications between the two hospital settings. A significant difference in outcomes between the two settings could potentially spark a discussion about centralization of this complicated procedure in more specialized academic hospitals.

However, if no significant differences in outcomes are found, DIEP flap breast reconstruction may be safely expanded to and applied in an increasing number of community hospital settings. The ensuing increase in volume of breast reconstructions performed would contribute to a shorter waiting list.

\section{CHAPTER 5}

Microvascular thrombosis remains a major concern as the primary cause of flap failure. Pharmacological prevention of thromboembolic events is an essential part of microsurgery, however, currently no evidence based thromboprophylaxis standards or algorithms exist.

Acetylsalicylic acid, or Aspirin, is a platelet aggregation inhibitor which is widely used for secondary prevention of myocardial infarction or stroke due to its ability to particularly inhibit platelet aggregation which prevents arterial occlusions. This characteristic is presumed advantageous in microvascular surgery as well. Side effects include (gastrointestinal) bleeding, gastritis, allergic reactions, and nephrotoxicity. We investigated the effect of acetylsalicylic acid on the incidence of microvascular thrombosis and the rate of 
flap failure in patients undergoing DIEP and free TRAM flap breast reconstruction. This study can contribute to the formation of evidence based guidelines on thromboprophylaxis in autologous breast reconstruction.

\section{CHAPTER 6}

Abdominal flap breast reconstruction (ABR) involves several important risk factors for venous thromboembolic events (VTE) and subsequent symptomatic pulmonary embolism (SPE). ${ }^{29}$ Total anesthesia time often exceeds six hours, especially when reconstruction is directly preceded by mastectomy (primary reconstruction). Furthermore, in primary cases after therapeutic mastectomy the presence of malignancy adds to the thrombogenic nature of the intervention. Also, an average age above 45 years in this patient population comprises a concomitant risk factor for VTE. ${ }^{30}$ The presence of sufficient abdominal fat is a prerequisite for ABR. Overweight, however, is a known risk factor for pulmonary embolism. ${ }^{31}$ Reported rates of SPE in literature vary from $0 \%$ to $6 \%{ }^{31-40}$

We assessed risk factors associated with SPE and constructed a prediction model to identify high risk patients.

\section{Part II: Optimization of surgical and aesthetic outcomes}

\section{CHAPTER 7}

Breast conservation surgery in the treatment of early stage breast cancer has become increasingly utilized as a means to avoid mastectomy. While the majority of remaining contour deficiencies after breast conservation surgery may often be cosmetically acceptable, some cases warrant consideration of reconstruction. We considered and evaluated the use of the DIEP flap for delayed reconstruction of selected larger partial mastectomy defects.

\section{CHAPTER 8}

Breast reconstruction often requires multiple operations. Next to reoperations for postoperative complications, additional procedures are frequently essential to complete the reconstructive process. These procedures aim to obtain breast symmetry, reconstruct the nipple areola complex and improve aesthetic outcome. The need for reoperation is an important part of the consultation process prior to reconstructive surgery, and patients should be informed of the need for revision surgery of both the ipsilateral and the contralateral breast as well as of the donor site. We assessed the need for additional procedures for either complications or aesthetic refinements following initial breast reconstruction.

\section{CHAPTER 9}

Breast reconstruction usually leads to improvements in different domains of psychosocial functioning. ${ }^{40-45}$ Although quality of life as an outcome measure has received much attention, the concept of self-esteem after breast reconstruction has been explored to a much lesser extent. We assessed patient satisfaction after DIEP flap breast reconstruction and assessed the impact of this procedure on self-esteem and analyzed the correlation between patient satisfaction and self-esteem using the Rosenberg self-esteem scale.

\section{Aims of this thesis}

In conclusion, the aims of this thesis are:

\section{Part l: Optimization of technique and perioperative measures}

1- To investigate the effect of venous augmentation on venous congestion and DIEP flap survival.

2- To assess the feasibility of performing two DIEP flaps within the working hours of a single day.

3- To compare the results of DIEP flap surgery in the university versus community hospital.

4- To investigate the effect of acetylsalicylic acid on microvascular thrombosis.

5- To assess the risk of pulmonary embolism after DIEP flap breast reconstruction and to develop preliminary prediction model which could predict this complication.

\section{Part II: Optimization of surgical and aesthetic outcomes}

6- To evaluate the application of the DIEP flap in reconstruction of large partial mastectomy defects.

7- To review all aesthetic refinements and re-operative procedures after DIEP flap breast reconstruction.

8- To investigate self-esteem and patient satisfaction after DIEP flap breast reconstruction. 


\section{REFERENCES}

1. www.iknl.nl. Integraal Kankercentrum Nederland, 2012

2. Struikmans H, Aarts, MJ, Jobsen JJ, et al. An increased utilisation rate and better compliance to guidelines for primary radiotherapy for breast cancer from 1997 till 2008: a population-based study in the Netherlands. Radiother Oncol 2011:100: 320-325.

3. Metcalfe KA, Birenbaum-Carmeli D, Lubinski J, et al. International variation in rates of uptake of preventive options in BRCA1 and BRCA2 mutation carriers. Int J Cancer 2008;122: 2017-2022.

4. Gopie JP, Vasen HF, Tibben A. Surveillance for hereditary cancer: does the benefit outweigh the psychological burden? A systematic review. Crit Rev Oncol Hematol 2012; 83: 329-340.

5. Gopie JP, Mureau MA, Seynaeve C, et al. Body image issues after bilateral prophylactic mastectomy with breast reconstruction in healthy women at risk for hereditary breast cancer. Fam Cancer 2013; 12: 479-487.

6. Bard M, Sutherland AM. Psychological impact of cancer and its treatment. IV. Adaptation to radical mastectomy. Cancer 1955;8: 656-672.

7. Gopie JP. The psychological impact of breast reconstruction after prophylactic or therapeutic mastectomy for breast cancer. Thesis, Leiden, January 2013.

8. Damen TH, Timman R, Kunst EH, et al. High satisfaction rates in women after DIEP flap breas reconstruction. J Plast Reconstr Aesthet Surg 2010;63: 93-100.

9. Markopoulos C, Tsaroucha AK, Kouskos E, et al. Impact of breast cancer surgery on the self-esteem and sexual life of female patients. J Int Med Res 2009;37: 182-188.

10. Rubino C, Figus A, Lorettu L, et al. Post-mastectomy reconstruction: a comparative analysis on psychosocial and psychopathological outcomes. J Plast Reconstr Aesthet Surg 2007;60: 509-518.

11. Sabino NM, da Silva AL, Garcia EB, et al. Quality of life and self-esteem after breast asymmetry surgery. Aesthet Surg J 2007;27: 616-621.
12. Veiga DF, Veiga-Filho J, Ribeiro LM et al. Quality-of-life and self-esteem outcomes after oncoplastic breast-conserving surgery. Plast Reconstr Surg 2010;125: 811-817.

13. Rozen WM, Ashton MW. Improving outcomes in autologous breast reconstruction. Aesthet Plast Surg 2009;33: 327-335.

14. Robbins TH. Rectus abdominis myocutaneous flap for breast reconstruction. AN Z J Surg 1979;49: 527 530

15. Holmstrom $\mathrm{H}$. The free abdominoplasty flap and its use in breast reconstruction. An experimental study and clinical case report Scand J Plast Reconstr Surg 1979;13: 423-427.

16. Arnez ZM, Smith RW, Eder E, et al. Breast reconstruction by the free lower transverse rectus abdominis musculocutaneous flap. Br J Plast Surg 1988;41: 500-505

17. Koshima I, Soeda S. Inferior epigastric artery skin flaps without rectus abdominis muscle. Br J Plast Surg 1989;42: 645-648.

18. Allen RJ, Treece P.Deep inferior epigastric perforator flap for breast reconstruction. Ann Plast Surg 1994;32: 32-38.

19. Blondeel PN. One hundred free DIEP flap breast reconstructions: a personal experience. Br J Plast Surg 1999;52: 104-111.

20. Busic V, Das-Gupta R, Mesic H, et al. The deep inferior epigastric perforator flap for breast reconstruction, the learning curve explored. J Plast Reconstr Aesthet Surg 2006;59: 580-584.

21. Gill PS, Hunt JP, Guerra AB, et al. A 10-year retrospective review of 758 DIEP flaps for breast reconstruction. Plast Reconstr Surg 2004;113: 1153-1160.

22. Acosta R, Enajat $M$, Rozen WM, et al. Performing two DIEP flaps in a working day: an achievable and reproducible practice. J Plast Reconstr Aesthet Surg 2010;63: 648-654. 
23. Vega S, Smartt JM, Jr, Jiang S, et al. 500 Consecutive patients with free TRAM flap breast reconstruction: a single surgeon's experience. Plast Reconstr Surg 2008;122: 329-339.

24. Selber JC, Kurichi JE, Vega SJ, et al. Risk factors and complications in free TRAM flap breast reconstruction. Ann Plast Surg 2006; 56: 492-497.

25. Hofer SO, Damen TH, Mureau MA, et al. A critical review of perioperative complications in 175 free deep inferior epigastric perforator flap breast reconstructions. Ann Plast Surg 2007;59: 137-142.

26. Momoh AO, Colakoglu S, Westvik TS, et al. Analysis of complications and patient satisfaction in pedicled transverse rectus abdominis myocutaneous and deep inferior epigastric perforator flap breast reconstruction. Ann Plast Surg 2012; 69: 19-23.

27. Colakoglu S, Khansa I, Curtis MS, et al. Impact of complications on patient satisfaction in breast reconstruction. Plast Reconstr Surg 2011;127: 1428-1436

28. Gopie JP, Timman R, Hilhorst MT, et al. The short-term psychological impact of complications after breas reconstruction. Psychooncology 2013;22: 290-298.

29. Lemaine V, McCarthy C, Kaplan K, et al. Venous thromboembolism following microsurgical breast reconstruction: an objective analysis in 225 consecutive patients using low-molecular-weight heparin prophylaxis. Plast Reconstr Surg 2011;127: 1399-1406.

30. Geerts WH, Pineo GF, Heit JA, et al. Prevention of venous thromboembolism: the Seventh ACCP Conference on Antithrombotic and Thrombolytic Therapy. Chest 2004;126: 338S-400S.

31. Lee SH, Lee TJ, Eom JS, et al. Incidence and risk factors of pulmonary thromboembolism in pedicled TRAM breast reconstruction. J Korean Soc Plast Reconstr Surg 2006 ;33: 193-197.

32. Mehrara BJ, Santoro, TD, Arcilla E, et al. Complications after microvascular breast reconstruction experience with 1195 flaps. Plast Reconstr Surg 2006;118: 1100-1109.

33. Olsson EH, Tukiainen E, Three-year evaluation of late breast reconstruction with a free transverse rectus abdominis musculocutaneous flap in a county hospital in Sweden: a retrospective study. Scand J Plast Reconstr Surg Hand Surg 2005;39: 33-38.
34. Wang $\mathrm{HT}$, Hartzell T, Olbrich KC, et al. Delay of transverse rectus abdominis myocutaneous flap reconstruction improves flap reliability in the obese patient. Plast Reconstr Surg 2005;116: 613-618.

35. Gabbay JS, Eby JB, Kulber DA. The midabdominal TRAM flap for breast reconstruction in morbidly obese patients. Plast Reconstr Surg 2005;115: 764-770.

36. Hamdi M, Blondeel P, Van LK, et al. Bilateral autogenous breast reconstruction using perforator free flaps: a single center's experience. Plast Reconstr Surg 2004;114: 83-89.

37. Hartrampf CR, Jr. The transverse abdominal island flap for breast reconstruction. A 7-year experience. Clin Plast Surg 1988;15: 703-716

38. Spear SL, Ducic I, Cuoco F, et al. The effect of smoking on flap and donor-site complications in pedicled TRAM breast reconstruction. Plast Reconstr Surg 2005;116: 1873-1880.

39. Hofer SO, Damen TH, Mureau MA, et al. A critical review of perioperative complications in 175 free deep inferior epigastric perforator flap breast reconstructions. Ann Plast Surg 2007;59: 137-142.

40. Spear SL, Ducic I, Cuoco F, et al. Effect of obesity on flap and donor-site complications in pedicled TRAM flap breast reconstruction. Plast Reconstr Surg 2007;119: 788-795.

41. Visser NJ, Damen TH, Timman R, et al. Surgical results, aesthetic outcome, and patient satisfaction after microsurgical autologous breast reconstruction following failed implant reconstruction. Plast Reconstr Surg 2010;126: 26-36.

42. Anderson SG, Rodin J, Ariyan S.Treatment considerations in postmastectomy reconstruction: their relative importance and relationship to patient satisfaction. Ann Plast Surg 1994;33: 263-270.

43. Nano MT, Gill PG, Kollias J, et al. Qualitative assessment of breast reconstruction in a specialist breast unit. ANZ J Surg 2005;75: 445-453.

44. Noyan MA, Sertoz OO, Elbi H, et al. Variables affecting patient satisfaction in breast surgery: a crosssectional sample of Turkish women with breast cancer. Int J Psychiatry Med 2006;36: 299-313. 
45. Pikler V, Winterowd C. Racial and body image differences in coping for women diagnosed with breast

cancer. Health Psychol 2003;22: 632-637. 


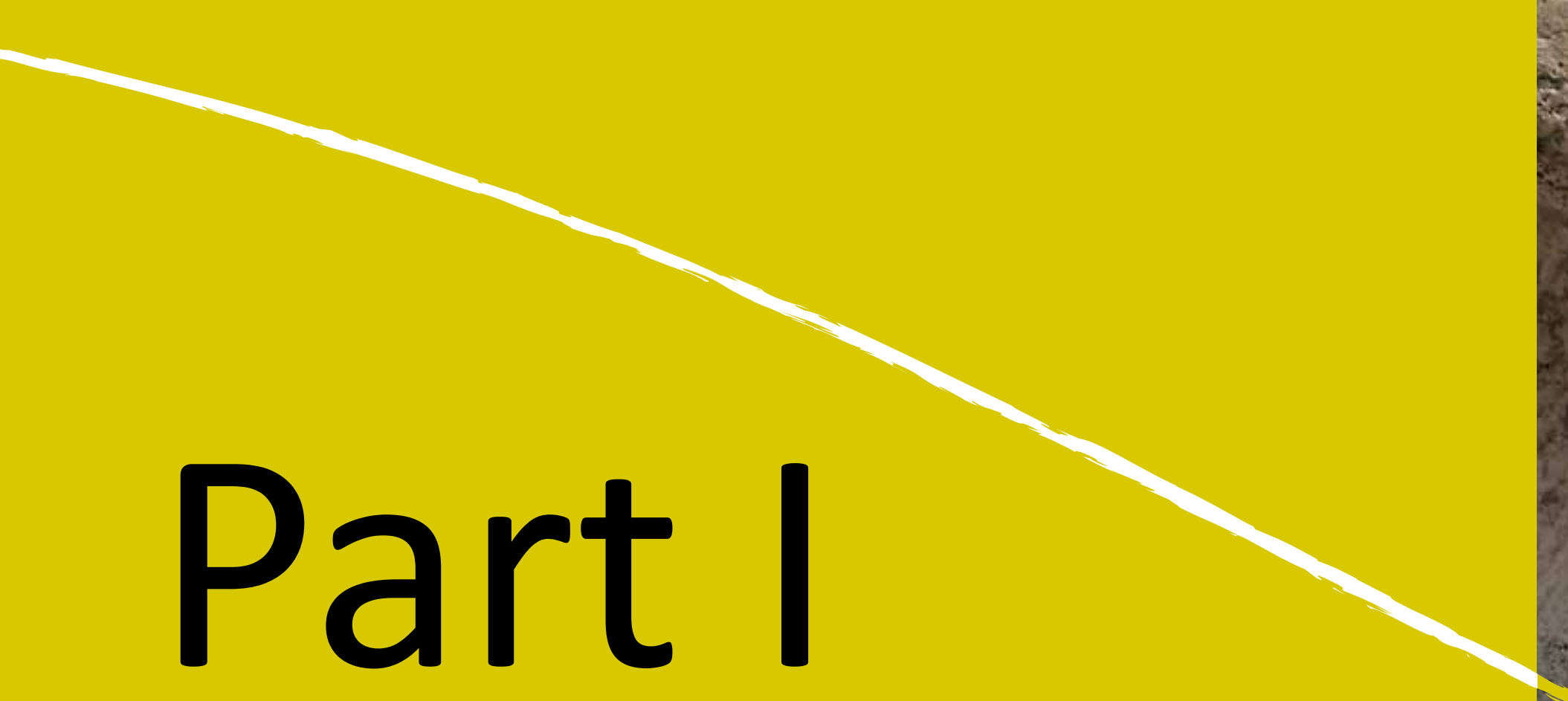

\section{Optimization of technique and perioperative measures}

A Single Center Comparison Of One Versus Two Venous Anastomoses In 564 Consecutive Diep Flaps: Investigating The Effect On Venous Congestion And Flap Survival

Enajat M, Rozen WM, Whitaker IS, Smit JM, Acosta R. 


\section{Background}

Venous complications have been reported as the more frequently encountered vascular complications seen in the transfer of deep inferior epigastric artery (DIEA) perforator (DIEP) flaps, with a variety of techniques described for augmenting the venous drainage of these flaps to minimize venous congestion. The benefits of such techniques have not been shown to be of clinical benefit on a large scale due to the small number of cases in published series.

\section{Methods}

A retrospective study of 564 consecutive DIEP flaps at a single institution was undertaken, comparing the prospective use of one venous anastomosis (273 cases) to two anastomoses (291 cases). The secondary donor vein comprised a second DIEA venae commitante in $7.9 \%$ of cases and a superficial inferior epigastric vein (SIEV) in $92.1 \%$. Clinical outcomes were assessed, in particular rates of venous congestion.

\section{Results}

The use of two venous anastomoses resulted in a significant reduction in the number of cases of venous congestion to zero ( 0 vs. $7, P=0.006$ ). All other outcomes were similar between groups. Notably, the use of a secondary vein did not result in any significant increase in operative time (385 minutes vs. 383 minutes, $\mathrm{P}=$ $0.57)$.

Conclusions

The use of a secondary vein in the drainage of a DIEP flap can significantly reduce the incidence of venous congestion, with no detriment to complication rates. Consideration of incorporating both the superficial and deep venous systems is an approach that may further improve the venous drainage of the flap.

\section{INTRODUCTION}

While the deep inferior epigastric artery perforator (DIEP) flap is a reliable choice of flap for breast reconstruction, with low rates of complications reported, venous complications continue to be described. In many large series, these have been the more frequently encountered vascular complications seen, with many authors describing insufficient venous drainage requiring reoperation in up to $5 \%$ of flaps and venous congestion in as many as $10 \%$ of flaps..$^{1-3}$ These studies have postulated that the DIEP flap is drained by an intricate network of deep and superficial veins, and that in select cases, the chosen perforating vein may not adequately drain the flap. While some venous complications are related to microsurgical problems (such as venous thrombosis), venous congestion is often due to the intrinsic anatomy of flap vasculature and flap design. While a functioning venous pedicle needs to be evaluated in such cases to exclude a microvascular complication, some cases are due to a relative inadequacy of venous drainage of some regions of the flap. In a move to minimize venous complications, the use of secondary alternate pathways in addition to the deep inferior epigastric vein (DIEV) for venous drainage has been described, albeit usually performed after venous congestion has already occurred. These options, described for augmenting or supercharging the venous drainage of congested flaps, have been broad, with the methods used comprising additional venae comitantes of the ipsilateral DIEA, ${ }^{4,5}$ venae comitantes of the contralateral DIEA, ${ }^{6}$ the ipsilateral superficial inferior epigastric vein (SIEV), ${ }^{2,3,7}$ and the contralateral SIEV. ${ }^{8}$ These reports have all comprised case reports or series of relatively low numbers, and given the low incidence of venous congestion, this has limited the formal evaluation of contributory factors for venous congestion. Despite the lack of clinical studies, experimental studies in rats have shown that the use of additional routes of venous drainage can have a statistically significant benefit, with a correlation shown between the number of venous outflow routes and survival in abdominal flaps. ${ }^{9-12}$ Inclusion of the SIEV as an alternative venous outflow tract further increased flap survival by almost $20 \% .{ }^{10}$ While these animal studies have yielded promising results, there has not been a clinical study to formally evaluate the effects of applying more than one route of venous drainage to DIEP flaps to minimize venous congestion. Anecdotally, many surgeons routinely dissect out secondary veins, in case of the need for their future use. However, the choice of vein and the routine use of such veins have not been definitively demonstrated. In addition, these studies vary in their accounts of the dominant venous drainage of the lower abdominal integument, with the SIEV largely thought to be the dominant venous drainage route, and through communications with DIEA perforators, the DIEA can vary in its venous dominance. As such, this study comprised a clinical study to compare the use of one vs. two veins for the drainage of a DIEP flap. 


\section{METHODS}

A retrospective study was undertaken for patients having undergone DIEP flap breast reconstructions during the period of January 2000 to September 2008. This was a consecutive series, with all operations undertaken by a single reconstructive surgical unit, of four core surgeons. The only exclusion criterion was flaps that were supplied by more than one artery (stacked or bipedicled flaps). All flaps were fasciocutaneous, included no rectus muscle, and were raised on a single DIEA. Recorded data comprised patient demographics, operation details, complications, implementation of secondary venous outflow routes, and details of the vascular basis for flap supply and drainage. Patients were stratified into two groups according to the number of veins used for venous drainage (one vs. two). Complications were compared, as well as differences in operative time. Uniform Surgical Technique Preoperative imaging was performed in all cases, with Doppler ultrasound performed before April 2006, and computed tomographic angiography (CTA) utilized thereafter. Both methods were used to map both arterial and venous anatomy preoperatively. Intraoperatively, the dissection and preservation of a length of the superficial inferior epigastric veins bilaterally was routinely performed. The flap was routinely harvested based on the single largest periumbilical perforator identified on imaging ( $97 \%$ of cases). Where this was not appropriate ( $3 \%$ of cases), two perforators were utilized in supply to the flap. Flap harvest and exposure of recipient vessels were performed simultaneously, and in al cases, the primary recipiënt vein of choice was the internal mammary vein. Where this was insufficient or inappropriate based on individual surgeon opinion, other sources were selected. The decision to use an alternative (secondary) source of venous drainage was made based upon individual surgeon preference, with factors influencing this decision including a good match of two donor and recipient veins, the presence of a subjectively enlarged (greater than $1.5 \mathrm{~mm}$ ) SIEV, a subjectively engorged (tense and dilated) SIEV, or in the presence of frank venous congestion during flap harvest or flap in-setting (where pedicle flow continuity was confirmed to be present). The donor vessel of choice was the SIEV, to achieve venous flow through both deep and superficial venous territories, with a second DIEV (DIEA concomitant vein) as an alternative option. The contralateral SIEV was the preferred choice of vessel ( $97 \%$ of cases), however, where inappropriate (inadequate size or absent vessel, or in bilateral reconstructions), the ipsilateral SIEV was used (3\% of cases). Where an SIEV was used, the cephalic vein was used as the recipient vessel of choice, harvested through a small incision in an anterior axillary skin crease with minimal operative time or scarring (Fig. 1). Venous anastomoses were performed with anastomotic devices that achieve fast anastomotic times: either "Anastoclip" Vascular Closure Staples (VCS) microstaple clips (AnastoClip Vessel Closure System, Le Maitre Vascular Inc, Sulzbach, Germany) or a microvascular anastomotic coupling device (Microvascular
Chapter 2 A single center comparison of one versus two venous anastomoses in 564 consecutive diep flaps: Investigating The effect on venous congestion and flap survival.

Anastomotic Coupling System, Synovis Micro Companies Alliance Inc, St Paul, MN). Flaps were monitored postoperatively with the use of the Cook-Swartz implantable Doppler probe (Cook Medical ${ }^{\circledR}$, Cook Ireland Ltd, Limerick, Ireland), in which an implantable Doppler probe is wrapped around the venous pedicle following successful venous anastomosis. Venous application of the probe was performed in concordance with both manufacturer and literature specifications, as this will monitor both arterial and venous flow-if arterial flow ceases, venous flow will cease shortly thereafter, providing a monitor for both pedicles. Where there were two venous pedicles, probes were applied to each pedicle. The Cook-Swartz probe was used as the primary monitoring technique, with flaps assessed routinely (half-hourly monitoring for the first postoperative day, hourly for the second day, two-hourly for the third day, and four-hourly thereafter until planned discharge on day 7), and thorough clinical assessment occuring once daily or following any detection of pedicle compromise by the probe. All blood pressures were normalized before surgery and actively managed in the perioperative period. Flaps were returned to theater for re-exploration if

there were clinical or Doppler evidence of pedicle compromise, or if there was venous congestion of uncertain significance. Venous congestion was defined as the presence of signs of venous congestion (i.e., brisk capillary refill or bleeding, or deep blue color of the flap or draining blood). In such cases, re-exploration of the flap and pedicle was undertaken, and if pedicle compromise was identified (thrombosis or kinking) this was managed directly. If there was relative venous congestion in the presence of a patent venous pedicle, augmentation of venous outflow was attempted to be achieved with the inclusion of a secondary venous pedicle. Venous congestion was noted regardless of outcome at re-exploration.

\section{Statistical Analysis}

Data was presented as means, and given with standard deviations and ranges. The distribution of data was skewed and did not normalize after sequential root transformations or log transformations. The Mann-

Whitney $\mathrm{U}$ test was used for the statistical analysis of nonparametric continuous data. Nominal data was analyzed with Fisher's exact test. Significance was set at $P<0.05$. Analyses were performed using Statistical Package For Social Sciences (SPSS) for Windows version 16.0 (SPSS Inc., Chicago, IL). 


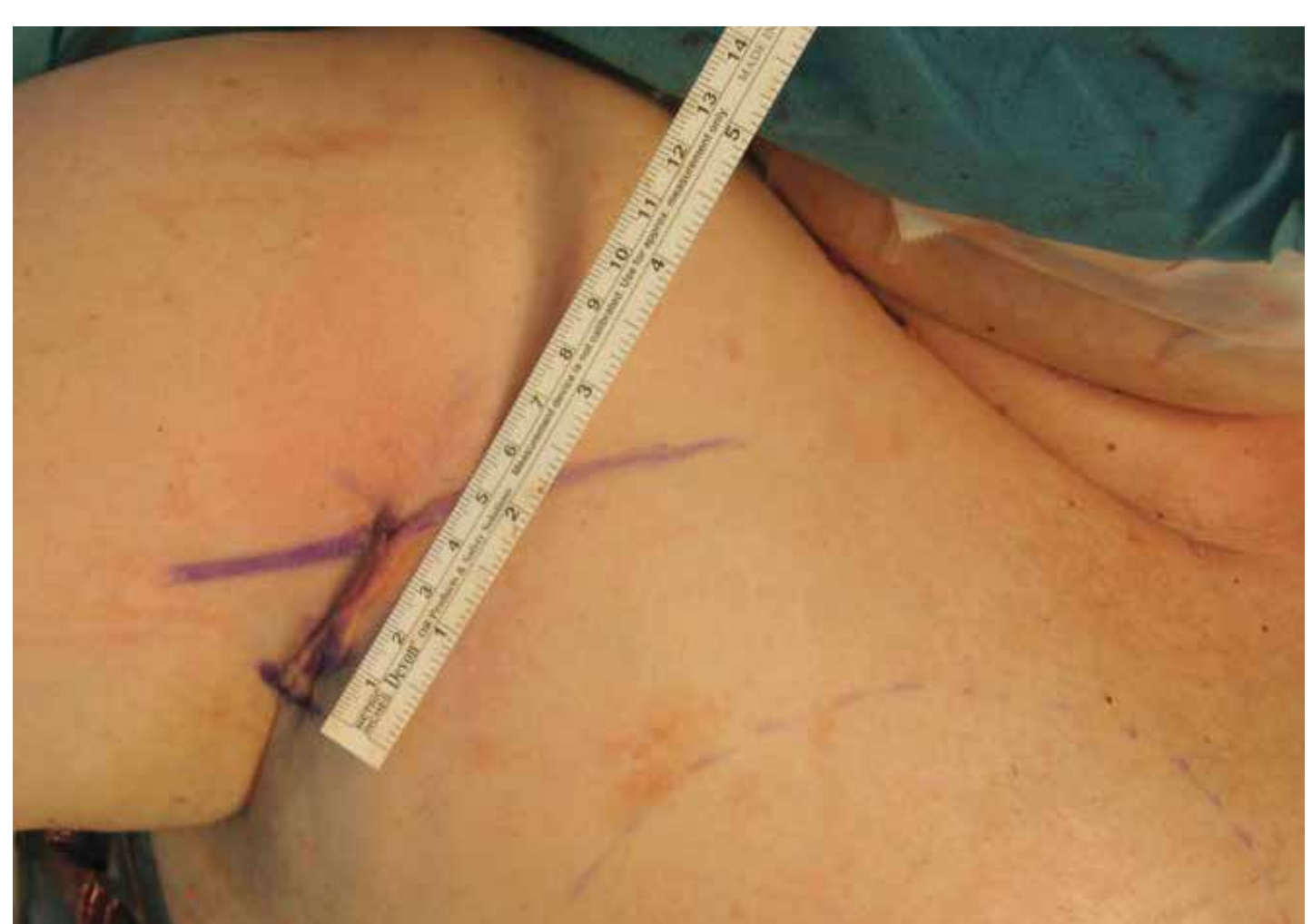

Figure 1. Intraoperative photograph following cephalic vein harvest, demonstrating a short scar in an anterior axillary skin crease.

\section{RESULTS}

A total of 564 DIEP flap breast reconstructions were performed in 501 patients, with 438 unilateral and 63 bilateral reconstructions. Of these, 273 breast reconstructions were performed in which only a single venous outflow route was implemented, and 291 cases had two veins used primarily for venous outflow (for the reasons listed in the Methods section). The patients in each of these groups were similar (Table 1), with similar comorbidites and were of similar age. The two-vein group had more unilateral reconstructions, and less immediate reconstructions, but these were not clinically significant.

The DIEV was the primary source of venous drainage in all cases (Table 2), and for secondary venous drainage, the SIEV was used most commonly $(92.1 \%)$, followed by a second DIEV (7.9\%). In the vast majority of cases where an SIEV was used, the cephalic vein was harvested as the recipient vein for these anastomoses ( $82.8 \%$ overall). There were no differences in outcomes when each of these venous outflow routes were compared for venous congestion (0 cases in either group).
Chapter 2 . A single center comparison of one versus two venous anastomoses in 564 consecutive diep flaps: Investigating The effect on venous congestion and flap surviva.

Table 1. Demographics and operative details for each of the two groups, comparing the use of one venous anastomosis to two venous anastomoses

One-vein group

Two-vein group

Pvalue

\begin{tabular}{llll}
$\begin{array}{l}\text { Mean age at breast reconstruction (years) } \\
\text { Risk factors (n) }\end{array}$ & 49.6 (SD 5 9.4) Range: 20-72 & 51.5 (SD 5 7.9) Range: 28-73 & $0.063 a$ \\
$\quad$ Previous stroke or myocardial infarction & $2 / 230$ & $2 / 271$ & $0.86 b$ \\
$\quad$ Type 2 diabetes mellitus & $4 / 230$ & $2 / 271$ & $0.30 b$ \\
$\quad$ Hypertension & $12 / 230$ & $28 / 271$ & $0.038 b$ \\
$\quad$ Corticosteroids & $7 / 230$ & $5 / 271$ & $0.37 b$ \\
Nature of reconstruction (n) & & & \\
$\quad$ Immediate reconstruction & $51 / 273$ & $27 / 291$ & $0.022 b$ \\
$\quad$ Delayed reconstruction & $222 / 273$ & $264 / 291$ & $0.022 b$ \\
$\quad$ Unilateral reconstruction & $188 / 230$ & $249 / 271$ & $0.001 b$ \\
$\quad$ Bilateral reconstruction & $42 / 230$ & $22 / 271$ & $0.001 b$ \\
Operation details (minutes) & & & \\
$\quad$ Mean ischemia time & 68.3 (SD 5 25.2) Range: 31-217 & 67.6 (SD 5 22.7) Range: $31-158$ & $0.712 a$ \\
$\quad$ Procedure time: all procedures & 383 (SD 5 122) range: $165-740$ & 385 (SD 5 118) range: $170-730$ & $0.57 a$ \\
$\quad$ Procedure time: unilateral reconstruction & 343 (SD 5 102) range: 165-670 & 355 (SD 5 110) range: $170-730$ & $0.33 a$ \\
$\quad$ Procedure time: bilateral reconstruction & 473 (SD 5 118) range: 285-740 & 487 (SD 5 94) range: $305-680$ & $0.24 a$ \\
\hline \hline
\end{tabular}

$S D$, standard deviation

a Two tailed Mann-Whitney $\cup$ test.

b Fisher's exact test.

Of note, the use of a secondary vein did not result in any increase in operative time (385 minutes vs. 383 minutes, $P=0.57)$. Of the 273 flaps in which a single vein was used, seven flaps demonstrated venous congestion on clinical examination postoperatively. Of the other 291 flaps, which received an additional vein during initial breast reconstruction, no flaps demonstrated any signs of venous congestion. This decrease in the rate of venous congestion with the use of two veins was statistically significant, $P=0.006$ (Table 3). Of the seven congested flaps, five were due to venous thrombosis and two were due to relative venous congestion with no pedicle compromise. All cases of venous congestion were taken back to theater for reexploration, and all cases of pedicle compromise were taken back to theater for re-exploration, with the ultimate cause for compromise identified in theater. Other complications were statistically similar between the groups, including complete flap failures (due to either arterial or venous thrombosis), partial flap losses, arterial or venous complications, and overall take-backs. Notably, while there were five cases of venous thrombosis in each group, all cases in which venous thrombosis did occur in the one-vein group resulted in global venous congestion identified on examination $(5 / 5=100 \%)$, however, in the two-vein group, venous thrombosis in a single vein (identified with the implantable Doppler probe) did not result in any clinical 
suggestion of venous congestion in any cases $(0 / 5=0 \%)$. There were no cases in which venous thrombosis occurred in both veins in the two-vein group. In the two-vein group, venous thrombosis was identified with the implantable Doppler probe and findings at theater, rather than the clinical manifestations of venous

failure. Of the cases of venous thrombosis, one case of venous thrombosis resulted in complete flap failure in the one-vein group (1/5 $520 \%$ ), whereas no cases resulted in complete flap failure in the two-vein group (0/5 $50 \%)$. All other cases of complete failure flap were due to arterial thrombosis.

Table 2. Vascular anatomy of the flaps, comparing the use of

one venous anastomosis to two venous anastomoses

\begin{tabular}{lll}
\hline & One-vein group & Two-vein group \\
\hline \hline Primary recipient artery (n/\%) & & \\
Internal mammary artery & $158 / 273(57.9 \%)$ & $244 / 291(83.8 \%)$ \\
Circumflex scapular artery & $99 / 273(36.3 \%)$ & $41 / 291(14.1 \%)$ \\
Thoracodorsal artery & $4 / 273(1.5 \%)$ & $6 / 291(2.1 \%)$ \\
$\quad$ Thoracoacromial artery & $10 / 273(3.7 \%)$ & 0 \\
Primary recipient vein (n/\%) & & \\
Internal mammary artery & $157 / 273(57.5 \%)$ & $244 / 291(83.8 \%)$ \\
Circumflex scapular artery & $97 / 273(35.5 \%)$ & $41 / 291(14.1 \%)$ \\
Thoracodorsal artery & $15 / 273(5.5 \%)$ & $6 / 291(2.1 \%)$ \\
Thoracoacromial artery & $1 / 273(0.4 \%)$ & 0 \\
Cephalic artery & $1 / 273(0.4 \%)$ & 0 \\
Secondary donor vein (n/\%) & & \\
$\quad$ Deep inferior epigastric vein & - & $23 / 291(7.9 \%)$ \\
Superficial inferior epigastric vein & - & $268 / 291(92.1 \%)$ \\
Secondary recipient vein (n/\%) & & \\
$\quad$ Internal mammary & - & $28 / 291(9.6 \%)$ \\
Circumflex scapular & - & $11 / 291(3.8 \%)$ \\
Thoracodorsal & - & $11 / 291(3.8 \%)$ \\
$\quad$ Cephalic & - & $241 / 291(82.8 \%)$ \\
\hline \hline
\end{tabular}

Chapter 2 . A single center comparison of one versus two venous anastomoses in 564 consecutive diep flaps:

$$
\text { Investigating The effect on venous congestion and flap survival. }
$$

Table 3. Operative complications, comparing the use of one venous anastomosis to two venous anastomoses

\begin{tabular}{lllc} 
& One-vein group & Two-vein group & P value \\
\hline \hline $\begin{array}{l}\text { Overall take-backs/reoperations (n/\%) } \\
\text { Venous congestion ( } \mathrm{n} / \%)\end{array}$ & $38 / 273(14 \%)$ & $48 / 291(16 \%)$ & 0.44 \\
$\quad$ & & & \\
$\quad$ Overall venous congestion & $7 / 273(2.6 \%)$ & $0 / 291(0 \%)$ & 0.006 \\
$\quad$ Venous congestion due to venous thrombosis & $5 / 7(71 \%)$ & - & - \\
$\quad$ Venous congestion due to relative venous insufficiency & $2 / 7(29 \%)$ & - & - \\
Vascular complications (n/\%) & & & \\
$\quad$ Arterial thrombosis & $10 / 273(4 \%)$ & $8 / 291(3 \%)$ & 0.54 \\
$\quad$ Venous thrombosis & $5 / 273(2 \%)$ & $5 / 291(2 \%)$ & 0.92 \\
Flap loss (n/\%) & & & \\
$\quad$ Overall complete flap loss & $5 / 273(2 \%)$ & $6 / 291(2 \%)$ & 0.38 \\
$\quad$ Complete flap loss due to venous thrombosis & $1 / 5(20 \%)$ & $0 / 6(0 \%)$ & 0.45 \\
$\quad$ Complete flap loss due to arterial thrombosis & $4 / 5(80 \%)$ & $6 / 6(100 \%)$ & 0.45 \\
$\quad$ Partial flap loss & $2 / 273(0.7 \%)$ & $2 / 291(0.7 \%)$ & 0.98 \\
Other complications (n/\%) & & & \\
$\quad$ Hematoma & $23 / 273(8 \%)$ & $21 / 291(7 \%)$ & 0.58 \\
$\quad$ Infection & $23 / 273(8 \%)$ & $37 / 291(13 \%)$ & 0.16 \\
$\quad$ Fat necrosis & $31 / 273(11 \%)$ & $25 / 291(9 \%)$ & 0.26 \\
$\quad$ Seroma & $2 / 273(0.7 \%)$ & $9 / 291(3 \%)$ & 0.08 \\
\hline \hline
\end{tabular}

Tests performed using Fisher's exact test.

DISCUSSION

This study has demonstrated that by prospectively embarking on a second venous anastomosis, the venous drainage of a free flap can be significantly improved, reducing the incidence of venous congestion. The study has also demonstrated that this can be readily achieved, without any demonstrable increase in operative times if planned effectively. In our series of over 500 DIEP flaps, we have reduced our venous congestion rate to zero if a secondary vein is performed. The use of the cephalic vein as a recipient vessel as described, and the use of anastomotic devices that achieve fast anastomotic times (either "Anastoclip" Vascular Closure Staples (VCS) microstaple clips or a microvascular anastomotic coupling device, allowed us to perform a second venous anastomosis with no increase in operative time. Our use of these anastomotic procedures has been described previously, ${ }^{13}$ and it should be noted that these occurred more frequently in the latter part of the series, and thus a learning curve is certainly an important consideration in evaluating surgical times. The need to augment the venous drainage of a free flap is not new, with both the DIEV and SIEV used adjunctively to augment venous drainage of the lower abdominal wall integument (Fig. 2). 


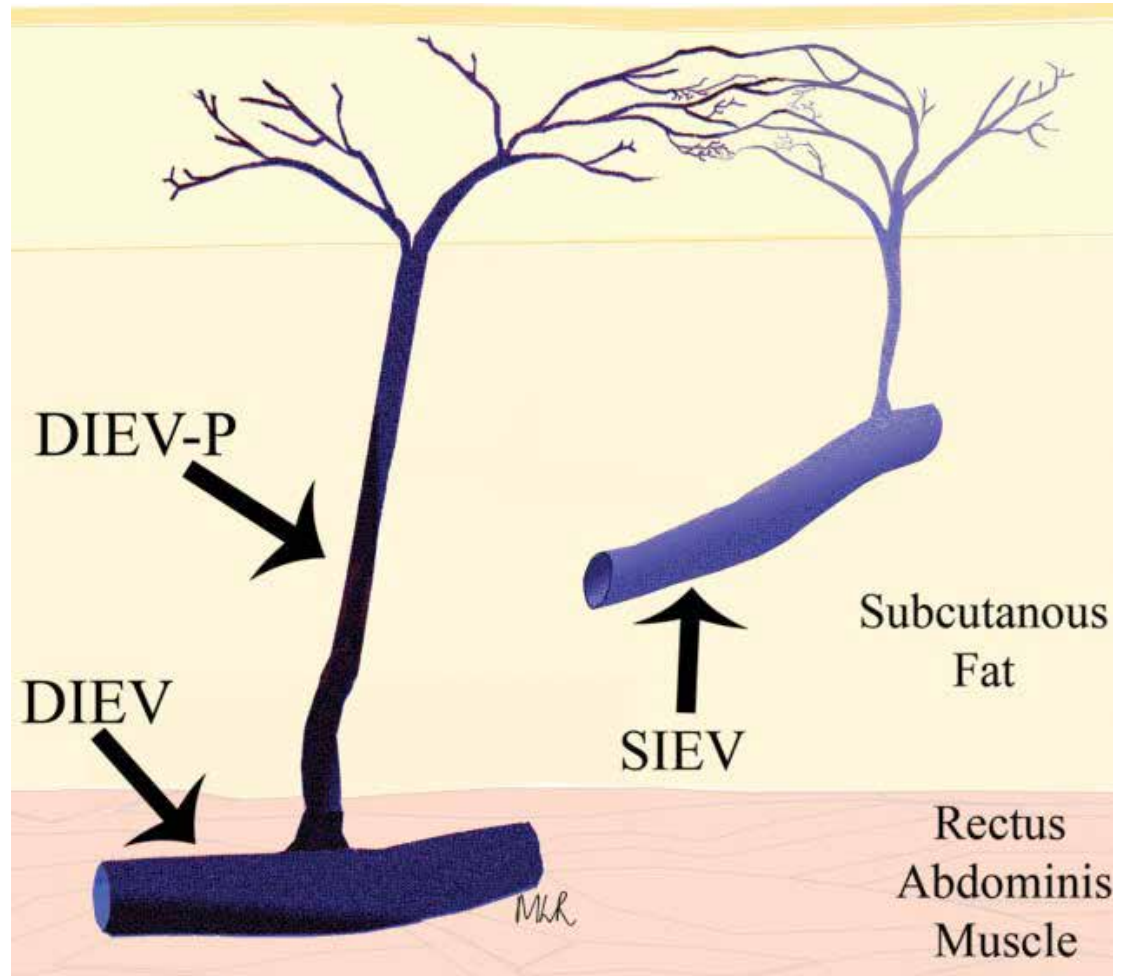

Figure 2. Representation of the venous anatomy of the anterior abdominal wall, with the subcutaneous tissues drained by both superficial and deep venous systems, the superficial inferior epigastric vein (SIEV) and the deep inferior epigastric vein (DIEV), respectively, through DIEV perforators (DIEV-P).

Previous experimental studies utilized "supercharging" techniques to improve flap survival, with both arterial supercharging ${ }^{14,15}$ and venous superdrainage $e^{9,11,16-18}$ both shown to be of benefit in reducing reoperative rates. Inadequate venous outflow particularly has been shown to incrementally reduce the chance of flap survival when compared with arterial failure. ${ }^{19,20}$ The limitation of all of these previous studies is the low incidence of venous complications in DIEP flap surgery, and the resultant difficulty in evaluating these small numbers. Our series of 564 DIEP flaps revealed only seven cases of venous congestion, highlighting this difficulty. Despite this, the statistical significance between groups was clear. While venous pedicle flow is essential for global venous drainage, relative venous insufficiency can ensue despite a patent venous pedicle. The venous drainage of a DIEP flap depends on the volume of supply by the DIEV and is thus dependant on the intrinsic individual vascular anatomy of the flap and on flap design. In some cases, there is inadequate drainage of some regions of the flap, leading to venous congestion. The physiology of venous
Chapter 2. A single center comparison of one versus two venous anastomoses in 564 consecutive diep flaps: Investigating The effect on venous congestion and flap survival.

failure is also pertinent for discussion. Inadequacy of local venous outflow results in a rise of venous pressure and venous distention. With venous return stimulated by autonomic venous tone, the denervation that occurs in a free flap compounds these changes. Increasing intravascular pressure increases the filtration rates across the vessel wall leading to an almost immediate formation of edema, ${ }^{21}$ with the increased interstitial fluid impairing the diffusion of oxygen to cells. ${ }^{22,23}$ In addition, the obstruction of venous outflow results in persisting arterial inflow and the accumulation of highly unstable ogygen-derived free radicals. ${ }^{24-26}$ These free radicals have detrimental effects on tissue viability. ${ }^{24,27}$ When this is profound and prolonged as in the case of venous thrombosis, this can result in complete flap failure, as demonstrated with the $20 \%$ of venous thromboses in the one-vein group being unsalvageable. If this is less profound, as occurs in the cases of relative venous congestion, flap failure is less likely to ensue, with no such cases failing in our cohort. The DIEP flap has been reported to have rates of venous congestion as high as $8 \%{ }^{2}$ It is thought that the dependence of venous drainage of the flap on one or several perforators provides a less dependable venous drainage than the TRAM flap. ${ }^{3}$ While the use of a second DIEV has been utilized in the past, and indeed we have used it, we prefer the use of the SIEV as a secondary route for venous drainage. While the use of the SIEV as a secondary source of venous drainage has been utilized in previous clinical studies, ${ }^{2,3,7,8}$ our study has demonstrated this on a broader scale. Other more novel studies have shown that the superficial venous drainage of a flap can also be used for such techniques as for venesection in a congested flap ${ }^{28}$ or for supercharging venous drainage by anastomosis to a DIEV branch. ${ }^{29}$ Several anatomical studies of the venous drainage of the abdominal wall have suggested that it is the SIEV that is the major venous drainage to the lower abdominal wall (i.e., the DIEP flap/TRAM flap skin paddle). In addition to cadaveric studies, ${ }^{30}$ studies with advanced imaging techniques such as computed tomographic angiography (CTA) have reiterated this. ${ }^{31}$ With the venous territory of the SIEV likely to be different to that of the DIEV, it is logical that a second DIEV may not contribute to the drainage of as much additional tissue as the use of the SIEV. Other studies have also demonstrated the broad drainage basin of the SIEV, with intercommunicating vessels between both SIEVs across the midline, facilitating contralateral drainage, ${ }^{30,31}$ and perforating branches of the DIEV penetrating the rectus abdominis muscle to anastomose with the DIEV. ${ }^{30}$ However, these anatomical studies have shown that the communicating branches between the DIEV and the SIEV, the DIEV diameter, and the DIEV branching patterns may each vary considerably between different DIEVs. It is thus likely that using a second DIEV is beneficial, a result shown in our study, with no difference when each method was compared. Additionally, the SIEV traverses the inguinal lymphatics, and as such has the potential to cause lymphatic leakage, however, in our series, seroma rates were similar between groups. Larger studies would be usefu 
to evaluate this phenomenon. In our study, we selected the use of an alternative source of venous drainage based upon individual surgeon preference, with key factors influencing this decision including the ease of matching two donor and recipiënt vessels, the presence of a subjectively enlarged or engorged SIEV, or the presence of venous congestion during flap harvest or flap in-setting. Although selection based on these specific factors does incorporate some selection bias, a uniform approach to including two sources of venous drainage necessarily would include all such cases, eliminating this bias. While these measures are subjective, SIEV measurement can be performed preoperativelyon either Doppler ultrasound or with the use of CTA, which we routinely perform preoperatively. ${ }^{32,33}$ The presence of a considerably larger diameter of the SIEV compared with the DIEV has been shown to point to a dominant venous drainage by the SIEV as a drainage route for the abdominal skin paddle. ${ }^{30}$ This has been translated to sizes of $1.5-2 \mathrm{~mm}$ or greater, with prospective dissection and preservation of the SIEV suggested as a safety net for salvage of congested flaps. ${ }^{17,10}$ In addition to preoperative and intraoperative techniques for predicting venous congestion, advance postoperative monitoring techniques (such as tissue oximetry and microdialysis) can identify early venous congestion and potentiate early flap salvage. We utilized one such tool in the monitoring of venous complications, namely the Cook-Swartz implantable Doppler probe, which was able to potentiate a high salvage rate of flaps complicated by venous thrombosis. In fact, with most cases of venous thrombosis salvaged, most of the flaps that failed in our cohort were due to arterial failure.

\section{CONCLUSIONS}

The use of a secondary vein in the drainage of a DIEP flap can significantly reduce venous congestion, with its resultant interventions, with no detriment to overall complication rates. This is a particularly feasible option where the prospective harvest of a cephalic vein occurs and the use of venous anastomotic devices can aid the use of a second vein without any increase in operative times over the use of a single vein Consideration of incorporating both the superficial and deep venous systems is an approach that may furthe mprove the venous drainage of the flap. We suggest that the use of both systems of venous drainage be planned prospectively in DIEP flap transfer as a means to improving operative outcomes.
Chapter 2. A single center comparison of one versus two venous anastomoses in 564 consecutive diep flaps: Investigating The effect on venous congestion and flap survival.

\section{REFERENCES}

1. Blondeel PN. One hundred free DIEP flap breast reconstructions: A personal experience Br. J Plast Surg 1999;52:104-111.

2. Wechselberger G, Schoeller T, Bauer T, et al. Venous superdrainage in deep inferior epigastric perforator flap breast reconstruction. Plast Reconstr Surg 2001;108:162-166.

3. Blondeel PN, Arnstein M, Verstraete K, et al. Venous congestion and blood flow in free transverse rectus abdominis myocutaneous and deep inferior epigastric perforator flaps. Plast Reconstr Surg 2000;106:12951299.

4. Tutor EG, Auba C, Benito A, et al. Easy venous superdrainage in DIEP flap breast reconstruction through the intercostal branch. J Reconstr Microsurg. 2002;18:595-598.

5. Marck KW, Van Der Biezen JJ, Dol JA. Internal mammary artery and vein supercharge in TRAM flap breast reconstruction. Microsurgery 1996;17:371-374.

6. Niranjan NS, Khandwala AR, Mackenzie DM. Venous augmentation of the free TRAM flap. Br J Plast Surg 2001:54:335-337.

7. Villafane $\mathrm{O}$, Gahankari D, Webster M. Superficial inferior epigastric vein (SIEV) “lifeboat" for DIEP/TRAM flaps. Br J Plast Surg 1999;52:599.

8. Lundberg J, Mark H. Avoidance of complications after the use of deep inferior epigastric perforator flaps for reconstruction of the breast. Scand J Plast Reconstr Surg Hand Surg 2006;40:79-81.

9. Miles DAG, Crosby NL, Clapson JB. The role of the venous system in the abdominal flap of the rat. Plast Reconstr Surg 1997:99:2030-2033.

10. Hallock GG, Rice DC. Efficacy of venous supercharging of the deep inferior epigastric perforator flap in a rat model. Plast Reconstr Surg 2005;116:551-555. 
11. Chow SP, Chen DZ, Gu YD. The significance of venous drainage in free flap transfer. Plast Reconstr Surg 1993;91:713-715.

12. Chang H, Minn KW, Imanishi N, et al. Effect of venous superdrainage on a four-territory skin flap survival in rats. Plast Reconstr Surg 2007;119:2046-2051.

13. Zeebregts C, Acosta R, Bo"lander L, et al. Clinical experience with non-penetrating vascular clips in freeflap reconstructions. Br J Plast Surg 2002;55:105-110.

14. Nakayama Y, Soeda S, Kasai Y. The importance of arterial inflow in the distal side of a flap: An experimental investigation. Plast Reconstr Surg 1982;69:61-67.

15. Ueda K, Harashina T, Oba S, et al. Which vessel is more important in the supercharged flap-Artery, vein or both? An experimental study. J Reconstr Microsurg 1994;10:153-155.

16. Fukui A, Tamai S, Williams HB. The importance of venous drainage in rat flaps: An experimental study. $J$ Reconstr Microsurg 1989;5: 19-30.

17. Sano K, Hallock GG, Rice DD. Venous supercharging augments survival of the delayed rat TRAM flap. Ann Plast Surg 2003;51:398-402.

18. Chiu DTW, Hu G, Wu J, et al. Extended rat-ear flap model: A new rodent model for studying the effects of vessel supercharging on flap viability. J Reconstr Microsurg 2002;18:503-508.

19. Harashina $T$, Sawada $Y$, Watanabe $S$. The relationship between venous occlusion time in island skin flaps and flap survival. Plast Reconstr Surg 1977;60:92-95.

20. Angel MF, Mellow CG, Knight KR, et al. Secondary ischemia time in rodents: Contrasting complete pedicle interruption with venous obstruction. Plast Reconstr Surg 1990;85:789-793.

21. Hjortdal VE, Hauge E, Hansen ES. Differential effects of venous stasis and arterial insufficiency on tissue oxygenation in myocutaneous island flaps: An experimental study in pigs. Plast Reconstr Surg 1992;89:521529.
22. Renkin EM. Control of microcirculation and blood tissue exchange. In: Geiger SR, editor. The Cardiovascular System, Part 2, Vol. 4: Microcirculation. Bethesda, MD: American Physiology Society; 1984.

23. Meldon JH, Garby L. The blood oxygen transport system: A numerical simulation of capillary tissue respiratory gas exchange. Acta Med Scand Suppl 1975;578:19-29.

24. Angel MF, Ramasastry SS, Swartz W, et al. Free radicals: Basic concepts concerning their chemistry, pathophysiology, and relevance to plastic surgery. Plast Reconstr Surg 1987;79: 990-997.

25. Swartz WM, Jones NF, Cherup L, et al. Direct monitoring of microvascular anastomoses with the 20-MHz ultrasonic Doppler probe: An experimental and clinical study. Plast Reconstr Surg 1988;81:149-161.

26. Warner KG, Durham-Smith G, Butler MD, et al. Comparative response of muscle and subcutaneous tissue $\mathrm{pH}$ during arterial and venous occlusion in musculocutaneous flaps. Ann Plast Surg 1989;22:108-116.

27. Korthuis RJ, Granger DN, Townsley MI, et al. The role of oxygen-derived free radicals in ischemia-induced increases in canine skeletal muscle vascular permeability. Circ Res 1985;57:599- 609.

28. Stasch T, Goon PK, Haywood RM, et al. DIEP flap rescue by venesection of the superficial epigastric vein. Ann Plast Surg 2009;62:372-373.

29. Shamsian N, Sassoon E, Haywood R. Salvage of a congested DIEP flap: A new technique. Plast Reconstr Surg 2008;122:41e-42e.

30. Carramenha e Costa MA, Carriquiry C, Vasconez LO, et al. An anatomic study of the venous drainage of the transverse rectus abdominis musculocutaneous flap. Plast Reconstr Surg 1987;79:208-217.

31. Schaverien M, Saint-Cyr M, Arbique G, et al. Arterial and venous anatomies of the deep inferior epigastric perforator and superficial inferior epigastric artery flaps. Plast Reconstr Surg 2008;121: 1909-1919.

32. Acosta R, Enajat M, Rozen WM, et al. Performing two DIEP flaps in a working day: An achievable and reproducible practice. J Plast Reconstr Aesthet Surg 2010; 63: 648-654 
33. Rozen WM, Garcia-Tutor E, Alonso-Burgos A, et al. Planning and optimising DIEP flaps with virtual

surgery: The Navarra experience. J Plast Reconstr Aesthet Surg 2010;63:289-97 

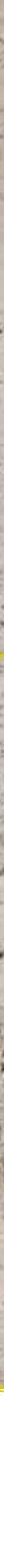

Performing two DIEP flaps in a working day: an achievable and reproducible practice.

Acosta R, Enajat M, Rozen WM, Smit JM, Wagstaff MJ, Whitaker IS, Audolfsson T. Journal of Plastic, Reconstructive \& Aesthetic Surgery (2010) 63, 648-654 


\section{ABSTRACT}

\section{Background}

While the deep inferior epigastric artery perforator (DIEP) flap is a reliable technique for autologous breast reconstruction, the meticulous dissection of perforators may require lengthy operative times. In our unit, we have performed 600 free flaps for breast reconstruction over 8 years and have reduced operative times with a combination of preoperative computed tomographic angiography (CTA), various anastomotic techniques and the Cook-Swartz implantable Doppler probe for perfusion monitoring. We sought to assess the feasibility of performing two DIEP flaps within the working hours of a single day.

\section{Methods}

A review of 101 consecutive patients undergoing DIEP flap breast reconstruction in a 12-month period was performed, comparing one DIEP flap per day $(n=43)$ to two DIEP flaps per day $(n=58)$. Complications, outcomes and techniques used were critically analysed. For cases of two DIEP flaps per day, a comparison was made between the use of two separate operating theatres $(n=44)$ and a single consecutive theatre $(n=14)$

\section{Results}

Complications did not increase when two DIEP flaps were performed in a single working day. The use of vascular closure staple (VCS) sutures and ring couplers resulted in statistically significant reductions in anastomotic times. The use of two separate theatres for performing two DIEP flaps resulted in a reduction of $59 \mathrm{~min}$ in operative time per case $(p=0.004)$

Conclusion

Two DIEP flaps can be safely and routinely performed within the hours of a single working day. By minimising operative times, these techniques can improve productivity and substantially decrease surgeon fatigue.

\section{INTRODUCTION}

The free deep inferior epigastric artery perforator (DIEP) flap has evolved into a reliable, safe and routine method for autologous breast reconstruction. ${ }^{1-4}$ By preserving the rectus abdominis muscle and anterior rectus sheath during flap harvest, the DIEP flap can reduce postoperative pain and hospital stay, enabling patients to return to their full range of normal daily activities. ${ }^{4-8} \mathrm{~A}$ limitation of the DIEP flap over the transverse rectus abdominis myocutaneous flap (TRAM) is the meticulous dissection of perforating vessels, which may increase operative times compared to the free TRAM flap. ${ }^{4,9,10}$ Although the DIEP flap may be considered technically more demanding and potentially more time consuming, surgical experience and the use of adjuncts to surgery can minimise operative times. In our unit, we have performed 600 microvascular free flaps for breast reconstruction over the past 8 years; of these, over 90\% comprise DIEP flaps and the others comprise superior gluteal artery perforator (SGAP) flaps and superficial inferior epigastric artery (SIEA) flaps. With an increase in surgical expertise and the application of different modifications to surgical technique and a variety of surgical tools, we have been able to show a decrease in overall operative times. By addressing inefficiencies at each step of the operation, we have been able to complete the entire operation in $3 \mathrm{~h}$ and $49 \mathrm{~min}$ on average across the past 100 cases, with a minimum time of $2 \mathrm{~h}$ and $15 \mathrm{~min}$ (an SIEA flap). Although we do not aim to rush this surgery, we are achieving quicker times routinely, and this has been achieved with thorough preoperative assessment of the vascular anatomy using computed tomographic angiography (CTA), integrating the use of micro-anastomotic staples or coupling devices and the use of the Cook-Swartz implantable Doppler probes for perfusion monitoring. ${ }^{11-14}$ The improved operating theatre use created using these methods has enabled us to perform two DIEP flap procedures during a single working day, all performed by the same senior surgeon. The current study comprises a review of 101 consecutive patients undergoing unilateral breast reconstruction with a DIEP flap over a 12-month period. The feasibility of performing two DIEP flap reconstructions within the working hours of a single day is assessed, comparing complication rates between the two-DIEP-flapsper- day and the one-DIEP-flap-per-day groups. The factors used to decrease operative times were also reviewed, in particular, the use of two separate operating theatres to conduct successive DIEP flap procedures. 


\section{METHODS}

Study design

A cohort study of 101 consecutive patients undergoing delayed, unilateral DIEP flap breast reconstruction following breast cancer was performed between 1 October 2007 and 30 September 2008. All procedures were performed with a single supervising senior surgeon (RA) and at a single institution. Of these patients, 43 patients were treated as full-day cases, with no other free flap surgery booked in for the senior surgeon. The remaining 58 cases were performed with two DIEP flaps booked in on a single day's operating list. These twocase operating lists were performed in two ways: with two cases occurring consecutively in a single operating theatre (14 cases), or the two cases occurring in two separate theatres ( 44 cases). Where a single theatre was used, the same nursing and anaesthetic teams were involved, while for the two theatre cases, different nursing and anaesthetic teams were involved. Where there was an overlap between the end of the First case and the start of the second, this period was not surgical time, but rather, it was the time expended for dressings and administration of anaesthesia. A comparison between the single-DIEP-flap-per-day and the two-DIEP-flaps-per-day groups was performed to assess the safety of this model. This included a comparison of demographic data, risk factors for complications, the use of varying microvascular anastomotic methods and sites and the incidence of complications. The comparison of anastomotic methods comprised three techniques used: standard sutures, the 'Anastoclip' Vascular Closure Staples (VCSs) micro-staple clips (AnastoClip Vessel Closure System, Le Maitre Vascular Inc., Sulzbach, Germany) and a microvascular anastomotic coupling device (Microvascular Anastomotic Coupling System, Synovis Micro Companies Alliance Inc., St Paul, MN, USA). Our use of these anastomotic procedures has been described previously. ${ }^{14}$ The two-DIEP-flaps-per-day group was subsequently analysed based on the use of a single operating theatre for both cases or the use of two separate operating theatres. This analysis included a comparison of surgical techniques and adjuncts to surgery, and particularly a comparison of operative times between the two settings, including anaesthetic times. Operative time was noted from the first incision to the application of dressings. These times included interoperative times in all cases as a means to assessing overall 'working' time for surgical staff (discussed further in the section titled Discussion).

Data analysis

Data were presented as the population mean, with standard deviations or $95 \%$ confidence intervals (Cls) of the difference given. The Student's t-test was used to compare the means of continuous outcome variables in the independent groups, calculated at $95 \% \mathrm{Cls}$, with two-tailed p-values given. The testing of statistical significance for nominal data was done by means of a two-tailed Fisher's exact test. Statistical significance was considered at $p<0.05$. Statistical analysis was done using the Statistical Package for the Social Sciences (SPSS) for Windows (version 16.0, SPSS Inc., Chicago, IL, USA).

\section{RESULTS}

Single DIEP flap versus two DIEP flaps per day

The safety and utility of performing two DIEP flap procedures per day was evaluated by comparison to the single-DIEP-flap-per-day group. As shown in Table 1, the two groups were highly comparable, with no difference in body weight, body mass index (BMI) or age. The two-DIEP-flaps-per-day group showed a significantly higher incidence of hypertensive patients, but other co-morbidities were comparable (see Table 1). All patients were class 2 based on the classification by the American Society of Anesthesiologists (ASA), with all patients being low risk and co-morbidities, such as hypertension, controlled preoperatively. The site of primary and secondary vessel anastomoses, and the technique used for anastomoses, was comparable between groups, with no differences demonstrated (see Table 2). While the mean ischaemia time was significantly shorter in the two-DIEP-flaps-per-day group (see Table 1), there were no differences in any outcome measures (see Table 3). The rates of overall complications, each individual complication, the take-back rate and the flap failure rate were all comparable between groups. There was, therefore, no significant increase in these aspects on performing two DIEP flaps per day compared to the completion of a single DIEP flap per day.

Table 1. Patient demographics and variables when comparing the single deep inferior epigastric artery perforator (DIEP) flap per day and two DIEP flaps per day groups

\begin{tabular}{|c|c|c|c|}
\hline & $\begin{array}{l}1 \text { DIEP flap per day } \\
\text { (nZ43) }\end{array}$ & $\begin{array}{l}2 \text { DIEP flaps per day } \\
\text { (nZ58) }\end{array}$ & $p$ value \\
\hline \multicolumn{4}{|l|}{ Patient demographics } \\
\hline Mean age (years) (SD) & 54 , range: $38-69(7.7)$ & 52 , range: $31-68(8.3)$ & 0.41 \\
\hline Mean bodyweight (kg) (SD) & $74.7(12.7)$ & $73.4(12.1)$ & 0.62 \\
\hline Mean body mass index (BMI) (SD) & $27.3(4.2)$ & $26.2(3.7)$ & 0.27 \\
\hline Mean ischaemia time (min) (SD) & 60 , range: 44-105 (13) & 55 , range: $31-75(10)$ & 0.03 \\
\hline $\begin{array}{l}\text { Mean volume of intra-operative } \\
\text { blood loss (ml) (SD) }\end{array}$ & $160(126)$ & $123(60)$ & 0.06 \\
\hline \multicolumn{4}{|l|}{ Risk factors (nr. of patients) } \\
\hline Corticosteroid use & 1 & & 21.00 \\
\hline Hypertension & 11 & & 50.03 \\
\hline Diabetes & 0 & & 20.51 \\
\hline Other (Factor 8 deficiency) & 0 & e & 11.00 \\
\hline
\end{tabular}

$P$ values are calculated with the Student's t-test.

$\mathrm{SD}=$ Standard Deviation 
Table 2. Anastomotic site and technique between the comparison groups of single deep inferior epigastric artery perforator (DIEP) flap per day and two DIEP flaps per day

\begin{tabular}{llll}
\hline & $\begin{array}{l}\text { 1 DIEP flap per } \\
\text { day }(\mathrm{n}=43)\end{array}$ & $\begin{array}{l}\text { 2 DIEP flaps per } \\
\text { day }(\mathrm{n}=58)\end{array}$ & $P$ \\
\hline \hline Primary arterial and venous anastomoses (\%) & & & \\
$\quad$ Internal mammary & 86 & 95 & 0.84 \\
$\quad$ Circumflex scapular & 14 & 5 & 0.53 \\
$\quad$ End to end & 100 & 98 & 1.00 \\
$\begin{array}{l}\text { Secondary venous anastomosis vessels (\%) } \\
\quad \text { Cephalic (\% total/\% secondary anastomoses) }\end{array}$ & $49(75)$ & $48(82)$ & 0.86 \\
$\quad$ Thoracodorsal (\% total/\% secondary anastomoses) & $2(4)$ & 0 & 0.34 \\
$\quad$ Internal mammary (\% total/\% secondary anastomoses) & $14(21)$ & $10(18)$ & 0.73 \\
$\quad$ End to end & 100 & 100 & 1.00 \\
Technique for arterial anastomoses (\%) & & & \\
$\quad$ Suture & 81 & 78 & 0.81 \\
$\quad$ VCS micro-staples (clips) & 10 & 19 & 0.46 \\
$\quad$ Ring coupling device & 9 & 3 & 0.24 \\
Technique for venous anastomoses (\%) & & & \\
$\quad$ Suture & 9 & 4 & 0.47 \\
$\quad$ VCS micro-staples (clips) & 12 & 17 & 0.57 \\
$\quad$ Ring coupling device & 79 & 79 & 1.00 \\
\hline \hline
\end{tabular}

$p$ values are calculated with the two-tailed Fisher's exact test.

Table 3. Outcome measures between the comparison groups of single deep inferior epigastric artery perforator (DIEP) flap per day and two DIEP flaps per day

\begin{tabular}{llll}
\hline & $\begin{array}{l}\text { 1 DIEP flap per } \\
\text { day }(\mathrm{n}=43)\end{array}$ & $\begin{array}{l}\text { 2 DIEP flaps per } \\
\text { day }(\mathrm{n}=58)\end{array}$ & $p$ \\
\hline \hline Complications (number/\%) & $13(29.5)$ & $14(24.1)$ & 0.74 \\
$\quad$ Scar dehiscence & $2(4.5)$ & $0(0)$ & 0.18 \\
Partial flap necrosis & $0(0)$ & $1(1.9)$ & 1.00 \\
Haematoma & $3(6.8)$ & $3(5.2)$ & 0.70 \\
Infection & $4(9.1)$ & $6(10.3)$ & 0.76 \\
Seroma & $0(0)$ & $2(3.4)$ & 0.26 \\
Anastomotic insufficiency & $2(4.5)$ & $1(1.7)$ & 0.57 \\
Superficial necrosis & $2(4.5)$ & $0(0)$ & 0.18 \\
Reoperation (number/\%) & $5(11.4)$ & $4(6.9)$ & 0.42 \\
Anastomotic insufficiency & 2 & 1 & 0.57 \\
Haematoma & 3 & 3 & 0.70 \\
Overall flap failure (number/\%) & $2(4.5)$ & $0(0)$ & 0.18 \\
\hline \hline
\end{tabular}

$p$ values are calculated with the two-tailed Fisher's exact test.
Anastomotic times

We compared the mean anastomotic times using three different anastomotic techniques (see Figures 1 and 2). For the venous anastomoses, a significantly lower mean venous anastomotic time was shown when using the ring coupling device compared to sutures ( $p<0.0001, \mathrm{Cl}$ : 9.63-13.72). Similarly, a significantly lower mean venous anastomotic time was shown when using the ring coupling device compared to the VCS microstaple clips ( $p=0.025, \mathrm{Cl}: 1.067-12.23$ ). No significant difference was found when comparing sutures and the VCS micro-staple clips ( $p=0.92, \mathrm{Cl}: 12.45-13.64$ ). The vast majority of arterial anastomoses were performed using sutures. Despite this, when the techniques were compared, significant findings were evident. The use of VCS micro-staple clips was significantly faster than sutured arterial anastomoses ( $p<0.0001, \mathrm{Cl}$ : 4.23 -

8.34). Similarly, the use of the ring coupler was also significantly faster than sutures ( $\mathrm{p}=0.001, \mathrm{Cl}: 4.73-16.6)$. In addition, the use of the ring coupler saved more time than VCS clips ( $p=0.028, \mathrm{Cl}: 0.62-8.13$ ). Collectively, these results demonstrate that in an operation with one arterial and two venous anastomoses, Total operative times can be reduced by up to $30 \mathrm{~min}$ simply by using the faster anastomotic devices at the appropriate vessels.

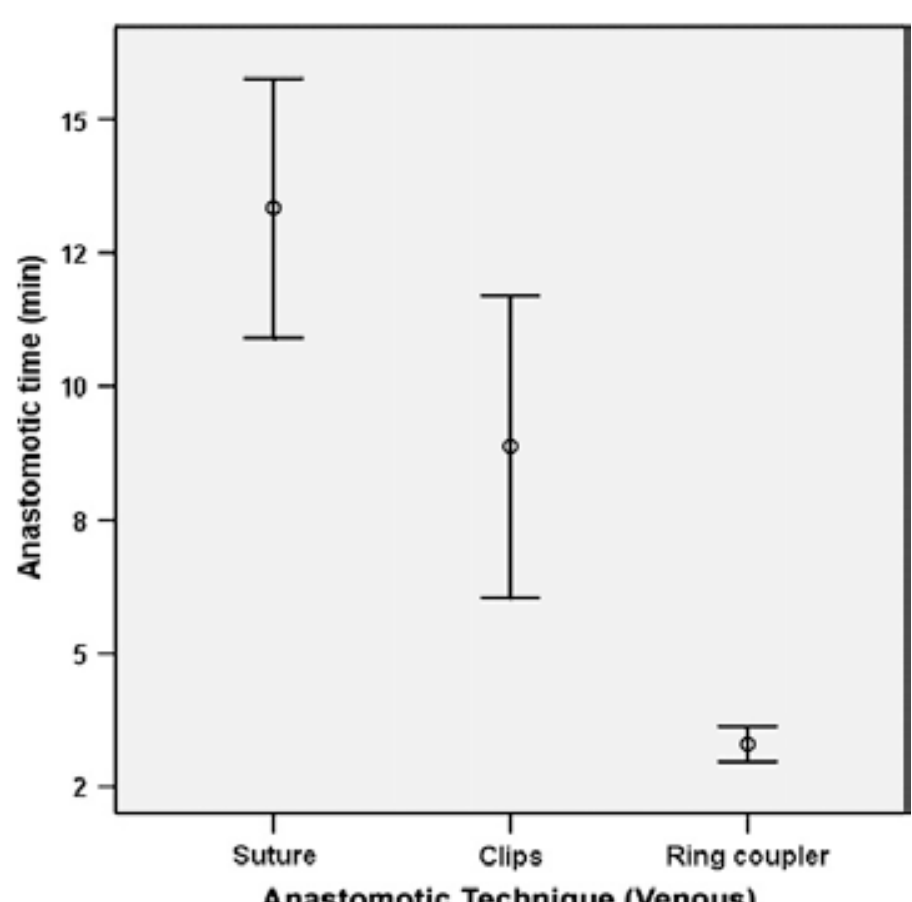

Figure 1 The mean time required to perform a venous anastomosis using each of the three anastomotic techniques investigated. Confidence intervals calculated using Student's $t$-test. 


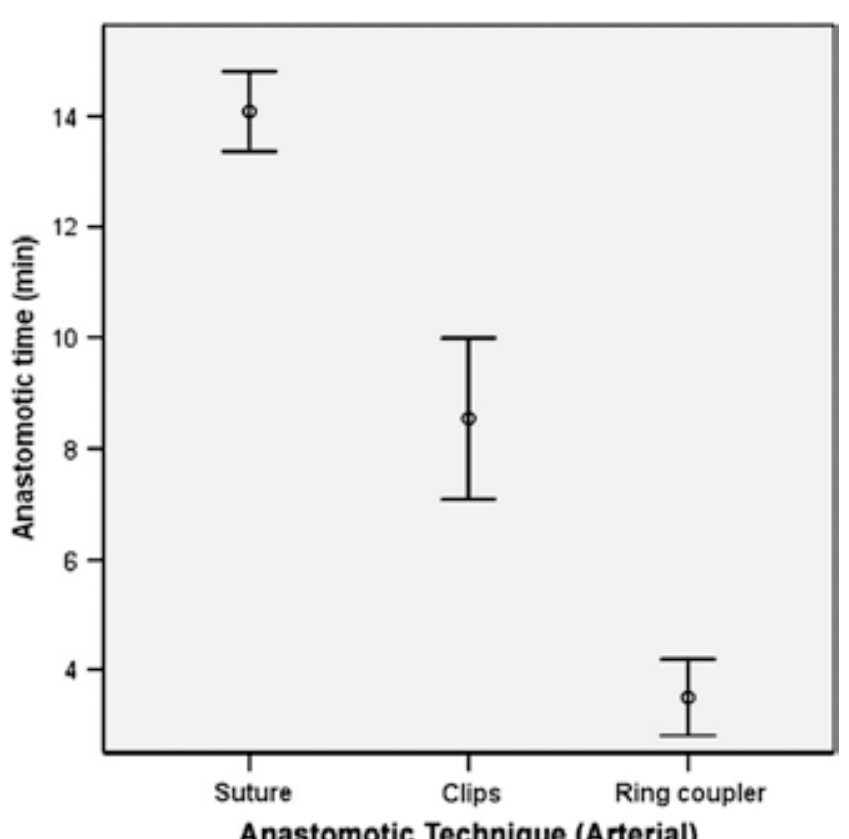

Figure 2 The mean time to perform an arterial anastomosis using each of the three anastomotic techniques investigated. Confidence intervals have been calculated using Student's t-test.

Two DIEP flaps in a single theatre versus two theatres

A comparison was made between the use of a single theatre and two theatres for the completion of two DIEP flaps in a single day. The two groups of patients were comparable, with no statistical difference in patient demographics or co-morbidities (see Table 4). There were some differences in the techniques used for anastomosis between the two groups (see Table 5). The sites for primary arterial and venous anastomosis were the same between groups, as was the rate for performing a secondary vein; however, a cephalic vein was harvested for the secondary vein in more cases for the 'two theatres' group. In terms of the technique used for anastomoses, arterial anastomoses were more commonly sutured and venous anastomoses more commonly coupled with the ring coupler in the 'two theatres' group, while the VCS staples were used more commonly for both arterial and venous anastomoses in the single-theatre group. While all operations were completed by a single senior surgeon, the use of two theatres was sought as a means to reduce interchange (or interoperative) times.
Table 4. Patient demographics and variables for those operated on in a single theatre with a second deep inferior epigastric artery perforator (DIEP) flap and those operated on in a second theatre to the second DIEP flap occurring in the same day

\begin{tabular}{llll}
\hline & $\begin{array}{l}\text { Single theatre } \\
(\mathrm{n}=14)\end{array}$ & $\begin{array}{l}\text { Two theatres } \\
(\mathrm{n}=44)\end{array}$ & $\mathrm{p}$ \\
\hline \hline Patient demographics & & & \\
$\quad$ Mean age (years) (SD) & 48, range: 31-62 (8.6) & 53, range:40-68 (7.9) & 0.73 \\
Mean body weight (kg) (SD) & $71.8(12.7)$ & $74.0(12.0)$ & 0.54 \\
Mean body mass index (BMI) (SD) & $25.5(3.6)$ & $26.5(3.7)$ & 0.34 \\
Mean ischaemia time (min) (SD) & 56, range: 31-72 (12) & 55, range: 32-75 (10) & 0.83 \\
Mean volume of intra-operative & $110(64)$ & $126(55)$ & 0.35 \\
$\quad$ blood loss (ml) (SD) & & & \\
Risk factors (number of patients) & & & \\
Corticosteroid use & 1 & 1 & 0.63 \\
$\quad$ Hypertension & 1 & 4 & 0.78 \\
$\quad$ Diabetes & 0 & 2 & 1.00 \\
$\quad$ Other (Factor 8 deficiency) & 0 & 1 & 1.00 \\
\hline \hline
\end{tabular}

Table 5. Anastomotic sites and techniques for those operated on in a single theatre with a second deep inferior epigastric artery perforator (DIEP) flap and those operated on in a second theatre for the second DIEP flap occurring in the same day. (Fisher's exact test used)

\begin{tabular}{llll} 
& $\begin{array}{l}\text { Single theatre } \\
(\mathrm{n}=14)\end{array}$ & $\begin{array}{l}\text { Two theatres } \\
(\mathrm{n}=44)\end{array}$ & $p$ \\
\hline \hline Primary arterial and venous anastomoses (\%) & & & \\
$\quad$ Internal mammary & 90 & 91 & 1.00 \\
$\quad$ Circumflex scapular & 6 & 9 & 0.59 \\
$\quad$ Thoracodorsal & 4 & 0 & 0.32 \\
$\quad$ End-to-end & 100 & 97 & 1.00 \\
Secondary venous anastomosis vessels (\%) & 64 & 50 & 0.28 \\
$\quad$ Cephalic (\% total / \% secondary anastomoses) & $43(67)$ & $50(100)$ & 0.03 \\
$\quad$ Internal mammary (\% total / \% secondary anastomoses) & $21(33)$ & 0 & 0.03 \\
$\quad$ End-to-end & 100 & 100 & 1.00 \\
Technique for arterial anastomoses (\%) & & & \\
$\quad$ Suture & 50 & 86 & 0.04 \\
$\quad$ VCS micro-staples (clips) & 50 & 9 & 0.03 \\
$\quad$ Ring coupling device & 0 & 5 & 1.00 \\
Technique for venous anastomoses (\%) & & & \\
$\quad$ Suture & 8 & 2 & 0.43 \\
VCS micro-staples (clips) & 55 & 5 & 0.03 \\
Ring coupling device & 37 & 93 & 0.02 \\
\hline \hline
\end{tabular}


The difference in interoperative time was shown to be significantly different between the two settings, with an average of $63.9 \mathrm{~min}$ for the single-theatre group versus an average of $5.2 \mathrm{~min}$ for the two-theatres setting. This mean difference of 59 min was statistically significant $(p=0.004)$. In calculating the overall operative time, the elapsed time was calculated from the first incision in the first case to the application of dressings in the second case, including the interoperative times. A significant difference was found between the overall elapsed time for two DIEP flap procedures between the single-theatre and the two theatres settings (see Figure 3). For the single-theatre setting, the mean total elapsed time for two operations was $9 \mathrm{~h}$ and $2 \mathrm{~min}$, while for the two-theatres setting the mean total elapsed time for two operations was $7 \mathrm{~h}$ and $38 \mathrm{~min}$. This difference in the mean total elapsed time for the duration of two DIEP flaps was $1 \mathrm{~h}$ and $23 \mathrm{~min}(\mathrm{p}<0.0001)$. In demonstrating the start and finish times for the two cases, it is apparent that both settings allow for the completion of two DIEP flap cases in a single day, with the two-theatres setting reliably finishing well within the limits of a single working day (see Table 6).

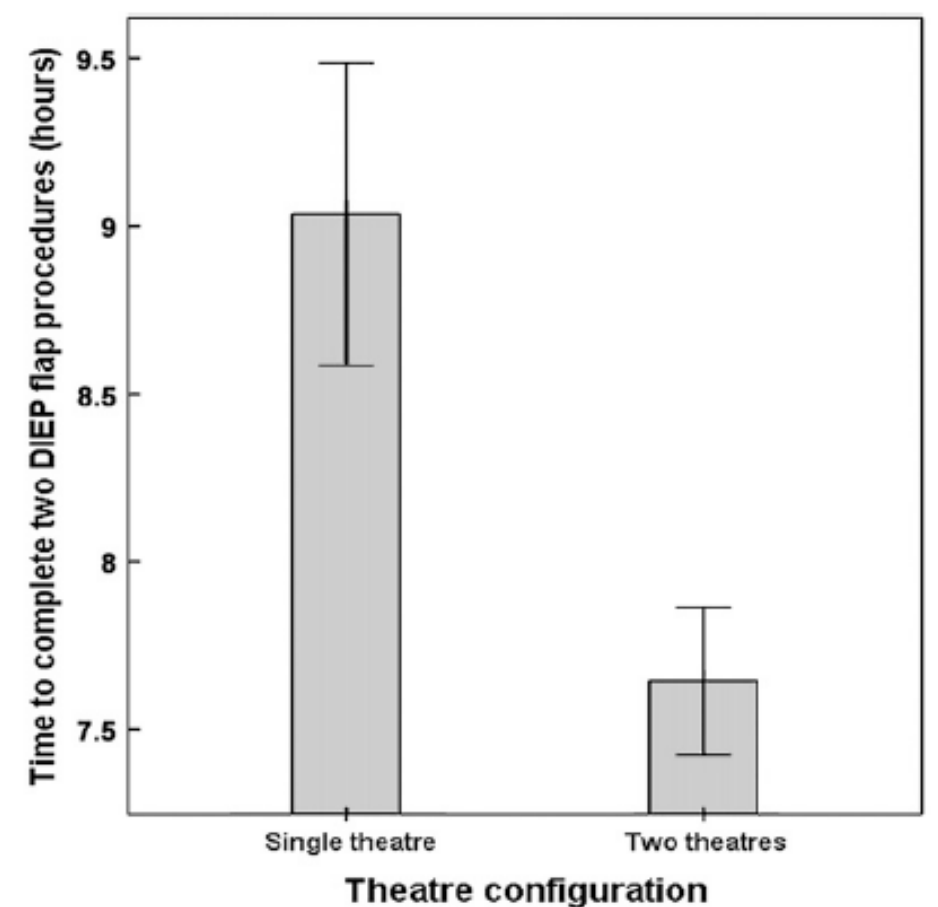

Figure 3 The overall time elapsed in completing two deep inferior epigastric artery perforator (DIEP) flap procedures, when performed consecutively in a single theatre, compared to using two theatres sequentially.
Table 6. The average start and finish times (using a 24-h clock) of each

deep inferior epigastric artery perforator (DIEP) flap case, demonstrating the finish times occurring within the limits of a single working day

\begin{tabular}{llll} 
& & $\begin{array}{l}\text { Start time } \\
(24-\mathrm{h} \text { clock })\end{array}$ & $\begin{array}{l}\text { Finish time } \\
(24-\mathrm{h} \text { clock })\end{array}$ \\
\hline \hline Single-theatre setting & First surgery & $8: 25$ & $12: 21$ \\
& Second surgery & $13: 25$ & $17: 26$ \\
& & & \\
Two-theatres setting & First surgery & $8: 25$ & $12: 09$ \\
& Second surgery & $12: 14$ & $16: 03$ \\
\hline \hline
\end{tabular}

\section{DISCUSSION}

The DIEP flap has been shown to be a reliable method for autologous breast reconstruction as it offers the advantages of the abdominal wall donor site, without the need of sacrificing the rectus abdominis muscle. ${ }^{2,6-8,10,15}$ By preserving the rectus abdominis muscle and overlying fascia, there is a significant reduction in donor-site complications such as abdominal wall herniation and bulge, and reduced postoperative pain with quicker convalescence and reduced hospital stay. ${ }^{5,6}$ Furthermore, with improved donor sites patients require a shorter period of time to return to their full range of normal daily activities. ${ }^{16} \mathrm{In}$ achieving these results, the DIEP flap is associated with the meticulous dissection of small perforating vessels, requiring long dissection times and a potentially greater technical challenge to the surgeon compared to the TRAM flap. ${ }^{17}$ Indeed, variability in the vascular anatomy may require conversion from the DIEP to TRAM flap, ${ }^{18,19}$ with conversion rates as high as $20 \%$ being reported. ${ }^{18,20}$ Recently, the muscle-sparing free TRAM flap procedure was described in the routine clinical setting as requiring $3 \mathrm{~h}$ for the surgery. ${ }^{21}$ This was a unique article, as it confirmed that autologous breast reconstruction, particularly with the abdominal wall integument, should not be considered as an unacceptably long surgical procedure. In our experience, the procedure time for a DIEP flap was approaching this level, and we have found that times are being further reduced with increases in surgical experience, and the use of several technologies that allow both reduction in operative time and postoperative complications. These factors, combined with a multidisciplinary approach to increasing output and productivity, have demonstrated surgical times for the DIEP flap of almost half that of previously reported DIEP flap procedure times. ${ }^{4,10}$ We feel that DIEP flaps need not be considered an overly length procedure. The current study has demonstrated that two DIEP flaps can be performed in a routine and safe manner within the working hours of a single day. In routinely performing two DIEP flaps well within $8 \mathrm{~h}$, we have adopted several key factors in our approach to the DIEP 
flap. An experienced surgeon and an experienced theatre team are paramount, with our nursing and anaesthetic teams having also been involved in several hundred cases each. A coordinated approach by these teams is paramount. This is in the context of all of these flaps performed in a teaching hospital, with any time taken for teaching shown to not adversely affect surgical times. As described in the section titled 'Methods', operative times were considered from the first incision to the application of dressings and thus included the interoperative times. This assessment of 'total working time' for the surgical staff is a usefu measure of the feasibility of performing such flaps during working hours, where overtime payments are potentially limiting factors. Preoperative planning with CTA is performed routinely, and we have shown previously that this improves our operative times. ${ }^{11,19,22,23}$ The preoperative use of CTA provides a detailed three-dimensional map of the vascular anatomy of the anterior abdominal wall, and facilitates 'virtual surgery' for each perforator throughout its entire course. ${ }^{24}$ With this information, we prospectively select suitable patients, the hemi-abdomen of choice, individual perforators of choice and, indeed, plan flap design In addition, assessment of the calibres of the superficial and deep venous systems within the desired territory enables the surgeon to prioritise the donor veins for anastomosis. By prospectively planning the need for a second venous anastomosis, we minimise the time associated with intra-operative decision making for a second recipient-vein harvest and have eliminated venous congestion completely. Although the harvest of a secondary vein such as the cephalic vein may take 10-20 min, if performed prospectively, this is incorporated into the operative times, rather than being a late decision that compounds overall times. With preoperative imaging, we have eliminated the need for conversion from a DIEP flap to a muscle-sparing TRAM flap (we have never converted, and instead have been able to prospectively select the need for between one and three perforators). In our practice, the use of preoperative CTA has shortened procedure times by 90 min, while reducing costs and complication rates associated with DIEP flap surgery. ${ }^{11}$

We use various techniques for anastomosis, ${ }^{14}$ and the current study has demonstrated that these significantly improve operative times. We have used both, the VCS micro-staple clip applicator and the ring coupling device, with success and shown in the current study that both systems are safe and can significantly shorten surgical times. With studies previously showing that vessel patency is equally good with micro-clips and the ring coupler compared to sutures, ${ }^{14}$ the benefit to surgical time is certainly attractive. In addition, these micro-anastomotic devices do not penetrate the lumen, while sutures necessitate the presence of foreign suture material intraluminally, which may trigger platelet aggregation and cause early anastomotic failure. ${ }^{25,26}$ Finally, we used the Cook-Swartz implantable Doppler probes for each operation, placing the Doppler across the primary venous anastomosis during flap insetting. The Cook-Swartz probe allows accurate and objective intra and postoperative assessment of anastomotic flow, and can relieve the surgeon of the need to continuously inspect the flap's capillary refill. With flap perfusion continually audible during insetting, the probe can alert the surgeon of early compromise and allow early re-exploration. ${ }^{12}$ By using this background audible measure of flap perfusion, there is no time spent assessing flap viability or time wasted if early assessment or revision of anastomoses are required. With financial considerations an everincreasing influence on hospital systems, the feasibility of means to safely reduce overall theatre and surgical times has become predominant. While we do not advocate the unnecessary undertaking of multiple microsurgical cases in a single day, we have demonstrated that there are multiple means available that can aid the reconstructive surgeon to safely minimise operative times. Although not all of these may be available in every centre, each factor is a valuable means to aiding surgical efficiency. We have described a 12-month series of unilateral DIEP flap breast reconstructions, during which time cases were performed as either a single DIEP flap per day or two DIEP flaps per day. The current study demonstrates that, by using preoperative CTA, various anastomotic devices and the use of two separate theatres, two DIEP flaps can safely and routinely be performed within the hours of a single working day. By minimising the overall operative times, these techniques can improve productivity and substantially decrease surgeon fatigue. We feel that the DIEP flap should not be considered an unreasonably lengthy procedure and should be increasingly considered a first-line option for breast reconstruction.

\section{CONFLICT OF INTEREST}

The authors declare that there are no financial or personal relationships with other people or organisations that could inappropriately influence (bias) this work. 


\section{REFERENCES}

1. Guerra $A B$, Metzinger $S E$, Bidros RS, et al. Bilateral breast reconstruction with the deep inferior epigastric perforator (DIEP) flap: an experience with 280 flaps. Ann Plast Surg 2004; 52:246-52.

2. Allen RJ. DIEP versus TRAM for breast reconstruction. Plast Reconstr Surg 2003;111:2478.

3. Allen RJ, Treece P. Deep inferior epigastric perforator flap for breast reconstruction. Ann Plast Surs 1994;32:32-38

4. Blondeel PN. One hundred free DIEP flap breast reconstructions: a personal experience. Br J Plast Surg 1999;52:104-111.

5. Allen RJ. Comparison of the costs of DIEP and TRAM flaps. Plast Reconstr Surg 2001;108:2165.

6. Blondeel N, Vanderstraeten GG, Monstrey SJ, et al. The donor site morbidity of free DIEP flaps and free TRAM flaps for breast reconstruction. Br J Plast Surg 1997;50:322-330.

7. Nahabedian MY, Momen B, Galdino G, et al. Breast Reconstruction with the free TRAM or DIEP flap: patient selection, choice of flap, and outcome. Plast Reconstr Surg 2002;110:466-475.

8. Nahabedian MY, Tsangaris T, Momen B. Breast reconstruction with the DIEP flap or the muscle-sparing (MS-2) free TRAM flap: is there a difference? Plast Reconstr Surg 2005;115:436-444.

9. Hamdi M, Weiler-Mithoff EM, Webster MHC. Deep inferior epigastric perforator flap in breast reconstruction: experience with the first 50 flaps. Plast Reconstr Surg 1999;103:86-95.

10. Garvey PB, Buchel EW, Pockaj BA, et al. DIEP and pedicled TRAM flaps: a comparison of outcomes. Plast Reconstr Surg 2006;117:1711-1719.

11. Smit JM, Dimopoulou A, Liss AG, et al. Preoperative $\mathrm{CT}$ angiography reduces surgery time in perforator flap reconstruction. J Plast Reconstr Aesthet Surg 2009;62:1112-1117.
12. Smit JM, Whitaker IS, Liss AG, et al. Post operative monitoring of microvascular breast reconstructions using the implantable Cook-Swartz Doppler system: a study of 145 probes \& technical discussion. J Plast Reconstr Aesthet Surg. 2009 Oct;62(10):1286-92.

13. Whitaker IS, Smit JM, Acosta R. A simple method of implantable Doppler cuff attachment: experience in 150 DIEP breast reconstructions. J Plast Reconstr Aesthet Surg 2008;61:1251e2.

14. Smit JM, Whitaker IS, Liss AG, et al. Post operative monitoring of microvascular breast reconstructions using the implantable Cook-Swartz Doppler system: a study of 145 probes \& technical discussion. J Plast Reconstr Aesthet Surg 2009;62:1286-1292.

15. Nahabedian MY, Dooley W, Singh N, et al. Contour abnormalities of the abdomen after breast reconstruction with abdominal flaps: the role of muscle preservation. Plast Reconstr Surg 2002;109:91-101.

16. Futter $\mathrm{CM}$, Webster $\mathrm{MH}$, Hagen $\mathrm{S}$, et al. A retrospective comparison of abdominal muscle strength following breast reconstruction with a free TRAM or DIEP flap. Br J Plast Surg 2000;53:578-583.

17. Kroll SS. Fat necrosis in free transverse rectus abdominis myocutaneous and deep inferior epigastric perforator flaps. Plast Reconstr Surg 2000;106:576-583.

18. Arnez ZM, Khan U, Pogorelec D, et al. Rational selection of flaps from the abdomen in breas reconstruction to reduce donor site morbidity. Br J Plast Surg 1999;52:351-354.

19. Rozen WM, Ashton MW, Grinsell D, et al. Establishing the case for CT angiography in the preoperative imaging of perforators for DIEA perforator flaps. Microsurgery 2008;28:227-232.

20. Keller A. Fat necrosis in free rectus abdominis and deep inferior epigastric perforator flaps. Plast Reconst Surg 2001;107: 1611-1612

21. Elliott LF, Seify H, Bergey P. The 3-Hour Muscle-Sparing Free TRAM Flap: safe and effective treatment review of 111 consecutive free TRAM flaps in a private practice setting. Plast Reconstr Surg 2007;120:127.

22. Rozen WM, Anavekar NS, Ashton MW, et al. Does the preoperative imaging of perforators with CT angiography improve operative outcomes in breast reconstruction? Microsurgery 2008;28:516-523. 
23. Rozen WM, Phillips TJ, Ashton MW, et al. Preoperative imaging for DIEA perforator flaps: a comparative study of Computed Tomographic Angiography and Doppler ultrasound. Plast Reconstr Surg 2008;121:9-16

24. Phillips TJ, Stella DL, Rozen WM, et al. Abdominal wall CT angiography: a detailed account of a newly established preoperative imaging technique. Radiology 2008;249:32-44.

25. Morecraft RJ, Blair WF, Maynard JA. Suture extrusion in small arteries and veins. Scand J Plast Reconstr Surg Hand Surg 1988; 22:121-126.

26. Zeebregts CJ, van den Dungen JJ, Kalicharan D, et al. Nonpenetrating vascular clips for small-caliber anastomosis. Microsurgery 2000;20:131-138. 


\section{ABSTRACT}

The deep inferior epigastric perforator (DIEP) flap is considered to be the gold standard for autologous breast reconstruction. This study evaluates the outcome of unilateral DIEP flap reconstructions, comparing university with a community hospital setting. A total of 77 unilateral DIEP flaps were performed at one university hospital and two community hospitals by the same two surgeons. Outcome parameters were: hospital stay, operating time, wound infection, wound dehiscence, fat necrosis, haematoma, (partial) flap necrosis and the need for surgical intervention. Fortynine unilateral DIEP flaps were performed in the university hospital and 28 in the community hospitals. Baseline characteristics were equal. No significan difference was found in total complication rate, flap loss or need for surgical intervention. Although wound dehiscence occurred more often in the community hospitals, unilateral DIEP flap breast reconstructions can be performed with a comparable degree of safety and complication risk in both university and community hospital settings.

\section{INTRODUCTION}

Since breast reconstruction with the deep inferior epigastric perforator (DIEP) flap was first described ${ }^{1}$, it has gained wide popularity and is considered by many to be the present-day gold standard for autologous breast reconstruction. ${ }^{2-6}$ Only a few years ago, complicated free tissue transfers like a DIEP flap reconstruction were not likely to be performed in community hospitals and patients were often referred to a university hospital. Nowadays, an increasing number of community hospitals offer breast reconstructive operation with the microvascular DIEP flap. This development has led to an increased capacity to help a vast number of women seeking autologous reconstruction. For a successful free flap procedure, meticulous technique and sufficient experience on the part of the surgeon are of key importance, but other factors also influence the outcome. A history of smoking, hypertension, diabetes, and radiotherapy are associated with increased complication rates. ${ }^{4,7,8}$ Also, experience of the nursing staff, quality of the intensive care unit and availability of resident coverage have been suggested as factors that might influence the outcome of free flap operation. ${ }^{9}$

To our knowledge, no published study to date has investigated and compared the outcome of DIEP flap breast reconstructions between community hospitals and a university hospital, although it is probably the most commonly performed free flap procedure in most parts of the world. Research has shown that, in the hands of an experienced microsurgeon, a variety of free flaps can be performed safely and efficiently in a community hospital, but the number of DIEP flaps in that study was limited. ${ }^{9}$ We have performed a multicentre, retrospective cohort study on the outcome and complications of DIEP flap breast reconstructions in one university hospital and two community hospitals. The purpose of this study was to evaluate and compare different outcome parameters and complications in the two hospital settings. A significant difference in outcome between the two settings could potentially spark a discussion about centralisation of this complicated procedure in more specialised (university) hospitals.

\section{PATIENTS AND METHODS}

Patients and procedures

Between January 2006 and September 2008, 77 unilateral DIEP flap breast reconstructions were performed in our university hospital and two nearby community hospitals. Only unilateral DIEP flaps were included in our study, as numbers of bilateral DIEP flaps in the community hospitals were very low. All patients were operated on by the same two surgeons with extensive experience in microsurgery (RH and LN), who both 
operated on patients in the university and community hospitals. Immediate as well as delayed reconstructions were performed in all three hospitals. There was no specific selection for patients to be operated on in the university hospital based on previous medical history or complexity of the reconstruction. Before the operation the DIE-perforators were marked on the abdomens of all patients using a hand-held Doppler device. During the operation zone four was always discarded and the internal mammary vessels were used as recipient vessels. All anastomoses were made using an operating microscope. Drains were placed under the flap and in the abdominal wound. In the university hospital patients were kept on the recovery ward overnight and went to the plastic surgical ward the next morning. In the community hospitals patients spent one night in the intensive or medium care unit before going to the ward. Flap monitoring was carried out by checking Doppler signal, colour, temperature, and capillary refill every hour for the first 24 hours, every 2 hours for the next 24 hours, every 4 hours on the third day, every 6 hours on the fourth day and once daily if patients remained in hospital for more than 4 days. Patients received prophylactic lowmolecular-weight heparin from the day before the operation until discharge and wore pressure stockings during and after the operation. There was no resident coverage in the community hospitals and in these hospitals the DIEP flap is the only free flap operation being performed. There has been a great amount of experience with free flaps in the university hospital, such as in breast, head and neck and lower extremity reconstruction. This implies a greater amount of experience of scrub nurses, anaesthesiologists and nursing personnel with the procedure itself, including microsurgery and postoperative flap monitoring.

\section{Measures}

All patient-specific data were collected from hospital and outpatient records by the first author (RW) Information was obtained regarding demographics and potential risk factors: age; timing of reconstruction (immediate or delayed); hypertension (any patient diagnosed with hypertension or treated with anti-hypertensive drugs at time of reconstruction); diabetes (regardless of type or treatment); smoking (active or in the past); abdominal scarring due to laparotomy (laparoscopy scars were not taken into account); and a history of radiotherapy or chemotherapy before time of reconstruction. Data about flap weight and ischaemia time were often not consistently documented and were therefore not taken into consideration, since evaluating them would not be reliable. Outcome parameters of our study were operating room time, length of hospital stay, and the following complications: wound infection, wound dehiscence, fat necrosis, haematoma, and partial or total flap necrosis. Furthermore, the need for surgical treatment of complications was evaluated. A minimum followup period of 3 months was maintained to facilitate an adequate observation of any postoperative complications.
Statistical analysis

Analytical evaluation of patient data and the comparison of outcome parameters were carried out by means of the Fisher's exact test and the independent $t$-test. A p-value of less than 0.05 was considered statistically significant. SPSS version 15.0.0 for Windows_ software (SPSS inc., Chicago, IL) was used for the statistical analysis

\section{RESULTS}

Patient characteristics and risk factors

A total of 77 women underwent a unilateral DIEP flap procedure, of which $49(64 \%)$ were performed in the university hospital and $28(36 \%)$ in the two community hospitals. The mean age of these patients at the time of operation in the university hospital was 48.8 years (range 26-70) and 49.4 years (range 35-71) in the community hospitals $(p=0.73)$. Eighteen per cent of the patients in the university hospital setting had an immediate reconstruction compared with $14 \%$ in the community hospital setting $(p=0.73)$. None of the baseline patient characteristics were significantly different between the two groups, a detailed description of which is presented in Table I. However, there seemed to be a trend towards more cases of hypertension among patients in the university hospital than among patients in the community hospitals ( $25 \%$ and $11 \%$, respectively) $(p=0.23)$, as well as a trend towards more smokers/former smokers in the community hospital setting than in the university hospital setting ( $32 \%$ and $18 \%$, respectively) $(p=0.26)$.

\begin{tabular}{llll} 
Table 1. Patient characteristics of 77 patients who had unilateral DIEP flap breast reconstruction. \\
\hline & $\begin{array}{l}\text { University hospital } \\
(\mathrm{n}=49)\end{array}$ & $\begin{array}{l}\text { Community hospital } \\
(\mathrm{n}=28)\end{array}$ & $p$ \\
\hline \hline Mean age in years (SD; range) & $48.8(7.9 ; 26-70)$ & $49.4(8.1 ; 35-71)$ & 0.73 \\
Immediate reconstruction (\%) & $9(18)$ & $4(14)$ & 0.76 \\
Hypertension (\%) & $12(25)$ & $3(11)$ & 0.23 \\
Diabetes (\%) & $2(4)$ & $1(4)$ & 1.00 \\
Smoker/former smoker (\%) & $9(18)$ & $9(32)$ & 0.26 \\
Abdominal scar (\%) & $5(10)$ & $4(14)$ & 0.72 \\
Radiotherapy (\%) & $16(33)$ & $7(25)$ & 0.61 \\
Chemotherapy (\%) & $16(33)$ & $12(43)$ & 0.46 \\
\hline \hline
\end{tabular}


Outcome and complications

Mean total operating time was 7 hours 29 minutes in the university hospital (range 3 hours 59 minutes-13 hours 1 minute) and in the community hospitals it was 6 hours 25 minutes (range 4 hours 16 minutes-8 hours 24 minutes) ( $p=0.002$ ). Mean length of hospital stay was 6.2 days in the university hospital (range 314 ) and 6.8 days in the community hospitals (range $5-14)(p=0.20)$. Detailed information about outcome is shown in Table 2. Fifteen postoperative complications (31\%) occurred in the university hospital setting, compared with $13(43 \%)$ in the community hospital setting, but this difference was not statistically significant $(p=0.33)$. Twenty-seven per cent of patients in the university hospital required one or more operations to treat these complications, compared with $21 \%$ in the community hospitals $(p=0.79)$. Wound dehiscence was more common in the community hospital setting than in the university hospital setting $36 \%$ and $6 \%$, respectively) $(p=0.001)$. Partial flap loss occurred in three cases $(6 \%)$ in the university hospital and in two cases $(7 \%)$ in the community hospitals $(p=1.00)$. There were two occurrences of total flap loss $(4 \%)$ in the university setting and none in the community setting $(p=0.53)$. The cumulative rate of flap loss (total flap loss plus partial flap loss) was $10 \%$ in the university hospitals and $7 \%$ in the community hospitals ( $p=$ 1.00). Fat necrosis was present in five patients $(10 \%)$ in the university setting and in two patients $(7 \%)$ in the community setting $(p=0.53)$.

Table 2. Outcome of 77 unilateral DIEP flaps.

\begin{tabular}{clll}
\hline & $\begin{array}{l}\text { University hospital } \\
(\mathrm{n}=49)\end{array}$ & $\begin{array}{l}\text { Community hospital } \\
(\mathrm{n}=28)\end{array}$ & $p$ \\
\hline \hline Total complications (\%) & $15(31)$ & $12(43)$ & 0.33 \\
Wound infection (\%) & $2(4)$ & 0 & 0.53 \\
Wound dehiscence (\%) & $3(6)$ & $10(36)$ & 0.001 \\
Haematoma (\%) & $3(6)$ & 0 & 0.30 \\
Fat necrosis (\%) & $2(4)$ & 0 & 0.53 \\
Flap necrosis (\%) & $5(10)$ & $2(7)$ & 1.00 \\
Partial flap necrosis (\%) & $3(6)$ & $2(7)$ & 1.00 \\
Total flap necrosis (\%) & $2(4)$ & 0 & 0.53 \\
Surgical intervention & $13(27)$ & $7(21)$ & 0.79 \\
\hline \hline
\end{tabular}

DISCUSSION

The purpose of our study was to compare outcome and postoperative complications of DIEP flap breast reconstruction between a university hospital setting and a community hospital setting. In our population, baseline patient characteristics of the two groups showed no significant differences. However, we found two significant differences in outcome parameters. First, total operating time of a unilateral DIEP flap procedure was longer in the university hospital than in the community hospitals ( 7 hours 29 minutes compared with 6 hours 25 minutes) ( $p=0.002$ ). These figures correspond to those found in previous reports on an early series of DIEP flaps ${ }^{8}$, although in centres with extensive experience with this procedure operative time can be reduced to a great extent. ${ }^{6}$ Factors that potentially contribute to a longer operative time in the university hospital are training of consultant plastic surgeons who are less experienced in microsurgery and the fact that part of the operation was carried out by residents. Secondly, a higher number of wound dehiscence was found in the community hospitals compared with the university hospital ( $36 \%$ and $6 \%$, respectively) ( $p=$ 0.001). Although no significant differences were found in patient characteristics to which this finding can be attributed, there was a trend towards more smokers or previous smokers in the community hospital setting, which could be an explanation for the difference in complications related to wound healing. Fisher's exact test pointed out that $33 \%$ of smokers/former smokers in the total population developed a wound dehiscence as compared to $12 \%$ of non-smokers. However, this finding, too, was not statistically significant $(p=0.07)$. In all hospitals, smokers were told to quit or minimise smoking, but some continued to smoke. One can propose that smokers should be counselled to stop smoking or the reconstruction be cancelled if they adhere to smoking. Flap necrosis did not significantly differ between university and community hospitals. The largest follow-up study for complications of DIEP flaps reports a partial flap necrosis rate of $2.5 \%$ and total flap necrosis rate of $0.5 \%{ }^{4}$ These numbers are lower than the numbers we found in our population.

However, the authors report $14 \%$ fat necrosis and most of their patients had an immediate reconstruction, whereas only 17\% of our patients had an immediate reconstruction. This difference may be explained by the possibility that a percentage of partial flap necrosis was mistakenly reported as fat necrosis in the abovementioned study. Especially in DIEP flap reconstruction after subcutaneous mastectomy, when most of the flap is buried and only a small skin paddle remains, it is more difficult to distinguish between fat necrosis and partial flap necrosis. No differences were found between the two groups in the need for surgical treatment of complications, and our figures compare to those reported in the literature. ${ }^{8}$ There was, nonetheless, a large number of patients that required one or more operations, apart from additional elective procedures such as reconstruction of the nipple-areola complex or scar revision. It must be pointed out, however, that most of these operations were minor procedures, for example, evacuation of a haematoma 
or debridement and closure of a small wound dehiscence. We did not observe a difference between the two hospital settings in postoperative risk of the most serious of complications in DIEP flap surgery: (partial) flap loss and fat necrosis. Another notable finding is the fact that the need for surgical treatment for any complication did not differ among the hospitals. In other words, when compared with the university setting, patients in the community hospital setting did not have an increased risk of complications, neither did they have to undergo more additional operations related to complications.

Limitations of this study include its retrospective nature and a relatively small patient population.

Furthermore, we were dependent on the documentation of different physicians involved in the follow-up of patients, so inter-observer variability cannot be ruled out. Also, data about flap weight and

ischaemia time was often incomplete. A prospective trial involving a larger population would be of value for further determining whether or not differences exist between university and community hospital settings. Our study provides insight into complication rates in both university and community hospitals, by taking account of the influence of hospital setting specific factors in addition to the skill and experience of the microsurgeon. It appears that unilateral DIEP flap breast reconstructions can be performed in a community hospital setting with the same degree of safety compared to a (specialised) university hospital setting. We feel that the minimum hospital-specific requirements necessary are: an experienced surgeon; an operating microscope; and a recovery or nursing ward equipped with enough staff to facilitate frequent flap monitoring. In addition, (nursing) staff should be trained to recognise flap failure, using protocols in which indicators of flap health, such as colour, capillary refill, temperature, and Doppler signal are combined. Also the facility to promptly return to the operating theatre in the event of a complication, such as arterial or venous thrombosis, is an important requirement. DIEP flap operation continues to be a difficult and timeconsuming operation and should be performed by a surgeon who has extensive experience in carrying out this procedure, but the hospital setting in which he or she performs this type of breast reconstruction seems to be of little importance if certain minimum requirements are met.

\section{ACKNOWLEDGEMENT}

Declaration of interest: The authors report no conflicts of interest. The authors alone are responsible for the content and writing of the paper.

\section{REFERENCES}

1. Allen RJ, Treece P. Deep inferior epigastric perforator flap for breast reconstruction. Ann Plast Surg 1994;32:32-38.

2. Blondeel PN. One hundred free DIEP flap breast reconstructions: a personal experience. Br J Plast Surg 1999;52:104-111.

3. Busic V, Das-Gupta R, Mesic H, et al. The deep inferior epigastric perforator flap for breast reconstruction, the learning curve explored. J Plast Reconstr Aesthet Surg 2006;59:580-584.

4. Gill PS, Hunt JP, Guerra AB, et al. A 10-year retrospective review of 758 DIEP flaps for breast reconstruction. Plast Reconstr Surg 2004;113:1153-1160.

5. Damen $T H$, Timman R, Kunst EH, et al. High satisfaction rates in women after DIEP flap breast reconstruction. J Plast Reconstr Aesthet Surg 2010;63:93-100.

6. Acosta R, Enajat M, Rozen WM, et al. Performing two DIEP flaps in a working day: an achievable and reproducible practice. J Plast Reconstr Aesthet Surg 2010;63:648-654

7. Sullivan $S R$, Fletcher $D R$, Isom $C D$, et al. True incidence of all complications following immediate and delayed breast reconstruction. Plast Reconstr Surg 2008;122:19-28.

8. Hofer SO, Damen TH, Mureau MA, et al. A critical review of perioperative complications in 175 free deep inferior epigastric perforator flap breast reconstructions. Ann Plast Surg 2007;59: 137-42.

9. Gusenoff JA, Vega SJ, Jiang S, et al. Free tissue transfer: comparison of outcomes between university hospitals and community hospitals. Plast Reconstr Surg 2006;118:671-675. 


\section{ABSTRACT}

Although advances in microsurgery have increased success rates of autologous breast reconstruction, microvascular thrombosis still remains a major concern as a cause of flap failure. At present, no evidencebased guidelines on pharmacological prevention of microvascular thrombosis exist. This study investigates the effect of acetylsalicylic acid on the incidence of microvascular complications in patients undergoing autologous breast reconstruction. Patients undergoing deep inferior epigastric artery perforator or free transverse rectus abdominis myocutaneous flap breast reconstruction at two academic centers in the Netherlands between 2005 and 2011 were included. Patients at one center received once daily $0.6 \mathrm{~mL}$ of nadroparine and $40 \mathrm{mg}$ acetylsalicylic acid, while patients at the other center received $0.6 \mathrm{~mL}$ nadroparine only. A total of 430 consecutive patients underwent 592 breast reconstructions. No statistically significant differences were found between the two groups in the incidence of flap failure (2.8 and $2.5 \%)$, microvascular thromboembolic complications (2.6 and 3.8\%), venous congestion (3.4 and 2.8\%), or overall complications (28.0 and 32.3\%). Hematoma tended to occur more often in the group receiving acetylsalicylic acid (9.2 and $4.7 \%$ ). It was found that no protective effect of acetylsalicylic acid on microvascular complications was present. Given its known risks and the somewhat increased occurrence of hematoma in the present study, we stopped to routinely administer acetylsalicylic acid after autologous breast reconstruction.

\section{INTRODUCTION}

Advances in microsurgical techniques and increased experience with the deep inferior epigastric artery perforator (DIEP) and free transverse rectus abdominis myocutaneous (TRAM) flap have led to flap survival rates of more than $95 \% .{ }^{1}$ However, microvascular thrombosis remains a major concern and can occur even in the absence of microsurgical errors. Endothelial trauma caused by the incision, manipulation, and suturing of the vessels is thought to play a central role in the pathophysiology. ${ }^{2,3}$ During this process, also known as the primary hemostasis, platelets adhere to the vascular subendothelium, release granules containing multiple mediators, and aggregate to form a hemostatic plug. ${ }^{4}$ In addition, the coagulation system is activated (secondary hemostasis), resulting in the generation of clotting factors and ultimately thrombin. Thrombin converts fibrinogen to fibrin, the final substrate of the clot and linkage between platelets. Primary and secondary hemostasis are not separate events but are intimately linked. ${ }^{4}$ Free flap failure occurs in 1 to $9 \%$ of the cases ${ }^{5}$ and is generally caused by microvascular thrombosis in the area of the vascular anastomosis or the distal flap microcirculation. ${ }^{2,6-8}$ While early diagnosis and revision of a thrombosed anastomosis have been shown to salvage free flaps, prevention of microvascular thrombosis remains of primary importance. ${ }^{9}$ Several experimental and clinical studies have investigated the preventive effect of various pharmacological agents. These agents include acetylsalicylic acid, ${ }^{10-12}$ heparin, ${ }^{6,13,14}$ dextran, ${ }^{15-18}$ various thrombolytics, ${ }^{19-29}$ and glycoprotein IIb/IIla inhibitors. ${ }^{20}$ Results of these studies are inconclusive, ${ }^{21}$ some agents have significant potential side effects, ${ }^{23}$ and all agents are known to carry risks of bleeding and hematoma formation. ${ }^{4,22}$ Therefore, at present still no consensus has been established on treatment guidelines in terms of ideal antithrombotic agents, timing, and dosage in reconstructive microsurgery. ${ }^{21,24} \mathrm{Few}$ clinical studies have investigated the effects of acetylsalicylic acid on free flap survival. ${ }^{6,9,25}$ These studies present conflicting outcomes because of different prophylaxis regimens and patient groups. Several literature reviews have been published as well, which made conflicting recommendations based on different inhomogeneous groups of patients. ${ }^{7,21,22,26,27}$ The development of evidence based algorithms to prevent microvascular thrombosis is essential to optimize outcomes and to increase comparability of postoperative results and complications. Therefore, the aim of this study was to investigate the value of acetylsalicylic acid for maintenance of postoperative microvascular patency in a homogeneous patient group undergoing DIEP or free TRAM flap breast reconstruction 


\section{PATIENTS AND METHODS}

All consecutive patients that underwent a DIEP or free TRAM flap breast reconstruction in the period of January 2005 to January 2011 at the Erasmus MC, University Medical Center Rotterdam (EMC) and Maastricht University Medical Center (MUMC), were included in this retrospective review. Patient demographics and perioperative data were extracted from the electronic medical record system and from hard copy medical charts. The primary outcome was the incidence of complete flap failure. Secondary outcomes were all clinically significant microvascular complications including microvascular thrombosis, venous congestion, partial flap necrosis, and hematoma leading to reoperation. At both the centers, to prevent systemic thromboembolic events all patients received perioperative elastic compression devices and once daily subcutaneous low molecular weight heparin (LMWH; nadroparine 5,700 aXa-IE 1/1/40.6 $\mathrm{mL}$ fraxiparine) until discharge, usually the 6th postoperative day. Administration of LMWH was initiated 12 hours before surgery with a second dose at 12 hours after the surgery. In the early postoperative period patients were positioned and nursed in a low- or semi-Fowler position. To prevent microvascular thrombosis, the vessels were intraoperatively locally irrigated with a heparinized solution before anastomosis at both the centers. At EMC all patients received additional $40 \mathrm{mg}$ acetylsalicylic acid once daily from the first postoperative day during a period of 6 weeks. At both the centers postoperative monitoring was performed clinically by an experienced nursing staff by checking flap color, temperature, and capillary refill. At the first postoperative day the flaps were monitored every 1 hour, the second day every 2 hours, and from the third postoperative day till discharge the flaps were monitored once every 4 hours.

\section{Statistical Analysis}

Fisher exact and chi-square tests were performed to analyze categorical variables and student $\mathrm{t}$-test was used for continuous variables. Version 17.0 of SPSS (SPSS Inc., Chicago, IL) was used for statistical analyses. Two-sided $p$ values $<0.05$ were considered statistically significant.

RESULTS

A total of 430 consecutive patients underwent 592 breast reconstructions, out of which 261 cases were included from EMC and 169 patients from MUMC. Patient demographics were similar between EMC and MUMC (Table 1), except for body mass index, which was significantly higher at EMC (EMC $27.2 \mathrm{~kg} / \mathrm{m2}$, MUMC $26.4 \mathrm{~kg} / \mathrm{m} 2 ; \mathrm{p}=0.02)$. Mean age at the time of breast reconstruction was 47.5 years at $\mathrm{EMC}$ and 47.8

years at MUMC $(p=0.54)$. At both the departments DIEP flaps were favored over free TRAM flaps. Timing of reconstruction was mostly secondary. Small but statistically significant differences between the two centers were found in operative approach. At EMC DIEP flaps were used more frequently than in MUMC ( $p=0.011)$, while at MUMC primary breast reconstructions were performed more often $(p<0.001)$. There were no statistically significant differences in potential risk factors for microvascular complications between the two groups (Table 1). The overall complication rate was similar at both centers (Table 2). We did not observe a statistically significant difference in the primary outcome, being complete flap failure (2.5\% at MUMC and $2.8 \%$ at EMC; $p=1.00$ ). Neither did we find any statistically significant differences in major microvascular complications such as arterial or venous thrombosis, venous congestion, partial flap necrosis, and hematoma leading to reoperation (Table 2).

Table 1. Patient, perioperative, and surgical characteristics of 430 ABR patients

EMC N=261 MUMC N=169

\section{Patient characteristics}

Age in years

BMI in $\mathrm{kg} / \mathrm{m}^{2}$

\section{Perioperative characteristics}

Total operating time (hours)

Total operating time for unilateral reconstruction (hours) Total operating time for bilateral reconstruction (hours)

Hospitalization duration in days

\section{Surgical characteristics}

Flap Type

DIEP flap

TRAM flap

Laterality of breast reconstruction

Unilateral

Bilateral

Timing of breast reconstruction

Primary

Secondary

tential risk
Mean (sd) Mean (sd)

$47.5(8.9) \quad 47.8(8.5)$

$27.2(4.2) \quad 26.4(4.1)$

$7.8(2.2) \quad 8.2(2.6)$

$6.5(1.3) \quad 7.0(1.7)$

$10.0(1.8) \quad 10.1(2.6)$

$8.7(5.5) \quad 7.6(2.3)$

$7.6(2.3)$

$96.6 \% 90.5 \%$

$63.8 \%$

$38.2 \% \quad 36.2 \%$

$23.0 \% \quad 47.5 \%$

$77.0 \% \quad 52.5 \%$

Adjuvant therapy (chemo, hormonal, radiotherapy) $\quad 41.8 \% \quad 43.3 \%$

Previous thromboembolic events

$1.8 \%$

Abbreviations: ABR, abdominal flap breast reconstruction; d, days; EMC, Erasmus MC, University Medic Center Rotterdam (nadroparine 5,700 aXa-IE + 40 mg acetylsalicylic acid once daily); h, hours; MUMC, Maastricht University Medical Center (nadroparine 5,700 aXa-IE once daily); y, years. 
Table 2. The occurrence of complications after ABR in 430 patients

\begin{tabular}{llll}
\hline Complications & EMC N=261 & MUMC N=169 & $p$ \\
\hline \hline Overall complication rate & $28.0 \%$ & $32.3 \%$ & 0.33 \\
Complete flap failure & $2.8 \%$ & $2.5 \%$ & 1.00 \\
Partial flap necrosis & $5.4 \%$ & $8.4 \%$ & 0.25 \\
Arterial thrombosis & $1.5 \%$ & $1.6 \%$ & 1.00 \\
Venous thrombosis & $1.1 \%$ & $2.2 \%$ & 0.45 \\
Venous congestion & $3.4 \%$ & $2.8 \%$ & 0.79 \\
Hematoma leading to reoperation & & & \\
\hline \hline
\end{tabular}

Tests performed with Fisher's exact tests.

\section{DISCUSSION}

Several experimental and clinical studies have investigated the effect of acetylsalicylic in prevention of thrombosis after arterial intimal injury. ${ }^{10-13,28}$ However, at present no consensus has been established on treatment guidelines. We analyzed the value of acetylsalicylic acid in preventing microvascular thrombosis and its complications in a homogeneous patient group undergoing DIEP and free TRAM flap breast reconstruction. In our study, patients received a postoperative anticoagulation regimen consisting of either once daily $40 \mathrm{mg}$ acetylsalicylic acid combined with 5,700 units LWMH subcutaneously, or 5,700 units LMWH subcutaneously once daily as a single prophylaxis. Acetylsalicylic acid, or aspirin, is a platelet aggregation inhibitor which acts as an inhibitor of thromboxane synthesis by antagonizing cyclooxygenase. It is widely used for secondary prevention of myocardial infarction or stroke due to its ability to particularly inhibit platelet aggregation which prevents arterial occlusions. This characteristic is presumed advantageous in microvascular surgery as well. Side effects include (gastrointestinal) bleeding, gastritis, allergic reactions, and nephrotoxicity. Nadroparin is a LMWH which, when bound to antithrombin III, accelerates the inactivation of factor II and factor Xa. Nadroparin halts the secondary coagulation pathway by inhibiting the activation of thrombin (factor Ila) by factor Xa. The amplification of the fibrin clotting cascade is stopped once factors Xa and Ila are inactivated.The effect of acetylsalicylic acid on anastomotic patency has been studied in several animal models with conflicting outcomes reported..$^{10-12,29-31}$ Some studies support the conclusion that low dose acetylsalicylic acid inhibits anastomotic venous thrombosis and improves microcirculatory perfusion. ${ }^{10,29}$ Other studies support the idea that platelets play a major role in arterial thrombosis, whereas fibrin is more important in venous thrombosis. ${ }^{30,31}$ Also several clinical studies have investigated the effects of acetylsalicylic acid on free flap survival. ${ }^{5,6,8,25}$ Ashjian et al compared a thromboprophylactic regimen consisting of $325 \mathrm{mg}$ acetylsalicylic acid once daily with 5,000 units of LMWH once daily in a population of patients undergoing free flap surgery for reconstruction of oncological defects of the head and neck, upper and lower extremity, trunk and breast and concluded that LMWH and acetylsalicylic acid $325 \mathrm{mg}$ daily are equally effective as postoperative anticoagulation agents in oncological free flap reconstruction. ${ }^{8}$ Chien et al concluded that $325 \mathrm{mg}$ acetylsalicylic acid once daily and subcutaneous heparin twice a day at 5,000 IU in head and neck free flap reconstruction was equally effective in preventing microvascular complications and flap failure compared with other existing regimens. ${ }^{25}$ Several studies made different recommendations based on a review of existing literature. ${ }^{7,26,27}$ Conrad et al proposed an anticoagulation algorithm for free flap thromboprophylaxis, consisting of low dose acetylsalicylic acid at a dose of $1.4 \mathrm{mg} / \mathrm{kg} / \mathrm{d}$ starting 2 weeks preoperatively which has to be continued for 2 weeks postoperatively, and heparin which is given intraoperatively as a bolus and local topical agent. ${ }^{26}$ Lecoq et al recommended the intraoperative use of heparin in microsurgery and the use of acetylsalicylic acid for inhibition of platelet aggregation. ${ }^{7}$ Stephan et al concluded that the combined use of acetylsalicylic acid with another anticoagulant would increase the risk of bleeding. ${ }^{27}$ Based on a recent literature review Brinkman et al recommended the use of LMWH monotherapy as this seems to be as effective as acetylsalicylic acid, and has the additional advantage to prevent systemic thromboembolic events, and unlike acetylsalicylic acid does not increase the risk of gastrointestinal bleeding. ${ }^{21}$ The aim of the present study was to analyze the effect of acetylsalicylic acid in preventing microvascular thromboembolic complications in a homogenous patient group undergoing DIEP and free TRAM flap breast reconstruction. Combined inhibition of primary and secondary hemostasis by administration of acetylsalicylic acid and nadroparine did not yield a lower rate of microvascular complications compared with monoprophylaxis by nadroparine. Our microvascular complication rates were comparable to previously reported incidence rates after DIEP and free TRAM flap breast reconstruction. ${ }^{32}$ Although, our study population was relatively large, the low rate of flap failure and low rate of microvascular complications may have reduced statistical power such that a potentially protective effect of acetylsalicylic acid could not be observed. We administered a rather low dose of acetylsalicylic acid $40 \mathrm{mg} / \mathrm{d}$, which is markedly lower than the $325 \mathrm{mg}$ once daily applied in the studies of Ashjian et al ${ }^{8}$ (aspirin only) and Chien et al ${ }^{25}$ (aspirin + heparin). The low dose of $40 \mathrm{mg} / \mathrm{d}$ was chosen because it has been shown that a dose as low as $30 \mathrm{mg}$ is sufficient to block approximately $95 \%$ of platelet cyclooxygenase 1 activity, which causes the antiplatelet effect. ${ }^{33}$ Other reasons to administer such a low dose were the risk of hematoma formation and gastrointestinal side effects, which are also dose dependent. ${ }^{33}$ The seeming absence of a protective effect of acetylsalicylic acid on flap failure may also be explained by the fact that its administration was started at the first postoperative day, which may have been 
too late. However, it has been shown that acetylsalicylic acid is rapidly absorbed in the stomach and upper intestine. Peak plasma levels occur 30 to 40 minute after aspirin ingestion, and inhibition of platelet function is evident by 1 hour after administration. ${ }^{33}$ Notably, we found a higher hematoma rate leading to reoperation in the LMWH and acetylsalicylic acid group (9.2\%) as compared with the LMWH monotherapy group (4.7\%). Although, this difference failed to reach statistical significance, this higher hematoma rate could be explained by the addition of acetylsalicylic acid causing a synergistic effect with LMWH. Given the known risks associated with the use of acetylsalicylic acid and the trend to lead to an increased occurrence of hematoma formation in the present study, we stopped the routine administration after autologous breast reconstruction.

This study has some limitations intrinsic to its retrospective design, which limit the level of evidence and mitigate the conclusions that can be drawn from the results. In the present study, we retrospectively compared two institutions with different regimens, which may have introduced some sort of bias. As free flap failure is multifactorial, future studies should ideally have a randomized controlled design to be able to provide the best level of evidence on the efficacy of different thromboprophylactic regimens.

\section{DISCLOSURE}

None of the authors has a financial interest in any of the products or drugs mentioned in this article.

\section{REFERENCES}

1 Jokuszies A, Herold C, Niederbichler AD, et al. Anticoagulative strategies in reconstructive surgery-clinical significance and applicability. Ger Med Sci 2012;10:Doc01

2 Adams WP Jr, Ansari MS, Hay MT, et al. Patency of different arterial and venous end-to-side microanastomosis techniques in a rat model. Plast Reconstr Surg 2000;105:156-161.

3 Acland R. Thrombus formation in microvascular surgery: an experimental study of the effects of surgical trauma. Surgery 1973;73:766-771.

4 Hanasono MM, Butler CE. Prevention and treatment of thrombosis in microvascular surgery. J Reconstr Microsurg 2008;24: 305-314.

5 Khouri RK, Cooley BC, Kunselman AR, et al. A prospective study of microvascular free-flap surgery and outcome. Plast Reconstr Surg 1998;102:711-721.

6 Kroll SS, Schusterman MA, Reece GP, et al. Timing of pedicle thrombosis and flap loss after free-tissue transfer. Plast Reconstr Surg 1996;98:1230-1233.

7 Lecoq JP, Senard M, Hartstein GM, et al. Thromboprophylaxis in microsurgery. Acta Chir Belg 2006;106:158-164.

8 Ashjian P, Chen CM, Pusic A, et al. The effect of postoperative anticoagulation on microvascular thrombosis. Ann Plast Surg 2007;59:36-39, discussion 39-40.

9 Peter FW, Franken RJ, Wang WZ, et al. Effect of low dose aspirin on thrombus formation at arterial and venous microanastomoses and on the tissue microcirculation. Plast Reconstr Surg 1997;99: 1112-1121.

10 Buckley RC, Davidson SF, Das SK. The role of various antithrombotic agents in microvascular surgery. Br J Plast Surg 1994;47:20-23.

11 Khouri RK, Cooley BC, Kenna DM, et al. Thrombosis of microvascular anastomoses in traumatized vessels: fibrin versus platelets. Plast Reconstr Surg 1990;86:110-117. 
12 Chung TL, Pumplin DW, Holton LH III, et al. Prevention of microsurgical anastomotic thrombosis using aspirin, heparin, and the glycoprotein IIb/IIla inhibitor tirofiban. Plast Reconstr Surg 2007;120:1281-1288.

13 Greenberg BM, Masem M, May JW Jr. Therapeutic value of intravenous heparin in microvascular surgery: an experimental vascular thrombosis study. Plast Reconstr Surg 1988;82:463-472.

14 Rooks MD, Rodriguez J Jr, Blechner M, Zusmanis K, Hutton W. Comparative study of intraarterial and intravenous anticoagulants in microvascular anastomoses. Microsurgery 1994;15:123-129.

15 Zhang B, Wieslander JB. Improvement of patency in small veins following dextran and/or low-molecularweight heparin treatment. Plast Reconstr Surg 1994;94:352-358.

16 Rothkopf DM, Chu B, Bern S, et al. The effect of dextran on microvascular thrombosis in an experimental rabbit model. Plast Reconstr Surg 1993;92:511-515.

17 Romano JE, Biel MA. Maintaining long-term vessel patency in microvascular surgery using tissue-type plasminogen activator. Otolaryngol Head Neck Surg 1991;105:391-395.

18 Jayaprasad K, Mathew J, Thankappan K, et al. Safety and efficacy of low molecular weight dextran (dextran 40) in head and neck free flap reconstruction. J Reconstr Microsurg 2013; 29:443-448.

19 Atiyeh BS, Hashim HA, Hamdan AM, et al. Local recombinant tissue plasminogen activator (rt-PA) thrombolytic therapy in microvascular surgery. Microsurgery 1999;19:265-271.

20 Rohrich RJ, Handren J, Kersh R, et al. Prevention of microvascular thrombosis with short-term infusion of human tissue-type plasminogen activator. Plast Reconstr Surg 1996;98:118-128.

21 Brinkman JN, Derks LH, Klimek M, et al. Perioperative fluid management and use of vasoactive and antithrombotic agents in free flap surgery: a literature review and clinical recommendations. J Reconstr Microsurg 2013;29:357-366.

22 Pugh CM, Dennis RH II, Massac EA. Evaluation of intraoperative anticoagulants in microvascular free-flap surgery. J Natl Med Assoc 1996;88:655-657.
23 Disa لJ, Polvora VP, Pusic AL, et al. Dextran-related complications in head and neck microsurgery: do the benefits outweigh the risks? A prospective randomized analysis. Plast Reconstr Surg 2003;112:1534-1539.

24 Brands MT, van den Bosch SC, et al. Prevention of thrombosis after microvascular tissue transfer in the head and neck. A review of the literature and the state of affairs in Dutch Head and Neck Cancer Centers. Int J Oral Maxillofac Surg 2010;39:101-106.

25 Chien W, Varvares MA,Hadlock T, et al. Effects of aspirin and low-dose heparin in head and neck reconstruction using microvascular freeflaps. Laryngoscope 2005;115:973-976.

26 Conrad MH, Adams WP Jr. Pharmacologic optimization of microsurgery in the new millennium. Plast Reconstr Surg 2001;108:2088-2096.

27 Stephan B, Schenk JF, Nemeh A, et al. The use of antithrombotic agents in microvascular surgery. Clin Hemorheol Microcirc 2009;43:51-56.

28 Savoie FH, Cooley BC, Gould JS. Evaluation of the effect of pharmacologic agents on crush-avulsion arterial injuries: a scanning electron microscopy study. Microsurgery 1991;12:292-300.

29 Ouriel K, Donayre C, Shortell CK, et al. The hemodynamics of thrombus formation in arteries. J Vasc Surg 1991;14:757-762, discussion 762-763

30 Esclamado RM, Carroll WR. The pathogenesis of vascular thrombosis and its impact in microvascular surgery. Head Neck 1999; 21:355-362.

31 Li X, Cooley BC. Effect of anticoagulation and inhibition of platelet aggregation on arterial versus venous microvascular thrombosis. Ann Plast Surg 1995;35:165-169, discussion 169-170.

32 Acosta R, Smit JM, Audolfsson T, et al. A clinical review of 9 years of free perforator flap breast reconstructions: an analysis of 675 flaps and the influence of new techniques on clinical practice. J Reconstr Microsurg 2011;27:91-98.

33 Patrono C, Coller B, Dalen JE, et al. Platelet-active drugs : the relationships among dose, effectiveness, and side effects. Chest 2001;119:39S-63S. 

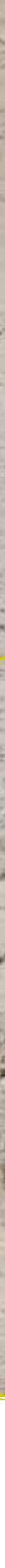

Pulmonary embolism after abdominal flap breast reconstruction: prediction and prevention.

Enajat M, Damen TH, Geenen A, Timman R, van der Hulst RR, Mureau MA.

Plast. Reconstr. Surg. 131: 1213, 2013. 
Background

Symptomatic pulmonary embolism constitutes a significant risk following abdominal flap breast reconstruction. Reported rates vary from 0 to 6 percent. The authors assessed risk factors associated with symptomatic pulmonary embolism and constructed a prediction model to identify high-risk patients.

\section{Methods}

Patients undergoing deep inferior epigastric perforator or transverse rectus abdominis musculocutaneous flap breast reconstructions at two academic centers from January 2005 through January 2011 were included. Thromboprophylaxis measures included early ambulation, low-molecular-

weight heparin, elastic stockings, A-V Impulse System foot pumps, and pneumatic stockings. Risk factors for symptomatic pulmonary embolism were analyzed and weights were assigned to these risk factors. Sensitivity and specificity were maximized using receiver operating characteristic curves.

\section{Results}

Of 430 consecutive patients, symptomatic pulmonary embolism occurred in 17 cases (4.0 percent). Two independent predictors for symptomatic pulmonary embolism were found, body mass index higher than 25 , additionally higher than 28 , and the $B R C A$ gene mutation. Operation duration and bilaterality of reconstructions were dependent on the $B R C A$ mutation and both indirect predictors for symptomatic pulmonary embolism. Optimization of sensitivity and specificity resulted in a prediction model. No significant differences in efficacy were found between the different thromboprophylaxis measures.

\section{Conclusions}

The rate of symptomatic pulmonary embolism was 4.0 percent, despite standard thromboprophylaxis. Body mass index and $B R C A$ were significant predictors for symptomatic pulmonary embolism. The authors integrated these factors into a prediction model, which provides a useful tool for identification of high-risk patients. This latter category may benefit from a more aggressive thromboprophylaxis approach.

\section{INTRODUCTION}

Despite thromboprophylaxis measures, symptomatic pulmonary embolism remains a significant risk and a potentially lethal complication after abdominal flap breast reconstruction. ${ }^{1-12}$ Rates of symptomatic pulmonary embolism after abdominal flap breast reconstruction vary from 0 to 6.3 percent. ${ }^{1-11}$ Thromboembolic complications such as deep venous thrombosis and pulmonary embolism often have a subclinical course. Consequently, incidence rates reported in the literature are likely to be an underestimation. Indeed, the combined incidence of symptomatic and asymptomatic pulmonary embolism after immediate transverse rectus abdominis musculocutaneous (TRAM) flap breast reconstruction was found to be 20.4 percent. ${ }^{13} \mathrm{Abdominal}$ flap breast reconstruction involves several important risk factors for venous thromboembolism. ${ }^{11}$ Total anesthesia time often exceeds 6 hours, especially when reconstruction is directly preceded by mastectomy (primary reconstruction). Furthermore, in primary cases after therapeutic mastectomy the presence of malignancy adds to the thrombogenic nature of the intervention. ${ }^{14}$ Also, an average age older than 45 years in this patient population constitutes a concomitant risk factor for venous thromboembolism. ${ }^{14}$ The presence of sufficient abdominal fat is a prerequisite for abdominal flap breast reconstruction. Overweight, however, is a known risk factor for pulmonary embolism. ${ }^{10}$ Finally, cancerspecific therapies such as chemotherapy, hormonal therapy, and radiotherapy constitute additional factors that may induce venous thromboembolism. ${ }^{15}$ In predicting the risk of venous thromboembolism, the Caprini Risk-Assessment Model has been applied. This model has been validated as a predictor of venous thromboembolism in different surgical specialties, ${ }^{16-18}$ including plastic surgery. ${ }^{19}$ The modified version of the Caprini Risk-Assessment Model, known as the Davison-Caprini Risk-Assessment Model, pertains to general plastic surgery ${ }^{19}$ Given the wide variability in patient-specific venous thromboembolism risk factors, the generic nature of this risk-assessment model can make it inaccurate for the individual patient undergoing abdominal flap breast reconstruction. It is imperative that the risk of symptomatic pulmonary embolism and asymptomatic pulmonary embolism after abdominal flap breast reconstruction be fully recognized and that it is acknowledged that the incidence of asymptomatic pulmonary embolism is likely to be much higher. Development of an accurate predictive model, with increased predictive power for symptomatic pulmonary embolism in the setting of abdominal flap breast reconstruction, may be a valuable adjunct to clinical experience. Based on this risk-assessment model, patients could be assigned to an appropriate venous thromboembolism risk category before abdominal flap breast reconstruction. Therefore, we evaluated the outcomes of 6 years of experience at two academic centers, both homogenous in their population and perioperative procedures. The objective was to accurately evaluate the incidence of symptomatic pulmonary embolism in patients undergoing abdominal flap breast reconstruction and to specify the relative 
contribution of established risk factors for symptomatic pulmonary embolism. In addition, we developed a risk-assessment model specifically for abdominal flap breast reconstruction to better define patients at increased risk of symptomatic pulmonary embolism and to formulate cutoff points for specific risk factors which, if exceeded, would mean a substantial increase in the risk of symptomatic pulmonary embolism.

\section{PATIENTS AND METHODS}

All consecutive patients who underwent deep inferior epigastric perforator (DIEP) or TRAM flap breast reconstruction at the Erasmus MC, University Medical Center Rotterdam and Maastricht University Medical Centre between January of 2005 and January of 2011 were included in this retrospective review. Patient demographics and perioperative data were collected. The primary outcome was the incidence of symptomatic pulmonary embolism. Other types of venous thromboembolism were excluded from analysis. Any episode of symptomatic pulmonary embolism occurring within 30 days after surgery was documented and included in the analysis. At both centers, the postoperative thromboprophylaxis regimens consisted of perioperative elastic compression devices, early ambulation, and low-molecular-weight heparin [Nadroparine 5700 aXa-IE (= 0.6 ml, Fraxiparine; GlaxoSmithKline, Brentford, United Kingdom)]. Lowmolecular weight heparin was administrated subcutaneously 12 hours before surgery and continued once daily starting 12 hours postoperatively. Patients received rocuronium bromide $(0.15$ to $0.50 \mathrm{mg} / \mathrm{kg})$ as a muscle relaxant during induction of general anesthesia and during dissection of the perforators within the rectus abdominis muscles. Elastic compression devices were applied preoperatively and were continued unti full mobilization. In the early postoperative period, patients were positioned and nursed in a low- or semiFowler position. Mobilization was initiated on the first postoperative day, starting with bedside mobilization that was increased to walking in the days following. Patients presenting with symptoms of pulmonary embolism (i.e., chest pain, shortness of breath, tachypnea, tachycardia, and decreased oxygen saturation) were screened for pulmonary embolism using the Wells criteria. Patients who scored more than 4 points underwent computed tomographic angiography. In accordance with Dutch guidelines, all patients with proven pulmonary embolism were treated with coumarins for a period of 6 months. Patient-specific risk factors that were analyzed as potential predictors for symptomatic pulmonary embolism after abdominal flap breast reconstruction included age, body mass index, BRCA1 and BRCA2 gene mutations, smoking, a history of cancer, presence of malignancy at the time of reconstruction, chemotherapy or hormonal therapy at the time of reconstruction, or previous radiotherapy. Perioperative variables that were analyzed as potential predictors included timing of reconstruction (primary or secondary), laterality of reconstruction (unilateral or bilateral), operation duration, the use of different elastic compression devices [i.e., A-V Impulse
System (Covidien, Mansfield, Mass.) foot pumps, pneumatic stockings, elastic stockings], the number of reoperations, and the occurrence of complications other than pulmonary embolism.

\section{Statistical Analysis}

The effects of potential predictors for pulmonary embolism were analyzed using Fisher's exact tests for dichotomous variables, chi-square tests for categorical variables, and Mann-Whitney $U$ tests for continuous variables. We performed a backward logistic regression analysis with symptomatic pulmonary embolism as the dependent variable and relevant variables (body mass index, smoking, oncologic mastectomy, BRCA gene, radiotherapy, primary/secondary reconstruction, operation time, number of reoperations, previous thromboembolic events, and mechanical thromboprophylaxis) as initial independent variables. For easy use of the screening instrument, significant continuous covariates were categorized into two, three, or four equal sized categories. Separate models were postulated including these categorized covariates. Receiver operating characteristic curve analyses were performed, and the best model was selected on the basis of the largest area under the curve. Version 20.0 of IBM-SPSS (IBM Corp., Armonk, N.Y.) was used for statistical analyses. Two-sided values of $p<0.05$ were considered statistically significant.

\section{RESULTS}

In our series, 430 consecutive patients underwent 592 breast reconstructions. A total of 261 patients were included from Erasmus MC, University Medical Center Rotterdam, and 169 patients were included from Maastricht University Medical Centre. Patient demographics were similar in both centers (Table 1). At both medical centers DIEP flaps were favored over TRAM flaps. Timing of reconstruction was mostly secondary. At Erasmus MC, University Medical Center Rotterdam, DIEP flaps were used more frequently $(p=0.03)$, whereas primary reconstructions were more frequently performed at Maastricht University Medical Centre $(p<0.001)$. Also, hospitalization was significantly longer at Erasmus MC, University Medical Center Rotterdam compared with Maastricht University Medical Centre $(p=0.01)$.

Overall complication rates including the occurrence of symptomatic pulmonary embolism did not differ significantly between the two centers (Maastricht University Medical Centre, 33 percent; Erasmus MC, University Medical Center Rotterdam, 28 percent; $p=0.33$ ). Symptomatic pulmonary embolism occurred in 17 cases, resulting in an overall incidence rate of 4.0 percent (Maastricht University Medical Centre, 2.4 percent; Erasmus MC, University Medical Center Rotterdam, 5.0 percent; $p=0.21$ ). The incidences of general complications and flap-related complications were similar in the symptomatic pulmonary embolism group and the non-symptomatic pulmonary embolism group (Table 2). 
Table 1. Baseline demographics and surgical intervention characteristics in $430 \mathrm{ABR}$ patients

\begin{tabular}{|c|c|c|c|}
\hline & $\mathrm{EMC} \mathrm{N}=\mathbf{2 6 1}$ & MUMC N=169 & \\
\hline Patient characteristics & Mean \pm sd (range) & Mean \pm sd (range) & $p^{1}$ \\
\hline Age in years & $47.5 \pm 9.0(27-73)$ & $47.9 \pm 8.6(23-70)$ & 0.54 \\
\hline $\mathrm{BMI}$ in $\mathrm{kg} / \mathrm{m}^{2}$ & $27.2 \pm 3.7(19.2-37.7)$ & $26.4 \pm 4.0(19.5-39.0)$ & 0.09 \\
\hline \multicolumn{4}{|l|}{ Perioperative characteristics } \\
\hline Total operating time in hours & $7.8 \pm 2.2(3.5-14.20)$ & $8.2 \pm 2.6(3.2-16.0)$ & 0.18 \\
\hline \multicolumn{4}{|l|}{ Total operating time for unilateral reconstruction in } \\
\hline \multicolumn{4}{|l|}{ Total operating time for bilateral reconstruction in } \\
\hline Hospitalization duration in days & $8.7 \pm 5.5(5-55)$ & $7.6 \pm 2.4(0-21)$ & 0.01 \\
\hline Davison-Caprini total scores & $5.5 \pm 1.4(2-10)$ & $5.6 \pm 1.1(3-10)$ & 0.57 \\
\hline Surgical characteristics & $n(\%)$ & $n(\%)$ & $p^{2}$ \\
\hline \multicolumn{4}{|l|}{ Flap type } \\
\hline DIEP & $252(96.6 \%)$ & 154 (91.1\%) & \\
\hline TRAM & $9(3.4 \%)$ & $15(8.9 \%)$ & 0.029 \\
\hline \multicolumn{4}{|l|}{ Laterality of breast reconstruction } \\
\hline Unilateral & $161(61.7 \%)$ & 107 (63.3\%) & \\
\hline Bilateral & $100(38.3 \%)$ & $62(36.7 \%)$ & 0.76 \\
\hline \multicolumn{4}{|l|}{ Timing of breast reconstruction } \\
\hline Primary & $48(18.4 \%)$ & $72(42.6 \%)$ & \\
\hline Secondary & $191(73.2 \%)$ & $87(51.5 \%)$ & \\
\hline Combined reconstruction & $22(8.4 \%)$ & $10(5.9 \%)$ & $<0.001$ \\
\hline \multicolumn{4}{|l|}{ Potential risk factors for SPE } \\
\hline Smoking & $19(7.3 \%)$ & $7(4.1 \%)$ & 0.22 \\
\hline Adjuvant therapy (chemo, hormonal, radiotherapy) & $109(41.8 \%)$ & $73(43.27 \%)$ & 0.84 \\
\hline Previous thromboembolic events & $3(1.1 \%)$ & $1(0.6 \%)$ & 1.00 \\
\hline BRCA $1 / 2$ gene mutation & $60(23.0 \%)$ & $29(17.2 \%)$ & 0.18 \\
\hline
\end{tabular}

$p^{1}=$ Mann-Whitney $U$ test; $p^{2}=$ Fisher's exact test.

ABR, abdominal flap breast reconstruction; EMC, Erasmus MC, University Medical Center Rotterdam; MUMC,

Maastricht University Medical Center; SPE, symptomatic pulmonary embolism.
Table 2. General and flap related complications in patients with and without SPE

Cases without SPE Cases with SPE

$n=413$ $\mathrm{n}=17$

\begin{tabular}{llll} 
& $\mathbf{n = 4 1 3}$ & $\mathbf{n = 1 7}$ & $P$ \\
\hline \hline General complications & & & \\
$\quad$ Pneumothorax & $0.5 \%$ & $0.0 \%$ & 1.00 \\
Seroma & $1.2 \%$ & $0.0 \%$ & 1.00 \\
$\quad$ Hematoma leading to reoperation & $7.5 \%$ & $5.9 \%$ & 1.00 \\
$\quad$ Infection & $4.1 \%$ & $0.0 \%$ & 1.00 \\
$\quad$ Wound healing problems & $2.2 \%$ & $0.0 \%$ & 1.00 \\
Flap related complications & & & \\
Arterial thrombosis & $1.5 \%$ & $5.9 \%$ & 0.25 \\
$\quad$ Venous thrombosis & $1.7 \%$ & $0.0 \%$ & 1.00 \\
Venous congestion & $3.1 \%$ & $5.9 \%$ & 0.44 \\
Partial flap necrosis & $7.0 \%$ & $0.0 \%$ & 0.62 \\
Complete flap failure & $3.9 \%$ & $0.0 \%$ & 1.00 \\
\hline Testspeformed & & &
\end{tabular}

Tests performed with Fisher's exact tests.

SPE, symptomatic pulmonary embolism.

No mortalities occurred and all patients recovered well from their episode of symptomatic pulmonary embolism. In accordance with Dutch guidelines for treatment of primary venous thromboembolism, we did not perform standard preoperative or postoperative laboratory assessments for coagulation abnormalities in these patients, because none of them had a positive family history or had experienced a previous episode of venous thromboembolism. Symptomatic pulmonary embolism occurred in the early postoperative period, with a range of 2 to 10 days. One patient developed multiple pulmonary embolisms 2 days after discharge, for which she was readmitted. One patient took off her A-V Impulse System foot pumps systematically because she felt uncomfortable wearing them. In another patient, atrial fibrillation was thought to be the cause of symptomatic pulmonary embolism, as this occurred de novo postoperatively without any signs of deep venous thrombosis. No significant differences in efficacy were found between the different elastic compression devices used. The reconstructive technique (DIEP or TRAM flap) did not influence the risk of symptomatic pulmonary embolism either $(p=0.61$ ) (Tables 3 and 4 ). Body mass index and BRCA gene mutations were significantly related to symptomatic pulmonary embolism (body mass index, $p=0.001$; $B R C A, p=0.01$ ) (Tables 3 and 4 ). 
Table 3. Risk factors for SPE after ABR

\begin{tabular}{|c|c|c|c|}
\hline Risk factors for SPE & $\begin{array}{c}\text { Cases without } \\
\text { SPE } \\
n=413\end{array}$ & $\begin{array}{c}\text { Cases with SPE } \\
n=17\end{array}$ & \\
\hline & Mean (sd) & Mean (sd) & $\frac{p^{1}}{1}$ \\
\hline Age (years) & $47.7(8.9)$ & $46.9(8.4)$ & 0.62 \\
\hline BMI $\left(\mathrm{kg} / \mathrm{m}^{2}\right)$ & $26.7(3.8)$ & $29.8(2.4)$ & $<0.001$ \\
\hline $\begin{array}{l}\text { Operation duration } \\
\text { (hours) }\end{array}$ & $7.9(2.4)$ & $9.0(2.4)$ & 0.07 \\
\hline $\begin{array}{l}\text { Davison-Caprini total } \\
\text { score }\end{array}$ & $5.5(1.3)$ & $5.5(1.3)$ & 0.98 \\
\hline Hospitalization (days) & $8.0(4.5)$ & $11.6(3.2)$ & $<0.001$ \\
\hline Number of reoperations & $0.3(0.5)$ & $0.2(0.4)$ & 0.97 \\
\hline
\end{tabular}

SPE, symptomatic pulmonary embolism; BMI, body mass index.

*Mann-Whitney U test.

Table 4. Risk Factors for Symptomatic Pulmonary Embolism after Abdominal Flap Breast Reconstruction

\begin{tabular}{|c|c|c|c|c|}
\hline Risk factors for SPE & $\begin{array}{c}\text { Cases without } \\
\text { SPE } \\
n=413\end{array}$ & $\begin{array}{c}\text { Cases with } \\
\text { SPE } \\
n=17\end{array}$ & $p^{*}$ & Odds Ratio \\
\hline \multicolumn{5}{|l|}{ BMI categories } \\
\hline$<25 \mathrm{~kg} / \mathrm{m}^{2}$ & $158(38 \%)$ & $0(0 \%)$ & $0.001 \dagger$ & \\
\hline $25-28 \mathrm{~kg} / \mathrm{m}^{2}$ & $130(31 \%)$ & $3(17 \%)$ & $0.23+$ & \\
\hline $28-30 \mathrm{~kg} / \mathrm{m}^{2}$ & $41(10 \%)$ & $5(29 \%)$ & $0.01+$ & \\
\hline$>30 \mathrm{~kg} / \mathrm{m}^{2}$ & $84(20 \%)$ & $9(53 \%)$ & $0.004+$ & \\
\hline Smoking & $25(6.1)$ & $1(5.9)$ & 1.00 & 0.97 \\
\hline BRCA gene mutation & $81(19.6)$ & $8(47.1)$ & 0.01 & 3.64 \\
\hline Bilateral reconstruction & $152(36.8)$ & $10(58.8)$ & 0.08 & 2.45 \\
\hline Malignancy present at time of surgery & $156(38.0)$ & $4(23.5)$ & 0.31 & 0.50 \\
\hline $\begin{array}{l}\text { Adjuvant therapy (chemo, hormonal, } \\
\text { radiotherapy) }\end{array}$ & $174(42.1)$ & $8(47.1)$ & 0.80 & 1.22 \\
\hline Postoperative radiotherapy & $115(27.8)$ & $6(35.3)$ & 0.58 & 1.41 \\
\hline Chemotherapy & $183(44.3)$ & $7(41.2)$ & 1.00 & 0.88 \\
\hline Hormonal therapy & $112(27.1)$ & $4(23.5)$ & 1.00 & 0.83 \\
\hline DIEP flap breast reconstruction & $389(94.2)$ & $17(100)$ & 0.61 & NA \\
\hline Primary reconstruction & $113(27.4)$ & $7(43.81)$ & & \\
\hline Secondary reconstruction & $269(65.1)$ & $9(56.3)$ & 0.46 & \\
\hline Combined reconstruction & $31(7.5)$ & $1(5.9)$ & & \\
\hline Previous thromboembolic events & $4(1.0)$ & - & 1.00 & NA \\
\hline Mechanical prophylaxis & $345(83.5)$ & $13(76.5)$ & 0.50 & 0.64 \\
\hline Pneumatic stockings & $91(22.0)$ & $2(11.8)$ & 0.55 & 0.47 \\
\hline AV-impulse foot pumps & $104(25.2)$ & $6(35.3)$ & 0.40 & 1.62 \\
\hline Elastic stockings & $150(36.3)$ & $5(29.4)$ & 0.62 & 0.73 \\
\hline
\end{tabular}

SPE, symptomatic pulmonary embolism; BMI, body mass index; NA, not applicable; †Fisher's exact test
Table 5. Result of backward logistic regression analysis.

\begin{tabular}{|c|c|c|c|c|}
\hline & Estimate & Standard error & $\mathbf{p}$ & $\begin{array}{c}\text { Odds ratio } \\
{[95 \% \mathrm{Cl}]}\end{array}$ \\
\hline BMI & 0.168 & 0.060 & 0.005 & $1.18[1.05-1.33]$ \\
\hline BRCA & 1.082 & 0.513 & 0.035 & $2.95[1.08-8.06]$ \\
\hline Constant & -82.880 & 1.789 & $<0.001$ & \\
\hline
\end{tabular}

Note: Nagelkerke's $R^{2}=0.110$ and Cox \& Snell $R^{2}=0.032$.

$\mathrm{BMI}$, body mass index; BRCA, breast cancer gene mutation

A nonsignificant trend was observed that operation duration $(p=0.07)$ and bilateral reconstruction $(p=0.08)$ were related to symptomatic pulmonary embolism. Positive BRCA status and bilateral reconstruction were both associated with a significantly longer operation duration compared with $B R C A$-negative status and unilateral reconstruction (BRCA negative versus $B R C A$-positive: 7.4 versus 10.2 hours, $p<0.001$; unilateral versus bilateral reconstruction: 6.7 versus 10.0 hours, $p<0.001$ ). Prediction models including the univariately identified symptomatic pulmonary embolism predictors (body mass index, BRCA gene mutations, operation duration, and bilaterality) yielded areas under the curve in the range of 0.652 to 0.683 . In the backward logistic regression analysis, body mass index and BRCA status remained significant predictors (Table 5). In the prediction models, using a weight of 2 for positive $B R C A$ status and a dichotomous body mass index resulted in an area under the curve of 0.718 and a body mass index in three equal sized categories in an area under the curve of 0.782 . In addition, body mass index in four equal sized categories resulted in an area under the curve of 0.740 . Using a weight of 1 for positive BRCA status and a dichotomous body mass index resulted in an area under the curve of 0.718 and a trichotomous body mass index in an area under the curve of 0.814 , and body mass index in four categories resulted in an area under the curve of 0.753 . It was concluded that the prediction model using $B R C A$ with weight 1 and body mass index in three categories $(<25$, 25 to 28 , and $>28$ ), using a cutoff score of 2 or higher was the most efficient model. The body mass index cutoff values derived from this approach differed from the World Health Organization standards for overweight and obesity. Using the World Health Organization classification $(<25,25$ to 30 , and $>30)$ resulted in an area under the curve of 0.744 . The most efficiënt model is defined by Equation 1.

Equation 1:

Risk factor $=B R C A+$ body mass index $\geq 25(1)+$ body mass index $\geq 28$ 
This model results in a score between 0 and 3 . Thus, for example, a woman carrying the BRCA mutation, with a body mass index of 30, will have the risk score of $1+1+1=3$, and is categorized as high risk. A woman not carrying the $B R C A$ mutation with a body mass index of 26 will get the score $0+1+0=1$ and is classified as low-risk. Cutoff scores, sensitivity, specificity, overall accuracy, and areas under the curve of the most efficient model, the second best, and one using the World Health Organization cutoff scores are presented in Table 6. Receiver operating characteristic curves are depicted in Figure 1. The determination of cutoff scores is a tradeoff between sensitivity and specificity, and false-negatives and false-positives. Patients exceeding a specific cutoff score would be at higher risk for symptomatic pulmonary embolism after abdominal flap breast reconstruction.

Table 6. Cut-off scores, sensitivity, specificity, false positives and area under the curve (AUC)

\begin{tabular}{llllll}
\hline Model & Cut-off & Sensitivity & Specificity & Overall accuracy & AUC \\
\hline \hline 1. Most efficient & & & & & \\
BRCA + & $\geq 1$ & $100 \%$ & $30 \%$ & $33 \%$ & 0.650 \\
BMI > 25+ & $\geq 2$ & $100 \%$ & $63 \%$ & $64 \%$ & 0.814 \\
BMI > 28 & $\geq 3$ & $29 \%$ & $92 \%$ & $89 \%$ & 0.605 \\
2. Second best & & & & & \\
BRCA + & $\geq 1$ & $100 \%$ & $23 \%$ & $27 \%$ & 0.617 \\
BMI > 24+ & $\geq 2$ & $100 \%$ & $51 \%$ & $53 \%$ & 0.753 \\
BMI > 27 + & $\geq 3$ & $65 \%$ & $75 \%$ & $75 \%$ & 0.700 \\
BMI > 30 & $\geq 4$ & $24 \%$ & $94 \%$ & $91 \%$ & 0.587 \\
3. WHO cut-off & & & & & \\
BRCA + & $\geq 1$ & $100 \%$ & $30 \%$ & $33 \%$ & 0.650 \\
BMI > 25 + & $\geq 2$ & $76 \%$ & $72 \%$ & $73 \%$ & 0.744 \\
BMI > 30 & $\geq 3$ & $24 \%$ & $94 \%$ & $91 \%$ & 0.587 \\
\hline \hline BMI, body mass index; BRCA, breast cancer gene mutation; AUC, area under the curve; WHO, World
\end{tabular}
Health Organization.

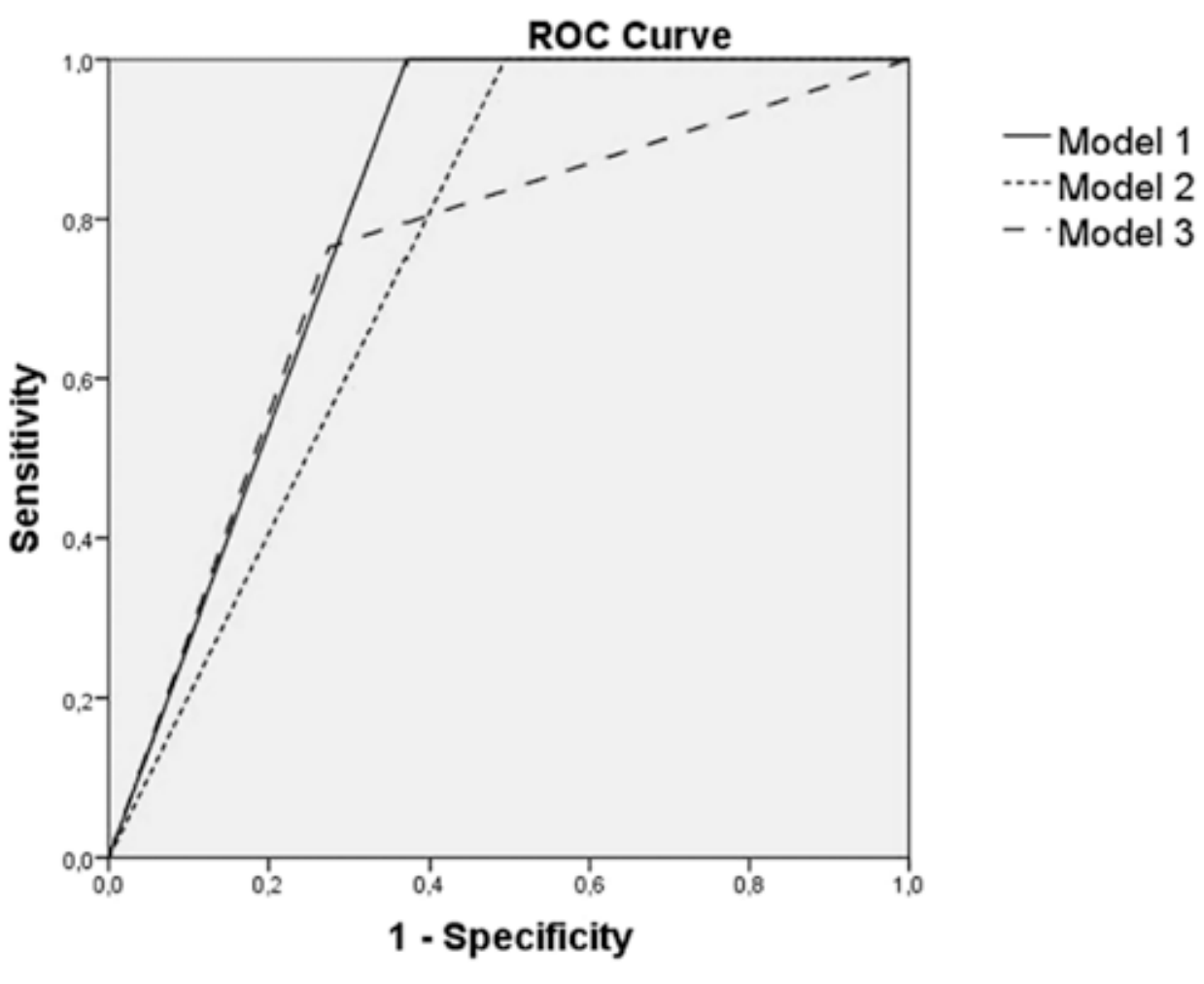

Model $1 \cdot \mathrm{BRCA}+\mathrm{BMI} \geq 25+\mathrm{BMI} \geq 28 ; \mathrm{AUC}=0.814$ (preferred)

Model 2 - $\mathrm{BRCA}+\mathrm{BMI} \geq 24+\mathrm{BMI} \geq 27+\mathrm{BMI} \geq 30 ; \mathrm{AUC}=0.753$

Model 3 - BRCA + BMI $\geq 25+$ BMI $\geq 30$ (WHO cut-off); $\mathrm{AUC}=0.744$

Fig. 1. Receiver operating characteristic (ROC) curves of selected models. $B R C A$, breast cancer gene mutation; BMI, body mass index; $A U C$, area under the curve; WHO, World Health Organization.

\section{DISCUSSION}

Symptomatic pulmonary embolism is a potentially fatal complication after abdominal flap breast reconstruction and is associated with significant morbidity. ${ }^{20-22}$ Reported incidence rates vary from 0 to 6 percent, in spite of standard thromboprophylaxis. ${ }^{1-11}$ Among plastic surgical procedures, the risk of symptomatic pulmonary embolism is highest in liposuction, with a reported maximum incidence of 23 percent. ${ }^{23}$ Breast reconstruction is second, with a maximum incidence of 6.0 percent, followed by thermal injuries ( 4.4 percent), abdominoplasty ( 0.3 to 3.4 percent), and oncologic head and neck reconstruction (0.1 to 0.4 percent). ${ }^{16,23-25}$ The current study focused on the incidence of symptomatic pulmonary embolism after abdominal flap breast reconstruction at two academic centers. In our series, 430 consecutive patients underwent 592 breast reconstructions. Symptomatic pulmonary embolism occurred in 17 cases, resulting in an incidence rate of 4.0 percent. 


\section{Risk Factors for Symptomatic Pulmonary Embolism}

Significant predictors for symptomatic pulmonary embolism were body mass index and BRCA gene mutations. Statistically nonsignificant predictors were operation duration and bilateral reconstruction (Table 5). In the following paragraphs, each individual risk factor is discussed.

\section{Body Mass Index}

Obesity is a known risk factor for pulmonary embolism. ${ }^{26}$ Several theories have emerged explainin the link between obesity and the increased risk of pulmonary embolism, including induced blood clotting by leptin, a hormone released by fat cells, ${ }^{27}$ a rise in estrogen and progesterone levels, ${ }^{28,29}$ and progressive atherosclerosis. ${ }^{30,31}$ We found a significantly higher body mass index in the symptomatic pulmonary embolism group $(29.8 \mathrm{~kg} / \mathrm{m} 2)$ than in the non-symptomatic pulmonary embolism group $(26.7 \mathrm{~kg} / \mathrm{m} 2)$. In contrast, not a single case of symptomatic pulmonary embolism occurred after abdominal flap breas reconstruction in a recent series of 25 women with a body mass index greater than $40 \mathrm{~kg} / \mathrm{m}^{2} .{ }^{32}$ The authors used low-molecular-weight heparin and applied pneumatic stockings. However, in their series, there was a trend toward performing muscle-sparing free TRAM flaps, which may explain the relatively short operation duration for both unilateral and bilateral breast reconstructions, averaging 360 and 500 minutes, respectively. In our series, the average operation duration was 402 minutes for unilateral and 600 minutes for bilateral breast reconstruction. Also, the low number of patients in the previous study is likely to preclude accurate risk estimation.

\section{General Anesthesia and Operation Duration}

Prolonged general anesthesia time is a known risk factor for deep venous thrombosis. ${ }^{11,33-35}$ In our series, total anesthesia time averaged 7.9 hours in the non-symptomatic pulmonary embolism group and 9.0 hours in the symptomatic pulmonary embolism group, although this difference did not reach statistical significance $(p=0.07)$. The same was true for bilateral reconstructions that have longer operative times; we found a nonsignificant trend for its effect on the risk of symptomatic pulmonary embolism $(p=0.08)$. In the multivariate backward logistic regression analysis, only body mass index and BRCA remained significant predictors for symptomatic pulmonary embolism because of their stronger effects. In this analysis, operation duration and bilaterality were not significant predictors, possibly because of their multicollinearity with $B R C A$.

\section{BRCA Mutations and Malignancy}

Cancer cells exert a procoagulant activity in their microenvironment that can extend systemically. ${ }^{36,37}$ The literature is increasingly supporting the idea that genetic mutations responsible for malignant transformation also influence genes that control hemostasis. Activation of hemostasis provides cancer cells with a fibrin scaffold that is beneficial for tumor growth and invasion. In addition, tumor progression is stimulated by signaling effects of factors such as tissue factor, plasminogen activator inhibitor-1, or cyclooxygenase-2, which control invasive growth, protection from apoptosis, and angiogenesis. ${ }^{38}$ Cancer-specific therapies such as chemotherapy, hormonal therapy, and radiotherapy, although often indispensable, constitute additional risk factors for venous thromboembolism. ${ }^{15}$ In our study, the presence of malignancy, as in primary breast reconstruction after therapeutic mastectomy, did not significantly increase the risk for symptomatic pulmonary embolism, nor did the application of chemotherapy, hormone therapy, or radiotherapy (Tables 3 and 4). Of note, the majority of our population had early-stage breast cancer. As such, the relative contribution of malignancy to symptomatic pulmonary embolism may have been limited. Fisher's exact test showed a significantly higher risk of symptomatic pulmonary embolism in patients with a BRCA mutation $(p=$ 0.01 ). Almost all patients with a positive $B R C A$ status underwent bilateral reconstruction, which is associated with a significantly longer operation duration compared with unilateral reconstruction. The significantly higher operation duration does not contribute to the increased risk of symptomatic pulmonary embolism by itself, which can be concluded from the backward logistic regression analysis. After removing the nonsignificant operation duration effect from the model, it was revealed that a positive BRCA status is an independent risk factor for symptomatic pulmonary embolism.

\section{Discrepancy in Risk of Symptomatic Pulmonary Embolism between Abdominal Flap Breast Reconstruction} and Head and Neck Reconstruction

Generally, patients undergoing head and neck reconstructive surgery have more risk factors for symptomatic pulmonary embolism than abdominal flap breast reconstruction patients. Patients undergoing head and neck surgery are generally older, and in nearly all cases cancer is present at the time of surgery. They too are often exposed to radiotherapy, chemotherapy, and lengthy reconstructive procedures with autologous free tissue transplants. Many patients undergoing head and neck reconstructive surgery have a history of excessive smoking, which causes additional comorbidities, predisposing them to venous thromboembolism. Nevertheless, the literature reports markedly lower rates of venous thromboembolism in patients undergoing head and neck reconstructive surgery compared with patients with abdominal flap breast reconstruction. ${ }^{39}$ 
A relatively high body mass index in abdominal flap breast reconstruction patients compared with head and neck patients partially explains this discrepancy. Also, the use of abdominal flaps may render a higher risk for venous thromboembolism compared with flaps harvested from other regions.

Tightening of the abdominal wall after flap harvest increases abdominal pressure and thereby reduces venous return. The effects of increased intraabdominal pressure include stasis in the iliac veins and reduced flow through the proximal femoral veins, with a subsequent increase in intravenous pressure and increased diameter of the proximal femoral veins. ${ }^{40}$ The necessity to position and nurse patients in a Fowler's position during the initial postoperative phase could cause additional pooling of blood in the venous system of the lower extremities. Furthermore, discontinuation of the superficial abdominal veins as a result of abdominal flap harvest could disrupt venous return in the abdomen, with possible implications for the deeper venous circulation. Finally, although oncogenes responsible for head and neck malignancies, such as epidermal growth factor receptor variant III mutations, are known to up-regulate tissue factor and initiate coagulation, ${ }^{38}$ they might be less prone to causing systemic coagulopathy compared with BRCA gene mutations.

The Davison-Caprini Risk-Assessment Model has been validated in a general plastic surgery population, with the main inclusion criteria being surgery under general anesthesia and postoperative hospital admission. ${ }^{19}$ Patients who received chemical thromboprophylaxis were excluded. ${ }^{19}$ These criteria are too generic in nature, and therefore this risk-assessment model is unlikely to be suitable for accurate prediction of symptomatic pulmonary embolism after abdominal flap breast reconstruction. We developed a more specific model and determined the optimal specificity and sensitivity at different cutoff scores (Table 6). Using model 1, patients with a score of 2 or higher are at increased risk for symptomatic pulmonary embolism. These patients could possibly benefit from a stronger thromboprophylaxis approach, such as an increased dosage of lowmolecularweight heparin. In case of BRCA-positive patients undergoing bilateral reconstruction, a body mass index exceeding 28 would indicate a very high risk for symptomatic pulmonary embolism. These patients should be explicitly warned about the risk of symptomatic pulmonary embolism after abdominal flap breast reconstruction. If other risk factors are also present (e.g., hereditary predisposition to venous thromboembolism), the reconstructive surgeon should strongly consider negative advice for abdominal flap breast reconstruction. As yet, we have not applied our prediction model in our own clinical practice and therefore cannot present any preliminary data. The data in this study are purely informational, and the presented model needs further clinical validation. However, to reduce the risk of thromboembolic complications, we have stopped operating on patients with a body mass index exceeding $35 \mathrm{~kg} / \mathrm{m}^{2}$. To reduce the risk of flap-related complications in obese patients, we liberally include two or more perforators or perform a muscle-sparing TRAM flap. Finally, patients must have stopped smoking at least 6 weeks preoperatively. The present study was a first effort for constructing a screening tool specifically for symptomatic pulmonary embolism after abdominal flap breast reconstruction. Although the total sample included a reasonable number of participants, the statistical power was reduced by a limited number of patients with pulmonary embolism. A power calculation using the procedure described by Buderer, ${ }^{41}$ with an acceptably judged sensitivity range of 80 to 100 percent, a specificity range of 70 to 90 percent, and a proportion of symptomatic pulmonary embolism of 4 percent, pointed out that 875 participants were needed. Future research, with the inclusion of more patients with pulmonary embolism, can refine our presented screening tool and can increase the sensitivity and specificity of this instrument. In addition, the role of $B R C A$ gene mutations in systemic coagulopathy is an interesting topic for future investigation.

\section{CONCLUSIONS}

The rate of symptomatic pulmonary embolism was 4.0 percent, despite standard thromboprophylaxis. Body mass index and BRCA mutation were significant predictors for symptomatic pulmonary embolism. We integrated these factors into a prediction model that provides a useful tool for identification of high-risk patients. This category may benefit from a more aggressive thromboprophylaxis approach. 


\section{REFERENCES}

1. Hofer SO, Damen TH, Mureau MA, et al. A critical review of perioperative complications in 175 free deep inferior epigastric perforator flap breast reconstructions. Ann Plast Surg. 2007;59:137-142.

2. Spear SL, Ducic I, Cuoco F, et al. Effect of obesity on flap and donor-site complications in pedicled TRAM flap breast reconstruction. Plast Reconstr Surg. 2007;119:788-795.

3. Spear SL, Ducic I, Cuoco F, et al. The effect of smoking on flap and donor-site complications in pedicled TRAM breast reconstruction. Plast Reconstr Surg. 2005;116:1873-1880.

4. Mehrara BJ, Santoro TD, Arcilla E, et al. Complications after microvascular breast reconstruction: Experience with 1195 flaps. Plast Reconstr Surg. 2006;118:1100-1109; discussion 1110.

5. Olsson EH, Tukiainen E. Three-year evaluation of late breast reconstruction with a free transverse rectus abdominis musculocutaneous flap in a county hospital in Sweden: A retrospective study. Scand J Plast Reconstr Surg Hand Surg. 2005;39:33-38.

6. Wang HT, Hartzell T, Olbrich KC, et al. Delay of transverse rectus abdominis myocutaneous flap reconstruction improves flap reliability in the obese patient. Plast Reconstr Surg. 2005;116:613-618; discussion 619.

7. Gabbay JS, Eby JB, Kulber DA. The midabdominal TRAM flap for breast reconstruction in morbidly obese patients. Plast Reconstr Surg. 2005;115:764-770

8. Hamdi M, Blondeel P, Van Landuyt K, et al. Bilateral autogenous breast reconstruction using perforator free flaps: A single center's experience. Plast Reconstr Surg. 2004;114:83-89; discussion 90.

9. Hartrampf CR. Breast reconstruction with a transverse abdominal island flap. Perspect Plast Surg. 1987;1:123-135.

10. Lee SH, Lee TJ, Eom JS, et al. Incidence and risk factors of pulmonary thromboembolism in pedicled TRAM breast reconstruction.J Korean Soc Plast Reconstr Surg. 2006;33:193-197.
11. Lemaine V, McCarthy C, Kaplan K, et al. Venous thromboembolism following microsurgical breast reconstruction: An objective analysis in 225 consecutive patients using lowmolecular-weight heparin prophylaxis. Plast Reconstr Surg. 2011;127:1399-1406.

12. Anderson FA Jr, Wheeler HB, Goldberg RJ, et al. A populationbased perspective of the hospital incidence and case-fatality rates of deep vein thrombosis and pulmonary embolism: The Worcester DVT Study. Arch Intern Med. 1991;151:933-938.

13. Lee JS, Son BH, Choi HS, et al. Pulmonary thromboembolism following mastectomy with immediate TRAM in the patients with breast cancer: A prospective study. J Breast Cancer 2006;9:354-360.

14. Geerts WH, Pineo GF, Heit JA, et al. Prevention of venous thromboembolism: The Seventh ACCP Conference on Antithrombotic and Thrombolytic Therapy. Chest 2004;126(Suppl):338S-400S.

15. Caine GJ, Stonelake PS, Rea D, et al. Coagulopathic complications in breast cancer. Cancer 2003;98:15781586

16. Motykie GD, Zebala LP, Caprini JA, et al. A guide to venous thromboembolism risk factor assessment. J Thromb Thrombolysis 2000;9:253-262.

17. Caprini JA. Thrombosis risk assessment as a guide to quality patient care. Dis Mon. 2005;51:70-78.

18. Caprini JA, Arcelus JI, Reyna JJ. Effective risk stratification of surgical and nonsurgical patients for venous thromboembolic disease. Semin Hematol. 2001;38(Suppl 5):12-19.

19. Pannucci CJ, Bailey SH, Dreszer G, et al. Validation of the Caprini risk assessment model in plastic and reconstructive surgery patients. J Am Coll Surg. 2011;212:105-112.

20. Levitan N, Dowlati A, Remick SC, et al. Rates of initial and recurrent thromboembolic disease among patients with malignancy versus those without malignancy: Risk analysis using Medicare claims data. Medicine (Baltimore) 1999; 78:285-291.

21. Chew HK, Wun T, Harvey DJ, et al. Incidence of venous thromboembolism and the impact on survival in breast cancer patients. J Clin Oncol. 2007;25:70-76. 
22. Pannucci MD, Edwin $Y$, Chang MD, et al. Venous thromboembolic disease in autogenous breast reconstruction. Ann Plast Surg. 2009;63:34-38.

23. Miszkiewicz K, Perreault I, Landes G, et al. Venous thromboembolism in plastic surgery: Incidence, current practice and recommendations. J Plast Reconstr Aesthet Surg. 2009;62:580-588.

24. Wahl WL, Brandt MM. Potential risk factors for deep venous thrombosis in burn patients. J Burn Care Rehabil. 2001;22:128-131.

25. Hatef DA, Trussler AP, Kenkel JM. Procedural risk for venous thromboembolism in abdominal contouring surgery: A systematic review of the literature. Plast Reconstr Surg. 2010;125:352-362.

26. Kabrhel C, Varraso R, Goldhaber SZ, Rimm EB, Camargo CA. Prospective study of BMI and the risk of pulmonary embolism in women. Obesity (Silver Spring) 2009;17:2040-2046.

27. Konstantinides S, Schäfer K, Neels JG, et al. Inhibition of endogenous leptin protects mice from arterial and venous thrombosis. Arterioscler Thromb Vasc Biol. 2004;24:2196-2201.

28. Simon T, Beau Yon de Jonage-Canonico M, Oger E, et al.; EStrogen and THromboEmbolism Risk (ESTHER) Study Group. Indicators of lifetime endogenous estrogen exposure and risk of venous thromboembolism. J Thromb Haemost. 2006;4:71-76.

29. Cushman M, Kuller LH, Prentice R, et al.; Women's Health Initiative Investigators. Estrogen plus progestin and risk of venous thrombosis. JAMA 2004;292:1573-1580.

30. Decensi A, Maisonneuve P, Rotmensz N, et al.; Italian Tamoxifen Study Group. Effect of tamoxifen on venous thromboembolic events in a breast cancer prevention trial. Circulation 2005;111:650-656.

31. Goldhaber SZ, Grodstein F, Stampfer MJ, et al. A prospective study of risk factors for pulmonary embolism in women. JAMA 1997;277:642-645.

32. Jandali S, Nelson JA, Sonnad SS, et al. Breast reconstruction with free tissue transfer from the abdomen in the morbidly obese. Plast Reconstr Surg. 2011;127:2206-2213.
33. Clayton JK, Anderson JA, McNicol GP. Preoperative prediction of postoperative deep vein thrombosis. BMJ 1976;2:910-912

34. Goldhaber SZ, Savage DD, Garrison RJ, et al. Risk factors for pulmonary embolism: The Framingham Study. Am J Med. 1983;74:1023-1028.

35. Ferrari E, Chevallier T, Chapelier A, et al. Travel as a risk factor for venous thromboembolic disease: A case-control study. Chest 1999;115:440-444.

36. Lip GY, Chin BS, Blann AD. Cancer and the prothrombotic state. Lancet Oncol. 2002:3:27-34.

37. Agnelli G, Bolis G, Capussotti L, et al. A clinical outcomebased prospective study on venous thromboembolism after cancer surgery: The @RISTOS project. Ann Surg. 2006;243:89-95.

38. Milsom CC, Yu JL, Mackman N, et al. Tissue factor regulation by epidermal growth factor receptor and epithelial-tomesenchymal transitions: Effect on tumor initiation and angiogenesis. Cancer Res. 2008;68:10068-10076.

39. Moreano EH, Hutchison JL, McCulloch TM, Graham SM,Funk GF, Hoffman HT. Incidence of deep venous thrombosis and pulmonary embolism in otolaryngology-head and neck surgery. Otolaryngol Head Neck Surg. 1998;118:777-784.

40. Pannucci CJ, Alderman AK, Brown SL, Wakefield TW, Wilkins EG. The effect of abdominal wall plication on intraabdominal pressure and lower extremity venous flow: A case report. J Plast Reconstr Aesthet Surg. 2012;65:392-394.

41. Buderer NM. Statistical methodology: I. Incorporating the prevalence of disease into the sample size calculation for sensitivity and specificity. Acad Emerg Med. 1996;3:895-900. 


\section{ABSTRACT}

\section{Background}

Breast conservation surgery in the treatment of early stage breast cancer has become increasingly utilized as a means to avoiding mastectomy. While partial mastectomy defects (PMDs) may often be cosmetically acceptable, some cases warrant consideration of reconstructive options, and while several reconstructive options have been described in this role, a series of deep inferior epigastric perforator (DIEP) flaps has not been reported to date.

\section{Methods}

A cohort of 18 patients undergoing PMD reconstruction with a DIEP flap were included. Patient-specific data operation details, cosmetic results, and complication rates were assessed. Oncologic outcomes, in particular recurrence rates, were also evaluated.

\section{Results}

In our series there were no cases of partial or total flap necrosis, and overall complications were low. There were two cases of wound infection (both had undergone radiotherapy), managed conservatively, and one case of reoperation due to hematoma. There were no cancer recurrences or effect on oncologic management. Cosmetic outcome was rated as high by both patients and surgeon. The results were thus comparable with other reconstructive options.

\section{Conclusion}

Although autologous reconstruction has an established complication rate, our results suggest that the DIEP flap may be of considerable value for delayed reconstruction of selected larger partial mastectomy defects.

\section{INTRODUCTION}

Breast conservation surgery (BCS) is widely the treatment of choice for early stage breast cancer, with BCS shown to significantly reduce breast deformity and minimize the invasiveness of breast cancer treatment, without compromising oncologic outcomes. ${ }^{1-3}$ Although BCS can preserve an adequate amount of breast tissue to avoid the use of reconstructive techniques, unacceptable disfigurement remains a problem in up to $30 \%$ of patients, many of whom will opt for reconstruction of their partial mastectomy defect (PMD). ${ }^{4,5}$ In such cases, a variety of reconstructive options have been described, ranging from immediate reconstruction with local tissue advancement or rotation, or with prosthetic implants. ${ }^{6}$ The use of distant autologous options have included latissimus dorsi flaps, ${ }^{7}$ transverse rectus abdominis myocutaneous (TRAM) flaps, ${ }^{8}$ and the superficial inferior epigastric artery (SIEA) flap, ${ }^{9}$ all of which have been effective in this setting. The deep inferior epigastric artery (DIEA) perforator (DIEP) flap has been popularized for postmastectomy reconstruction, and offers a range of advantages over the other reconstructive options described. ${ }^{10,11}$ It has been shown to have a consistent blood supply, versatility in volume and shape, and a donor site profile considerably superior to other myocutaneous flap options. ${ }^{10,11}$ While free flaps based on the DIEA have been described in postmastectomy breast reconstruction and in augmentation mammoplasty, reports of their use in the reconstruction of PMDs are limited to case reports only. ${ }^{12,13}$ The current study is the first to consider the DIEP flap in this role in a consecutive series of patients, providing a detailed assessment of outcomes and comparing this approach with other established reconstructive options.

\section{METHODS}

The study comprised a cohort of 18 consecutive patients with PMDs after BCS for breast carcinoma. All patients were recruited through a single reconstructive surgeon at a single institution, with all referrals through a single oncologic surgeon at the same institution. BCS was planned based on a tumor size of $3 \mathrm{~cm}$ or less, lack of palpable axillary lymph nodes, and the absence of distant metastases. Adjuvant radiotherapy, chemotherapy, and endocrine therapies and all oncologic follow-up were dictated by the oncologic surgeon, and the decision for reconstruction was made between patient and oncologic surgeon. All patients were delayed reconstructions, with a minimum of 6 months following oncologic surgery before any of the referrals were made. While over $20 \%$ of patients in this series did not have adjuvant radiotherapy (see Table 1 ), delayed reconstruction was selected in all cases as a means to avoiding any delay in the administration of adjuvant therapy and to minimize the effects of radiotherapy (on both the skin paddle and subcutaneous 
tissues of the flap). However, in cases where it is known that radiotherapy is not going to be used, immediate reconstruction may certainly be considered. The reconstructive options were discussed in each case, with decision for DIEP flap partial breast reconstruction made between patient and reconstructive surgeon.

Demographic data was collected in each case, including age, associated risk factors, and oncologic data which included tumor specifics, the use of adjuvant therapies, and axillary staging (Table 1). Operative outcomes and complications were assessed, with patients followed up every 6 months following reconstruction, and a minimum of 3 years follow-up in each case. Cosmetic outcome was evaluated qualitatively by both the surgeon and patients, with patients asked for their subjective opinion (poor, average, good) and surgeons asked to assess outcome based on shape, symmetry, and overall appearance

(poor, average, good).

\section{Table 1. Patient Demographic and Oncologic Details}

\begin{tabular}{ll}
\hline \hline Demographic data & $53.5(\mathrm{SD}=8.2)$; range: $34-$ \\
Mean age (years) & 66 \\
& \\
Oncologic details & mean $23(\mathrm{SD}=8)$ \\
Tumor size (maximal dimension) $(\mathrm{mm})$ & \\
Tumor histology & $22 \%$ \\
$\quad$ Ductal carcinoma in situ & $56 \%$ \\
$\quad$ Invasive ductal carcinoma & $22 \%$ \\
$\quad$ Invasive lobular carcinoma & $14 / 18(78 \%)$ \\
Adjuvant radiotherapy & $5 / 18(28 \%)$ \\
Adjuvant chemotherapy & $9 / 18(50 \%)$ \\
Adjuvant endocrine therapy & \\
Axillary staging & $2 / 18(11 \%)$ \\
$\quad$ None & $1 / 18(6 \%)$ \\
$\quad$ Sentinel lymph node biopsy & $15 / 18(83 \%)$ \\
$\quad$ Axillary clearance &
\end{tabular}

$\mathrm{SD}=$ standard deviation
Surgical Technique

Surgical approach to DIEP flap harvest was performed in a routine manner, as per full mastectomy reconstruction, with a full lower abdominal ellipse marked preoperatively, and DIEA perforators marked on the abdomen based on localization with imaging. This preoperative flap planning was achieved with the use of computed tomographic angiography (CTA) imaging in all cases, aiding perforator selection and the planning of flap harvest (Table 2). In all cases a two-surgeon team was used, with one team undertaking flap harvest and the other preparing recipient vessels. The DIEA and deep inferior epigastric vein (DIEV) comprised the donor vessels in all cases, and the recipient vessels were the internal mammary artery (IMA) and veins (IMVs) or the circumflex scapula artery and veins, and the cephalic vein used as a source of secondary venous drainage (Table 2). In all cases, the defect was extended to the chest wall, with selective undermining of the remaining breast tissue at the level of the pectoral fascia, and exposure of internal mammary perforators and the circumflex scapula vessels. Selection of the vascular pedicle was then made based on the ability for relative exposure of the vascular pedicle, proximity of the defect to the exposed pedicles, and the effect of radiotherapy changes on the exposed vascular pedicles. As such, there was no correlation between the location of the defect and the chosen recipient pedicle. Arterial anastomoses were sutured in all cases, while venous anastomoses were performed with a microvascular anastomotic coupling device (Microvascular Anastomotic Coupling System, Synovis Micro Companies Alliance, St Paul, MN). After venous anastomosis has been completed, an implantable Doppler probe is placed around the veins to monitor anastomotic patency during insetting and in the postoperative period (Cook-Swartz implantable Doppler probe; Cook Medical1, Cook Ireland, Limerick, Ireland). Postoperative monitoring was achieved with a combination of the implantable Doppler probe and clinical assessment, and all cases were monitored for 7 postoperative days. 


\section{Table 2. Operative Details}

\section{Timing \\ Sides}

Defect

$\begin{array}{ll}\text { Upper medial quadrant } & 1 / 18(6 \%) \\ \text { Upper lateral quadrant } & 10 / 18(56 \%) \\ \text { Lower medial quadrant } & 2 / 18(11 \%) \\ \text { Lower lateral quadrant } & 5 / 18(28 \%)\end{array}$

Preoperative imaging (donor site) 18 Doppler ultrasound/18 computed tomographic angiography (CTA)

Imaging findings $\quad 18 / 18$ cases suitable deep inferior epigatric artery (DIEA) perforators $>1$

Imaging concordance

Primary donor vessels

Primary recipient vessels

Secondary donor vein

Secondary recipient vein

$18 / 18$ cases suitable deep inferior epigatric artery (DIEA) perforators $>1 \mathrm{~mm}$

$100 \%$ concordance Doppler ultrasound and CTA

Deep inferior epigastric artery/vein (all cases)

Internal mammary artery/vein or circumflex scapula artery/vein

Superficial inferior epigastric veins (all cases)

Cephalic vein (all cases)

Data is presented as population means, with standard deviations and/or $95 \%$ confidence intervals of

differences given. Statistical analysis was performed using statistical package for the social sciences (SPSS) for

Windows (version 16.0, SPSS Incorporated, Chicago, IL).

RESULTS

Eighteen patients underwent delayed, unilateral DIEP flap breast reconstruction of a PMD. Mean patient age was 53.5 years (range 34-66), patients had a range of body habitus (no patients were morbidly obese), and mean time interval between initial BCS and reconstruction was 2.4 years. Patients had relatively large tumors (mean size $23 \mathrm{~mm}$ ) and a range of tumor histology. Adjuvant therapies were used in the majority of cases (Table 1), with 14 of the 18 patients having undergone adjuvant radiotherapy (mean dosage of 50 Gy). All defects were considered deforming by the patient, and were all large defects in small to medium sized breasts. The majority of defects were in the lateral half of the breast $(15 / 18=83 \%$ of cases). There was only one major complication in the series, comprising a hematoma requiring return to theater (Table 3). Otherwise, there were no cases of partial or total flap necrosis, no anastomotic revisions, and overall complications were low. There were two cases of wound infection (both had undergone radiotherapy), managed conservatively. There was no donor site morbidity on either subjective questioning or examination t any followup appointments. There were no cancer recurrences or effect on oncologic management. Cosmetic outcome was rated as high by both patients and surgeon in all cases (see Figs. 1A and 1B).

\begin{tabular}{ll} 
Table 3. Operative Outcomes & \\
\hline Operative complications & (n/\%) \\
\hline \hline Complete flap loss & $0(0 \%)$ \\
Partial flap loss & $0(0 \%)$ \\
Arterial trombosis & $0(0 \%)$ \\
Venous thrombosis & $0(0 \%)$ \\
Venous congestion & $1 / 18(6 \%)$ \\
Hematoma & $1 / 18(6 \%)$ \\
Superficial wound infection & $2 / 18(11 \%)$ \\
Fat necrosis & $1 / 18(6 \%)$ \\
Seroma & $0(0 \%)$ \\
Reoperation & $1 / 18(6 \%)$ \\
Donor site morbidity & \\
Abdominal weakness (subjective or objective) & $0(0 \%)$ \\
Abdominal bulge & $0(0 \%)$ \\
Abdominal herniation & $0(0 \%)$ \\
Oncologic outcomes & $(\mathrm{n} / \%)$ \\
Delays in administering adjuvant therapies & $0(0 \%)$ \\
Tumor recurrence & $0(0 \%)$ \\
Cosmetic outcomes & \\
Patient-rated score (mean) & high \\
Surgeon-rated score (mean) & high \\
\hline \hline
\end{tabular}

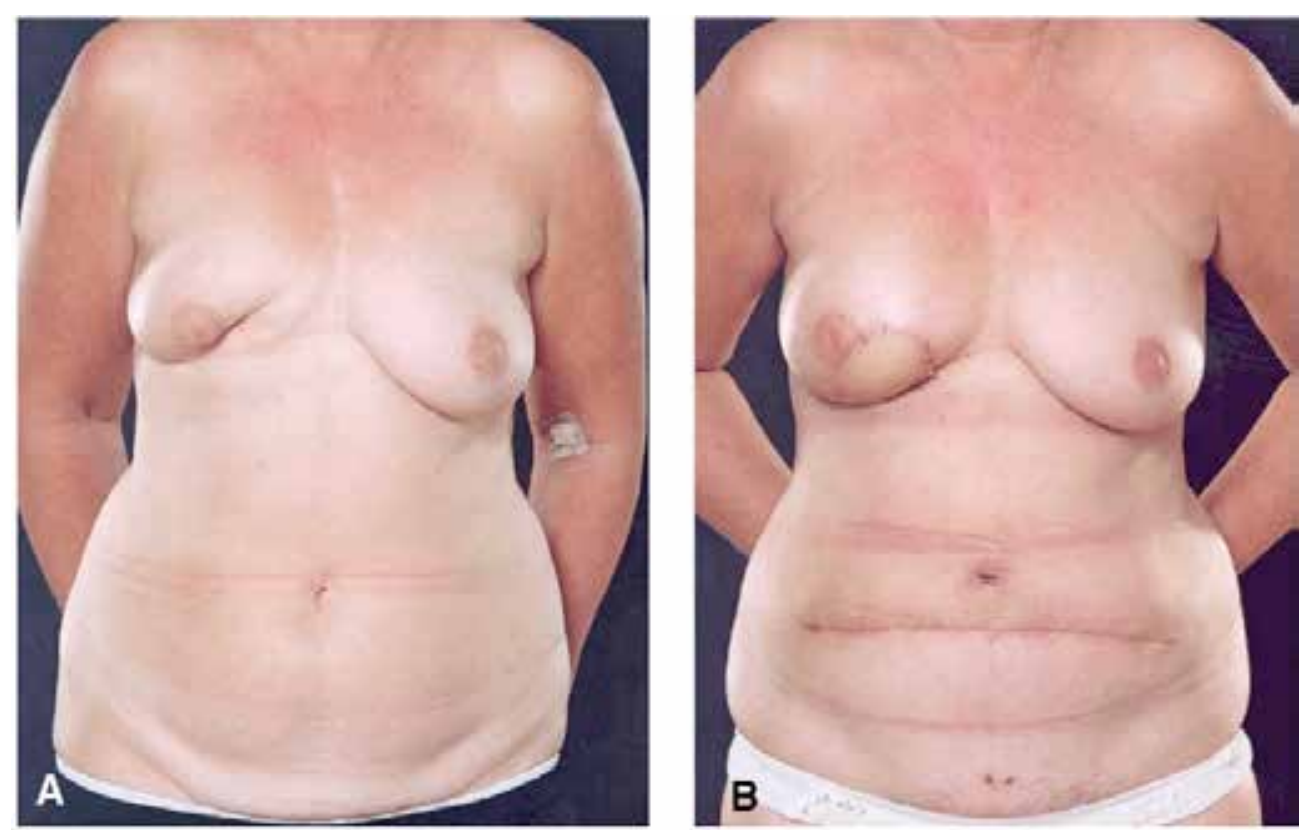

Figure 1. A: Preoperative photograph of a patient with a right partial mastectomy defect (PMD). B: Postoperative photograph after deep inferior epigastric artery perforator (DIEP) flap reconstruction of the partial mastectomy defect $(P M D)$ 


\section{DISCUSSION}

BCS has become increasingly utilized in the management of breast cancer, and while cosmetic outcomes may be achieved in many cases, BCS can include a broad spectrum of resection volumes, and thus preservation of an adequate amount of breast tissue for esthetically pleasing outcomes may not be uniform. Specific predictors of an unsatisfactory result after BCS included large tumor size relative to the size of the breast and the use of radiotherapy. Reconstructive options have thus been sought, including single-stage implant-based reconstruction, with or without the use of tissue expansion, autologous reconstruction using local tissue or free flaps, and reconstruction using a combination of autologous tissue and prosthetic implants.

Reconstruction with the use of prosthetic implants has been proposed as technically easier and less invasive compared to autologous reconstruction, and with quicker convalescence may require shorter hospitalization times. ${ }^{14-16}$ However, there are notable disadvantages with the use of implants when compared to autologous reconstruction. Where tissue expansion is needed, the use of expansion can be associated with pain for the patient, and where irradiation has been performed (a majority of BCS cases) tissue expansion can be problematic and associated with increased pain and inadequate expansion. Implant-related complications are also of concern, with the risk of infection, capsular contracture, and implant extrusion markedly increased in the presence of irradiated tissue. ${ }^{14,15}$ Given these problems, autologous tissue reconstruction has been described as a preferred option. ${ }^{15,17}$ While the effects of radiotherapy are certainly more marked for implant-based reconstruction, the effects on autologous tissues are certainly a concern, and our preference is to delay reconstruction in all cases. These effects can occur on both fat and skin, with the effects on subcutaneous fat most feared, with fat necrosis not uncommon after irradiation. ${ }^{18} \mathrm{~A}$ recent review by Losken and Hamdi provided a comprehensive overview of reconstructive options after PMDs. ${ }^{19}$ While reconstructive options with local tissue or flaps were clearly outlined and described as preferred options, the use of distant flaps in this setting were not extensively explored. Given the increasingly low complications rates described in the literature and in our experience, free tissue transfer is fast becoming a safe and potentially improved reconstructive option in this setting. In fact, Kronowitz et al. found free tissue transfer to PMDs to have significantly less complications compared to local tissue options. ${ }^{6}$ One particular benefit of free tissue transfer is the ability to inset the flap into defects in all four quadrants of the breast with relative ease. Local tissue flaps require somewhat more planning in this regard. The thoracodorsal artery perforator flap is of particular benefit for lateral and central defects, similar to that of the latissimus dorsi myocutaneous flap., ${ }^{6,17,20}$ Medial defects are more difficult to reconstruct with local options, and may be particularly suited to free flap reconstruction. In addition, many patients do not have sufficient volume within local tissue for such an option. Autologous options described in the setting of BCS include the use of local tissue, ${ }^{6}$ free latissimus dorsi myocutaneous flaps, ${ }^{7}$ muscle-sparing TRAM flaps, ${ }^{8}$ SIEA flaps, ${ }^{9}$ and thoracodorsal artery perforator (TDAP) flaps. ${ }^{17}$ While we prefer the DIEP flap, with its known benefits in terms of versatility in shape and volume and its good donor site profile, other authors have offered other options, each with their own morbidity profiles. The latissimus dorsi flap has been described with rates of partial flap loss of $6 \%$, total flap loss of $2 \%$, and an overall complication rate of $33 \%,{ }^{21}$ and being a denervated musculocutaneous flap, volume changes with muscle atrophy can be problematic. Similarly, the pedicled and free muscle-sparing TRAM flaps described in this setting are associated with worse donor site outcomes than the DIEP flap..$^{8,10,11,22,23}$ The DIEP flap has a long pedicle for ease of reconstruction of all breast defects, is widely outside of the irradiated field, and has been associated with good donor- and flap-related outcomes in many reported series. The current series highlights that the complication rates of DIEP flaps in the repair of PMDs are similar to that in postmastectomy reconstruction, and to delayed reconstruction after BCS using other reconstructive options. The good cosmetic results universally reported add to these benefits. The additional esthetic benefit of the abdominoplasty was noted by many patients. In the current series, a DIEP flap was used in all cases, with this decision made based on surgeon and patient preference after performing a preoperative CTA for vascular mapping. The CTA is used to define the dominant vascular supply to the lower abdominal wall, with all perforators over $1 \mathrm{~mm}$ identified, and the superficial inferior epigastric artery (SIEA) also identified. While we do consider the use of an SIEA flap, the SIEA itself is frequently absent altogether or too small for use in free tissue transfer, and thus the DIEP flap is preferred, as occurred in all cases of the current series. ${ }^{24}$ In cases where a SIEA flap may be considered, the same lower abdominal elipse would be designed, with flap design based on the course of the SIEA as demonstrated on CTA. An additional technical consideration is the use of a skin paddle as part of the flap. In all cases within this series, there was a skin defect included as part of the partial mastectomy specimen, and/or radiation changes that warranted excision. The skin paddle of the DIEP flap was thus useful for reconstruction of such a deficit, and also able to be used as a monitoring paddle for postoperative monitoring of the flap clinically. A deepithelialized flap may be used where skin is not required, with the flap inset as a buried flap, and able to be monitored postoperatively with an implantable Doppler probe. ${ }^{25,26}$ While the argument exists for preservation of the abdominal donor site for the case of future need for postmastectomy reconstruction, recurrence rates in patients having undergone BCS after breast cancer are low overall, with only 5-8\% requiring salvage mastectomy. ${ }^{14,16}$ In these few cases, other satisfactory reconstructive options (both prosthetic and autologous) still remain and thus preservation of this tissue in up to $95 \%$ of cases where it can be effectively used may not be warranted. Case selection is thus highly important in employing this reconstructive option, with clear margins, lack of regional spread, and time to reconstruction all important selection considerations. With no detriment to oncologic outcomes identified in the current series, it is pertinent that 
postreconstruction oncologic follow-up is essential, with timely administration of adjuvant therapies,

ongoing clinical examination and mammography, and consideration of advanced imaging technologies all important. Magnetic resonance imaging (MRI) in particular has been shown to be useful in this setting. ${ }^{27,28}$ The majority of local recurrences after BCS are known to occur within the first 2 years of presentation, ${ }^{1}$ and while recurrence rates of 5-8\% over a 5 -year period are described, ${ }^{1,2}$ delayed reconstruction minimizes the need for revision surgery. The longer the interval between BCS and reconstruction, the more likely it is that recurrence is detected prior to reconstruction, and we prefer delayed reconstruction for this reason.

\section{CONCLUSION}

BCS has become a valuable option in the treatment of breast cancer, but does not rule out the need for breast reconstruction. There are many variables that can influence the choice of reconstruction in this setting, and thus many options have been described. We have described our experience with the use of the DIEP flap in delayed breast reconstruction after BCS. We have found the DIEP flap to be a safe, effective, and esthetic tool for reconstruction of larger partial mastectomy defects, particularly in small to medium sized breasts. The technique thus offers a useful alternative to other reconstructive options in this setting.

\section{REFERENCES}

1. Fisher B, Anderson S, Redmond CK, et al. Reanalysis and results after 12 years of follow-up in a randomized clinical trial comparing mastectomy with lumpectomy, with or without irradiation in the treatment of breast cancer. N Engl J Med 1995;333:1456-1461.

2. Jacobson JA, Danforth DN, Cowan KH, et al. Tenyear results of a comparison of conservation with mastectomy in the treatment of stage I and II breast cancer. N Engl J Med 1995;332:907-911.

3. Fisher B, Redmond C, Fisher ER, et al. Ten-year results of a randomized clinical trial comparing radical mastectomy and total mastectomy with or without radiation. N Engl J Med 1985;312:674-681.

4. Bajaj AK, Kon PS, Oberg KC, et al. Aesthetic outcomes in patients undergoing breast conservation therapy for the treatment of localized breast cancer. Plast Reconstr Surg 2004;114:1442-1449.

5. Petit JY, Rietjens M, Garusi C, et al. Integration of plastic surgery in the course of breast conserving surgery for cancer to improve cosmetic results and radicality of tumour excision. Recent Results Cancer Res 1998;152:202-211

6. Kronowitz SJ, Feledy JA, Hunt KK, et al. Determining the optimal approach to breast reconstruction after partial mastectomy. Plast Reconstr Surg 2006; 17:1-11.

7. Monticciolo DL, Ross D, Bostwick J III, et al. Autologous breast reconstruction with endoscopic latissimus dorsi musculosubcutaneous flaps in patients choosing breast-conserving therapy: Mammographic appearance. Am J Roentgenol 1996;167: 385-389.

8. Moran SL, Serletti JM, Fox I. Immediate free TRAM reconstruction in lumpectomy and radiation failure patients. Plast Reconstr Surg 2000;106:1527-1531.

9. Rizzuto RP, Allen RJ. Reconstruction of a partial mastectomy defect with the superficial inferior epigastric artery (SIEA) flap. J Reconstr Microsurg 2004;20:441-445.

10. Allen RJ. DIEP versus TRAM for breast reconstruction. Plast Reconstr Surg 2003;111:2478 
11. Blondeel PN, Demuynck M, Mete D, et al. The donor site morbidity of free DIEP flaps and free TRAM flaps for breast reconstruction. Br J Plast Surg 1997;50:322-330.

12. Munhoz AM, Ishida LH, Duarte GG, et al. Aesthetic refinements in breast augmentation with deep inferior epigastric perforator flap: A case report. Aesthetic Plast Surg 2003;27:107-111.

13. Allen RJ, Heitland AS. Autogenous augmentation mammaplasty with microsurgical tissue transfer. Plast Reconstr Surg 2003;112:91-100.

14. Forman DL, Chiu J, Restifo RJ, et al. Breast reconstruction in previously irradiated patients using tissue expanders and implants: A potentially unfavorable result. Ann Plast Surg 1998;40:360.

15. Bostwick J III, Paletta C, Hartrampf CR. Conservative treatment for breast cancer. Ann Surg 986;203:481490.

16. Kroll SS, Evans GR, Reece GP, et al. Comparison of resource costs between implantbased and TRAM flap breast reconstruction. Plast Reconstr Surg 1996;97:364-372.

17. Hamdi M, Van Landuyt K, Monstrey S, et al. Pedicled perforator flaps in breast reconstruction: A new concept. Br J Plast Surg 2004;57:531-539.

18. Rozen WM, Ashton MW, Taylor GI. Defining the role for autologous breast reconstruction after mastectomy: Social and oncologic implications. Clin Breast Cancer 2008;8:134-142.

19. Losken A, Hamdi M. Partial breast reconstruction: Current perspectives. Plast Reconstr Surg 2009;124:722-736.

20. Rainsbury RM. Breast sparing reconstruction with latissimus dorsi miniflaps. Eur J Surg Oncol 2002;28:891-895.

21. Munhoz AM, Montag E, Fels KW, et al. Outcome analysis of breast-conservation surgery and immediate latissimus dorsi flap reconstruction in patients with T1 to T2 breast cancer. Plast Reconstr Surg 2005;116: $741-752$
22. Singletary SE, Hortobagyi GN, Kroll SS. Surgical and medical management of local-regional treatment failures in advanced primary breast cancer. Surg Oncol Clin N Am 1995;4:671-684.

23. Kroll SS, Schusterman MA, Reece GP, et al. Breast reconstruction with myocutaneous flaps in previously irradiated patients. Plast Reconstr Surg 1994;93:460-469.

24. Rozen WM, Chubb D, Grinsell D, et al. The variability of the superficial inferior epigastric artery (SIEA) and its angiosome: A clinical anatomical study. Microsurgery 2010;30:386-391.

25. Rozen WM, Whitaker IS, Wagstaff MJ, et al. Buried free flaps for breast reconstruction: A new technique using the Cook-Swartz implantable Doppler probe for postoperative monitoring. Plast Reconstr Surg 2010;125:171e-172e

26. Rozen WM, Chubb D, Whitaker IS, et al. The efficacy of postoperative monitoring: A single surgeon comparison of clinical monitoring and the implantable Doppler probe in 547 consecutive free flaps. Microsurgery 2010:30:105-110.

27. Drew PJ, Kerin MJ, Turnbull LW, et al. Routine screening for local recurrence following breast conserving therapy for cancer with dynamic contrast-enhanced magnetic resonance imaging of the breast. Ann Surg Oncol 1998;5: 265-270.

28. Weinreb JC, Newstead G. MR imaging of the breast. Radiology 1995;196:593-610. 


\section{Background}

Breast reconstruction often requires multiple operations. In addition to potential complications requiring reoperation, additional procedures are frequently essential in order to complete the reconstructive process, with aesthetic outcome and breast symmetry shown to be the most important factors in patient satisfaction Despite the importance of these reoperations in decision-making and the consent process, a thorough review of the need for such operations has not been definitively explored.

\section{Methods}

A review of 370 consecutive autologous breast reconstructions (326 patients) was undertaken, comprising 365 deep inferior epigastric artery perforator (DIEP) flaps and 5 superficial inferior epigastric artery (SIEA) flaps. The need for additional procedures for either complications or aesthetic refinement following initial breast reconstruction was assessed.

\section{Results}

Overall, there was an average of 1.06 additional interventions for every patient carried out after primary reconstructive surgery. Of 326 patients, 46 underwent early postoperative operations for surgical complications ( 0.17 additional operations per patient as a consequence of complications). Procedures for aesthetic refinement included those performed on the reconstructed breast, contralateral breast, or abdominal donor site. Procedures for aesthetic refinement included nipple reconstruction, nippleareola complex tattooing, dog-ear correction, liposuction, lipofilling, scar revision, mastopexy, and reduction mammaplasty.

\section{Conclusion}

While DIEP flap surgery for breast reconstruction provides favorable results, patients frequently require additional procedures to improve aesthetic outcomes. The need for reoperation is an important part of the consent process prior to reconstructive surgery, and patients should recognize the likelihood of at least one additional procedure following initial reconstruction.
Chapter 8. Aesthetic refinements and reoperative procedures following 370 consecutive DIEP and SIEA flap breast reconstructions: important considerations for patient consent.

\section{INTRODUCTION}

Breast reconstruction postmastectomy requires complex decisions to be made by a multidisciplinary team, with the patient at the forefront. From implant to autologous reconstruction, there is a range of techniques available to the patient. The abdominal donor site in particular has become increasingly popular, to both surgeons and patients alike. Fasciocutaneous flaps based on the abdominal wall integument, such as the deep inferior epigastric artery perforator (DIEP) flap ${ }^{1-4}$ or the superficial inferior epigastric artery (SIEA) flap ${ }^{5}$, are reliable and versatile options for breast reconstruction, with low complication profiles compared with other options. While infrequent, complications can include risks to flap vascularity. Particular benefits include a low donor site morbidity compared to other autologous options and a more natural shape and feel when compared to prosthetic options. In discussing the reconstructive options, the need for multiple operations as part of the reconstructive process is a substantial consideration for the patient. In addition to potential complications requiring reoperation, additional procedures are frequently essential in order to complete the reconstructive process. In fact, revisions potentiating improved aesthetic outcome and breast symmetry have been shown to be the most important factor in patient satisfaction. ${ }^{6}$ Such procedures include modification of the reconstructed breast, including lipofilling and liposuction; treatment of the contralateral breast with augmentation, reduction, or mastopexy in order to match the reconstructed breast; donor site revision surgery in autologous reconstruction; and the need for repeated tissue expansions and definitive implant insertion in prosthetic reconstruction. In addition to these, nipple-areola complex (NAC) reconstruction is an important factor in completing aesthetic breast reconstruction and has a considerable influence on patient satisfaction. ${ }^{7}$ Despite the importance of these reoperations in the decision-making process, a thorough review of the need for such operations has not yet been definitively explored in literature. This information may play a significant role in patient decision making, and indeed during the consent process. As such, the current study comprises a review of a large series of consecutive autologous breast reconstructions using an abdominal wall free flap at a single institution, assessing the need for additional procedures for either complications or aesthetic refinement following initial breast reconstruction. 


\section{METHODS}

A retrospective review of all patients who underwent autologous breast reconstruction postmastectomy at a single institution from January 1, 2000 to December 31, 2005 was undertaken. All surgery was performed by three senior surgeons as primary surgeon, with the majority of cases (62\%) performed by the senior author (RA). Inclusion criteria comprised the use of a free fasciocutaneous flap with the abdominal wall integument. As such, only DIEA or SIEA flaps were included. All patients were fully informed and offered the range of options for aesthetic refinement, with the decision made as part of a multidisciplinary discussion. For those cases included in the study, demographic data and primary surgery data were collected and tabulated. In addition, all surgical procedures occurring after the primary reconstructive surgery were reviewed. Data collected included the number of procedures, details of each procedure, and time course between procedures. These additional procedures were defined as procedures other than the initial breast reconstruction, aimed to either manage complications or improve aesthetic outcome. This included surgery on the reconstructed breast, contralateral breast, and/or donor site. The end point of the reconstructive process for any individual patient was a decision made between patient and surgeon and was documented as such. This period of follow- up was at least 3 years for all cases.

\section{Statistical Analysis}

Data are presented as the mean with standard deviation and range. The distribution of data was skewed and did not normalize after sequential root transformations or log transformations. The Mann-Whitney $\mathrm{U}$ test was used for the statistical analysis of nonparametric continuous data. Two-by-two contingency tables were constructed for nominal data and analysis was carried out with Fisher's exact test. Significance was set at $\mathrm{P}<0.05$. Analyses were performed using Statistical Package for Social Sciences (SPSS) for Windows version 16.0 (SPSS Inc., Chicago, IL, USA).
Chapter 8. Aesthetic refinements and reoperative procedures following 370 consecutive DIEP and SIEA flap breast reconstructions: important considerations for patient consent

\section{RESULTS}

During the 6-year study period, 349 patients underwent postmastectomy autologous breast reconstruction. Of these, 2 patients underwent anterolateral thigh (ALT) flaps and 21 patients underwent superior gluteal artery perforator (SGAP) flaps for their reconstructions and were excluded from this review. Thus, 326 patients ( 370 breast reconstructions) were included, of which 282 underwent unilateral breast reconstruction and 44 underwent bilateral breast reconstruction. This comprised 365 DIEP flaps and 5 SIEA flaps. All data were able to be collected for each of these patients, and overall average follow-up was 19.2 months. Patient characteristics are given in Table 1.

Table 1. Demographics and patient characteristics

\begin{tabular}{ll}
\hline Patient characteristics & \\
\hline \hline Mean age at primary reconstruction (years) (SD/range) & $50.35(8.8 / 20-73)$ \\
Risk factors & $\mathrm{n}(\%)$ \\
Previous stroke or myocardial infarction & $2(0.6)$ \\
Type 2 diabetes mellitus & $4(1.2)$ \\
Hypertension & $19(5.8)$ \\
Corticosteroids & $5(1.5)$ \\
BRCA gene mutation & $31(9.5)$ \\
Operation details & $\mathrm{n}(\%)$ \\
Unilateral/bilateral breast reconstruction & $282(86.5) / 44(13.5)$ \\
Immediate/delayed reconstruction & $33(10.1) / 293(89.9)$ \\
Number of venous anastomoses & $\mathrm{n}(\%)$ \\
1 venous anastomosis & $179(48.4)$ \\
2 venous anastomoses & $191(51.6)$ \\
Donor site & \\
Deep inferior epigastric artery perforator (DIEP) flaps & $365(98.6)$ \\
Superficial inferior epigastric artery (SIEA) flaps & $5(1.4)$ \\
Recipient site/vessels & $\mathrm{n}(\%)$ \\
Internal mammary artery/vein & $264(71.4)$ \\
Circumflex scapular artery/vein & $92(24.9)$ \\
Thoracodorsal artery/vein & $7(1.9)$ \\
Thoracoacromial artery/vein & $7(1.9)$ \\
\hline \hline
\end{tabular}


Secondary Procedures

For patients who underwent secondary procedures, the mean time between initial surgery and the first additional procedure was 17.6 months. Of the 326 patients, 238 (73\%) underwent a total of 346 additional procedures after primary reconstruction. Of these, 291 interventions (84\%) were for aesthetic refinement and 54 were to manage complications. Overall, there was an average of 1.06 additional interventions for every patient carried out after primary reconstructive surgery (Table 2). There was no statistical difference when immediate or delayed cases were compared. When comparing unilateral and bilateral cases, a statistically significant decrease was found in the number of total interventions for bilateral cases compared to unilateral $(P=0.009)$. This was still significant when only the number of aesthetic procedures were assessed $(P=0.024)$ (Table 3$)$

Table 2. Number of secondary procedures and operations, comparing immediate and delayed breast reconstruction

\begin{tabular}{lllll}
\hline & $\begin{array}{l}\text { Immediate } \\
\text { breast } \\
\text { reconstruction } \\
(\mathbf{n}=\mathbf{3 3})\end{array}$ & $\begin{array}{l}\text { Delayed breast } \\
\text { reconstruction } \\
\mathbf{( n = 2 9 3 )}\end{array}$ & \multicolumn{1}{l}{} & Overall \\
\hline \hline $\begin{array}{l}\text { No. of patients who underwent secondary } \\
\text { procedures [n (\%)] }\end{array}$ & $21 / 33(63.6)$ & $217 / 293(74.1)$ & $0.217^{* *}$ & $238 / 326(73.0)$ \\
$\begin{array}{l}\text { No. of secondary procedures per patient [mean } \\
\text { (SD/range] }\end{array}$ & $2.60(2.47 / 0-7)$ & $2.31(1.92 / 0-7)$ & $0.698^{*}$ & $2.33(1.98 / 0-7)$ \\
$\begin{array}{l}\text { No. of secondary operations per patient [mean } \\
\text { (SD/range] }\end{array}$ & $0.85(0.83 / 0-3)$ & $1.08(0.94 / 0-5)$ & $0.194^{*}$ & $1.06(0.93 / 0-5)$ \\
$\begin{array}{l}\text { No. of procedures for aesthetic refinement only } \\
\text { per patient [mean (SD/range] }\end{array}$ & $2.45(2.37 / 0-7)$ & $2.13(1.83 / 0-7)$ & $0.634^{*}$ & $2.17(1.89 / 0-7)$ \\
$\begin{array}{l}\text { No. of operations for aesthetic refinement only } \\
\text { [mean (SD/range] }\end{array}$ & $0.7(0.68 / 0-2)$ & $0.91(0.78 / 0-5)$ & $0.155^{*}$ & $0.89(0.78 / 0-3)$ \\
\hline \hline
\end{tabular}

Chapter 8. Aesthetic refinements and reoperative procedures following 370 consecutive DIEP and SIEA flap breast reconstructions: important considerations for patient consent.

Table 3. Number of secondary procedures and operations, comparing cases of unilateral and bilateral breastr

\begin{tabular}{llll}
\hline & $\begin{array}{l}\text { Unilateral breast } \\
\text { reconstruction } \\
(\mathbf{n = 2 8 2})\end{array}$ & $\begin{array}{l}\text { Bilateral breast } \\
\text { reconstruction } \\
(\mathbf{n}=\mathbf{4 4})\end{array}$ & $\boldsymbol{P}$ \\
\hline \hline $\begin{array}{l}\text { No. of patients who underwent secondary procedures } \\
\text { [n (\%)] }\end{array}$ & $213 / 282(75.5)$ & $25 / 44(56.8)$ & $0.016^{* *}$ \\
$\begin{array}{l}\text { No. of secondary procedures per patient [mean } \\
\text { (SD/range] }\end{array}$ & $2.36(1.95 / 0-7)$ & $2.16(2.2 / 0-7)$ & $0.41^{*}$ \\
$\begin{array}{l}\text { No. of secondary operations per patient [mean } \\
\text { (SD/range] }\end{array}$ & $1.11(0.96 / 0-5)$ & $0.7(0.7 / 0-2)$ & $0.009^{*}$ \\
$\begin{array}{l}\text { No. of procedures for aesthetic refinement only per } \\
\text { patient [mean (SD/range] }\end{array}$ & $2.17(1.8 / 0-7)$ & $2.10(2.21 / 0-7)$ & $0.57^{*}$ \\
$\begin{array}{l}\text { No. of operations for aesthetic refinement only [mean } \\
\text { (SD/range] }\end{array}$ & $0.93(0.8 / 0-4)$ & $0.64(0.63 / 0-2)$ & $0.024^{*}$ \\
\hline
\end{tabular}

Statistical significance was calculated with Fisher's exact test $\left({ }^{* *}\right)$ and Mann-Whitney $\mathrm{U}$ test $\left({ }^{*}\right.$

Procedures for Complications

Of the 326 patients in the study, 46 patients underwent a total of 55 early postoperative operations for surgical complications following primary reconstructive surgery. This equated to an average of 0.17 additional operations per patient as a consequence of complications. Of these 46 patients, 39 required a single reoperation, 5 needed 2 reoperations, and 2 needed 3 additional reoperations for complications (Table 4). 


\section{Table 4. Complications following primary breast reconstruction}

\section{Patients requiring reoperation due to complications [n (\%)]}

$46 / 32$

$(14.1)$

$39 / 32$

(12.0)

Patients who underwent 1 reoperation due to complications [n (\%)] Patients who underwent 2 reoperations due to complications [ $\mathrm{n}(\%)]$

Patients who underwent 3 reoperations due to complications $[n(\%)]$

$2 / 326(0.6)$

Complications requiring reoperation

Flap recipient site

Anastomotic insufficiency [n (\%)] 21/326 (6.4)

Hematoma [n (\%)]

Debridement of necrotic tissue [n (\%)] 9/326 (2.8)

Flap donor site

Nil

N/A

\section{Other complications}

Flap recipient site

Flap failure $[n(\%)]$

Infection [n (\%)]

$10 / 326(3.1)$

$30 / 326(9.2)$

Fat necrosis [n (\%)]

Flap donor site

Seroma [n (\%)]
Infection [n (\%)]
(14.1)

$6 / 326(1.8)$

$10 / 326(3.1)$
Procedures for Aesthetic Refinement

Procedures for aesthetic refinement were divided into those that were performed on the ipsilateral reconstructed breast, the contralateral breast, or the abdominal donor site. There were also several secondary procedures performed on the ipsilateral axilla following axillary dissection or secondary vein harvest. Procedures for aesthetic refinement included nipple reconstruction, nipple-areola complex tattooing (Fig. 1a, b), dog-ear correction, liposuction, lipofilling, scar revision, mastopexy, and reduction mammaplasty.
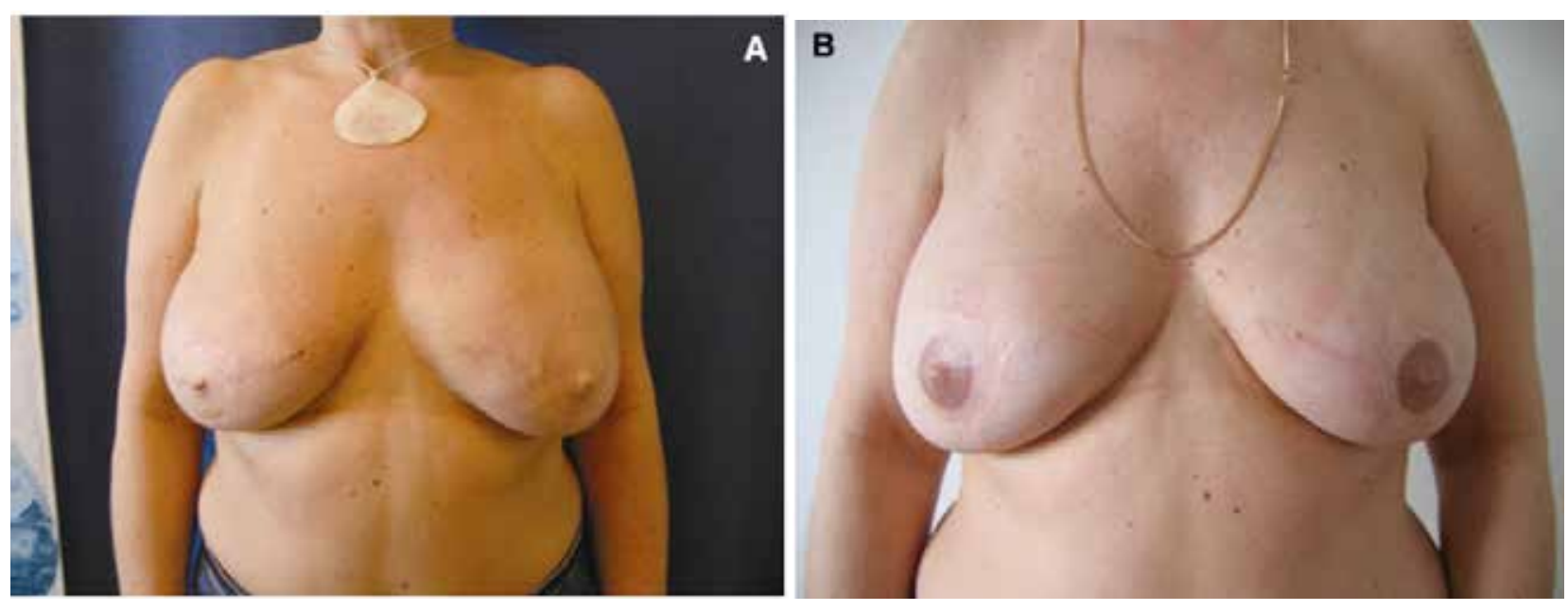

Tables 5, 6, 7 demonstrate the range of procedures and their incidence. Of note, patients were more likely to have revision surgery on the reconstructed breast than the contralateral breast, and were more likely to have revision surgery (second or third aesthetic operations) on the reconstructed breast than the contralateral breast. In addition, while aesthetic procedures on the contralateral breast were more frequent in the early postreconstruction period, later procedures were more likely to be requested on the reconstructed breast. Donor site procedures were found to be commonly performed. In addition, there were 18 operations performed on the axilla of the ipsilateral side of the reconstructed breast. These comprised liposuction $(n=$ 12) and scar revision $(n=6)$

Table 5. Patients who underwent secondary aesthetic operations on their reconstructed breast

\begin{tabular}{lll} 
Reconstructed breast & $\mathbf{n}(\%)$ & Mean time interval to operation (months) (SD/range) \\
\hline \hline Liposuction & $83 / 326(25.5)$ & $18.9(13 / 2.87-57.7)$ \\
Repeat liposuction & $4 / 326(1.2)$ & $38.44(27.8 / 12.2-76.4)$ \\
Scar revision & $52 / 326(16.0)$ & $21.0(16.0 / 5.3-95.5)$ \\
Repeat scar revision & $3 / 326(0.9)$ & $30.6(9.5 / 21.2-40.3)$ \\
Dog-ear correction & $10 / 326(3.1)$ & $17.1(5.4 / 9.4-25.9)$ \\
Lipofilling & $6 / 326(1.8)$ & $22.6(15.0 / 6.7-46.7)$ \\
Nipple reconstruction & $146 / 326(44.8)$ & $20.2(12.1 / 0-73.6)$ \\
Nipple-areola complex (NAC) tattooing & $122 / 326(37.4)$ & $29.8(13.2 / 3.37-73.6)$ \\
\hline \hline
\end{tabular}


Table 6. Patients undergoing unilateral breast reconstruction who underwent secondary aesthetic operations on their contralateral breast

\begin{tabular}{lll}
\hline Contralateral breast & $\mathbf{n}(\%)$ & Mean time interval to procedure (months) (SD/range) \\
\hline \hline Reduction mammoplasty & $41 / 282(14.5)$ & $17.3(11.6 / 0-46.7)$ \\
Mastopexy & $39 / 282(13.8)$ & $14.9(11.0 / 0-45.3)$ \\
Liposuction & $28 / 282(9.9)$ & $19.2(13.4 / 0-49.5)$ \\
Scar revision & $1 / 282(0.4)$ & $20.6(12.5)$ \\
Repeat scar revision & $1 / 282(0.4)$ & $25.7(15)$ \\
\hline \hline
\end{tabular}

Table 7. Patients who underwent secondary aesthetic operations at their abdominal donor site

\begin{tabular}{lll}
\hline Abdominal donor site & $\mathbf{n}(\%)$ & Mean time interval to procedure (months) (SD/range) \\
\hline \hline Liposuction & $68 / 326(20.9)$ & $18.1(11.4 / 4.47-49.5)$ \\
Repeat liposuction & $4 / 326(1.2)$ & $40.0(27.2 / 10.5-76.4)$ \\
Scar revision & $27 / 326(8.3)$ & $20.0(14.9 / 1.70-57.7)$ \\
Dog-ear correction & $46 / 326(14.1)$ & $19.5(12.9 / 4.47-73.6)$ \\
\hline
\end{tabular}

\section{DISCUSSION}

There has been an increasing trend toward autologous breast reconstruction in many centers, with the DIEP flap becoming the standard in autologous microsurgical reconstruction. Unlike the transverse rectus abdominis myocutaneous(TRAM) flap, considered by many the previous standard, the DIEP flap does not have the inherent disadvantage of harvesting the rectus abdominis muscle. ${ }^{2,8,9}$ With reduced donor site morbidity, the DIEP flap can result in shorter convalescence and reduced postoperative stay. ${ }^{8,10}$ With the SIEA flap minimizing donor site morbidity even further by avoiding any incision to the anterior rectus sheath, the postoperative hospital stay and abdominal wall weakness are further reduced. ${ }^{5}$ With clear patient benefits, the cost effectiveness of autologous reconstruction is also a key factor in procedural selection for hospitals. ${ }^{11}$ In addition to cost and functional outcomes, the aesthetic outcome of breast reconstruction is a key determinant to operative success. With breast reconstruction shown to improve the psychosexual functioning of a woman postmastectomy ${ }^{12}$, the degree to which the reconstructed breast is aesthetically pleasing intuitively will lead to better psychological outcomes. A significant benefit of autologous reconstruction is the ability to modify volume, shape, and texture to better resemble the premastectomy breast. Despite this, secondary procedures are often required in order to improve the outcome of the reconstructed breast, to modify the contralateral breast, or to correct the donor site after flap harvest. Information regarding the need for additional procedures after DIEP flap surgery is particularly valuable to
Chapter 8. Aesthetic refinements and reoperative procedures following 370 consecutive DIEP and SIEA flap breast reconstructions: important considerations for patient consent.

patients during the consent process and should play an important role in decision making. In addition detailed education will allow patients to better shape their expectations. In comparing autologous reconstruction to implant reconstruction, anecdotally it has often been thought that the number of interventions (i.e., the insertion of a tissue expander, multiple tissue expansions, and the need for definitive implant insertion) is a key factor for patients in selecting autologous reconstruction. The current study has shown that autologous reconstruction is not a one-stage procedure. Rather, more than one secondary procedure can be expected at the very least following initial reconstruction, with many patients having two or three procedures as long as 8 years after the initial procedure. Knowing this can help surgeons better consult with patients and help hospitals plan procedures and better allocate funds. Although secondary procedures were widely performed in our cohort, the number of secondary operations per patient (1.06) was not overly high and was not a deterrent for patients offered these procedures prospectively. In fact, many of these procedures were discussed and requested prospectively, with many procedures of the contralateral breast occurring at the time of initial reconstruction. A previous study reported the number of secondary procedures to be higher for autologous tissue transplants than for implants ${ }^{13}$, with TRAM flaps requiring an average of 4.1 additional procedures for unilateral and 6.2 procedures for bilateral breast reconstructions ${ }^{13}$; these figures far exceeded our own. In our series we found a correlation between bilateral breast reconstruction and a reduction in the number of interventions for aesthetic refinement. This was largely due to the ability to modify the symmetry and shape of both breasts intraoperatively at the primary operation. With a good preoperative understanding of the patient's wishes, the breasts can be reconstructed in line with the patient's expectations. Notably, there was no difference between immediate and delayed reconstructions, and in contrast to previous reports, there was no statistical difference in secondary procedures based on patient age ${ }^{7,14,15}$. The mean age of patients undergoing any additional procedures was 50.42 years compared to 50.16 for patients that did not undergo any additional procedures $(P=0.81)$. Individual procedures were performed for different individual concerns, with liposuction, for example, performed for correction of shape, size, and/or symmetry in varying cases. Previous studies have described the appearance of the NAC, symmetry of the breasts, and scar appearance. on the reconstructed breast as the main factors influencing patient satisfaction., ${ }^{76}$ In our series, nipple reconstruction was the most frequently requested procedure (44.8\%), followed by NAC micropigmentation/tattooing (37\%), liposuction (36.5\%), and scar revision (25.5\%). Our rate of nipple reconstruction is substantially lower than that of previous reports. ${ }^{7,14,15}$ While the cause of this is unclear, time allocation, a relatively high rate of nipple-sparing mastectomies, and unknown factors relating to our cohort are all possibilities. The impact of timing a reoperation is also an important factor, given the potential 
effect on the oncologic treatment of patients with breast cancer. It is known that immediate breast reconstruction does not impair the oncologic safety of breast cancer management; there is no increase in local recurrence rates and no delays in the initiation of adjuvant chemotherapy or radiotherapy. ${ }^{12}$ Autologous breast reconstruction is usually chosen with the need for adjuvant therapies known and thus can be timed effectively, but when adjuvant therapy is needed postoperatively, aesthetic refinements can be delayed until after therapy is concluded. This cannot be said for reoperations due to complications, which obviate the need for immediate surgery. As such, patients in consultation for breast reconstruction should be advised of the frequent need for secondary operations following primary reconstructive surgery. At least one additional procedure can be expected, with multiple reoperations not uncommon. Of these procedures, revision surgery is more common on the reconstructed breast than on the contralateral breast, and procedures on the contralateral breast are more frequent in the early postreconstruction period. Procedure on the reconstructed breast are more frequent later in the postreconstruction period. Donor site procedures are frequently performed as well. In a small number of patients, previous axillary surgery or the need to harvest a secondary vein for venous augmentation results in the need for revision surgery to the axilla.

\section{CONCLUSION}

While DIEP flap surgery for breast reconstruction yields favorable results, patients frequently require additional procedures to improve aesthetic outcomes. The need for reoperation is an important part of the consultation process prior to reconstructive surgery, and patients should be informed of the need for revision surgery of both the ipsilateral and the contralateral breast as well as of the donor site. While the number and degree of reoperations is a decision made by the patient and the surgeon together, patients should recognize the likelihood of at least one additional procedure following initial reconstruction.
Chapter 8. Aesthetic refinements and reoperative procedures following 370 consecutive DIEP and SIEA flap breast reconstructions: important considerations for patient consent.

\section{REFERENCES}

1. Guerra AB, Metzinger SE, Bidros RS, et al. Bilateral breast reconstruction with the deep inferior epigastric perforator (DIEP) flap: an experience with 280 flaps. Ann Plast Surg 2004;52:246-252

2. Allen RJ, DIEP versus TRAM for breast reconstruction. Plast Reconstr Surg 2003; 111:2478.

3. Allen RJ, Treece P. Deep inferior epigastric perforator flap for breast reconstruction. Ann Plast Surg 1994; $32: 32-38$.

4. Blondeel PN. One hundred free DIEP flap breast reconstructions: a personal experience. Br J Plast Surg 1999;52:104-111.

5. Chevray PM. Breast reconstruction with superficial inferior epigastric artery flaps: a prospective comparison with TRAM and DIEP flaps. Plast Reconstr Surg 2004;114:1077-1083; discussion, 1084-1085

6. Giacalone PL, Bricout N, Dantas MJ, et al. Achieving symmetry in unilateral breast reconstruction: 17 years experience with 683 patients. Aesthetic Plast Surg 2002;26:299-302.

7. Damen TH, Mureau MA, Timman R, et al. The pleasing end result after DIEP flap breast reconstruction: a review of additional operations. J Plast Reconstr Aesthet Surg 2009;62:71-76.

8. Blondeel N, Vanderstraeten GG, Monstrey SJ, et al. The donor site morbidity of free DIEP flaps and free TRAM flaps for breast reconstruction. Br J Plast Surg 1997;50:322-330.

9. Nahabedian MY, Dooley W, Singh N, et al. Contour abnormalities of the abdomen after breast reconstruction with abdominal flaps: the role of muscle preservation. Plast Reconstr Surg 2002;109:91-101

10. Allen RJ. Comparison of the costs of DIEP and TRAM flaps. Plast Reconstr Surg 2001;108:2165.

11. Kroll SS, Evans GR, Reece GP, et al. Comparison of resource costs between implant-based and TRAM flap breast reconstruction. Plast Reconstr Surg 1996;97:364-372. 
12. Rozen WM, Ashton MW, Taylor GI. Defining the role for autologous breast reconstruction after mastectomy: social and oncologic implications. Clin Breast Cancer 2008;8:134-142.

13. Losken A, Carlson GW, Schoemann MB, et al. Factors that influence the completion of breast reconstruction. Ann Plast Surg 52(3): 2004;258-261; discussion, 262

14. Malyon AD, Husein M, Weiler-Mithoff EM. How many procedures to make a breast? Br J Plastic Surg 2001;54:227-231.

15. Schover LR, Yetman RJ, Tuason L, et al. Partial mastectomy and breast reconstruction. A comparison of their effects on psychosocial adjustment, body image, and sexuality. Cancer 1995;75:54-64.

16. Andrade WN, Semple JL. Patient self-assessment of the cosmetic results of breast reconstruction. Plast Reconstr Surg 2006;117:44-47; discussion, 48-49. 


\section{ABSTRACT}

The objective of this article is to assess the impact of deep inferior epigastric perforator (DIEP) flap breast reconstruction on self-esteem and to analyze the correlation between aesthetic outcome and self-esteem. Global self-esteem was evaluated using the Rosenberg Self- Esteem Scale in 31 patients who underwent DIEP flap breast reconstructions. A study-specific questionnaire and photographic evaluation were used by the patient, the plastic surgeon, and the oncological surgeon to measure satisfaction with the aesthetic outcome. Patients' satisfaction and self-esteem were analyzed for any existing correlation. Overall patients' satisfaction had a mean score of 6.55 (range, $0-10$ ) on the Patient Satisfaction Questionnaire. A mean score of 32.48 (range, 10-40) was found on the Rosenberg Self-Esteem Scale. More than $80 \%$ of patients were content with their decision to undergo this procedure and would recommend this to a friend. Surgeons tended to rate the aesthetic outcome better than patients. Patients' satisfaction and self-esteem were found to be positively correlated. Patients are generally content with the outcome of primary DIEP flap breast reconstruction. The favorable aesthetic result of this procedure has a beneficial effect on patients' self-esteem.

\section{INTRODUCTION}

Psychosocial adjustment to breast cancer and mastectomy has long been a focus of attention and still remains a major focus of research. Earlier studies have described a wide range of lasting psychological disturbances. ${ }^{1-9}$ Indeed, the loss of a body part that symbolizes womanliness, sexuality, and nurturance wil inevitably disrupt body image and negatively impact a woman's selfesteem. Self-esteem reflects a person's overall appreciation of personal value. It encompasses beliefs about talents, capabilities, and shortcomings and accordingly influences one's ability to cope with cancer. ${ }^{10,11}$ Breast reconstruction aims to diminish the impact of mastectomy on self-esteem and to improve patients' quality of life. Indeed, the psychosocial benefits of breast reconstruction have been documented manifold. ${ }^{12-18}$ Although quality of life as an outcome has received much attention, the concept of self-esteem after breast reconstruction has been explored to a much lesser extent. This study set out to evaluate the impact of deep inferior epigastric perforator (DIEP) flap breast reconstruction on self-esteem using the Rosenberg Self-Esteem Scale (RSES). This valid, reliable, and simple tool allows measurement of self-esteem after breast reconstruction.
The RSES has been applied previously in the assessment of self-esteem after breast reconstruction. ${ }^{13,15-18}$ Whereas these studies evaluated differences in selfesteem pre- and postoperatively, we set out to compare self-esteem levels in women having undergone mastectomy and subsequent breast reconstruction to previously defined self-esteem levels in the general Dutch female population. Furthermore, we evaluated and compared both patients' and surgeons' satisfaction with the aesthetic result after reconstruction.

\section{METHODS}

Patients who underwent a primary DIEP flap breast reconstruction postmastectomy during the period of February 2005 to July 2007 were included in a cross-sectional survey. "Combined" bilateral reconstructions, that is, reconstructions comprising both a primary reconstruction on one side and a secondary or tertiary reconstruction on the contralateral side performed during the same operative procedure, were also included in our survey. All patients were operated at the Academic Hospital of Maastricht. Exclusion criteria comprised development of breast cancer in the contralateral breast or the presence of distant metastases at the time of survey. Patient characteristics and surgical data were obtained from medical records.

Patient-Based Outcome Measures

All patients were asked to complete two questionnaires, including the RSES (Dutch translation) and a study-specific questionnaire to measure satisfaction with the aesthetic result after reconstruction. Patients were asked to score their degree of satisfaction with reconstruction on a scale of 1-10. They were also asked to indicate whether they would choose the same procedure again and if they would recommend the procedure to a close friend or family member. The RSES is composed of a continuum of selfworth statements and is designed to assess feelings of self-worth and self-acceptance. Subjects are instructed to rate each item, using a 4-point scale ranging from strong agreement to strong disagreement. The total score ranges from 10 to 40, with higher scores indicating higher self-esteem. 


\section{Objective Aesthetic Evaluation}

Three standardized digital photographs were taken of each patient showing frontal, left oblique, and right oblique views. Each photograph was then assessed by two surgeons, a female oncological surgeon and a male plastic surgeon. Photographs of the reconstructed breast were compared with photographs of the contralateral breast, using a studyspecific questionnaire consisting of 14 items. The questionnaire assessed several cosmetic determinants such as aesthetic result, size, shape, symmetry, nipple-areola complex, color, and scar appearance. In case of bilateral surgery, both breasts were evaluated. Items were given a score of 1-10, with higher scores representing better results.

\section{Subgroup Analysis}

A subgroup analysis was conducted with subgroups comprising patients with previous mastectomy, patients with oncological or prophylactic mastectomy, and patients with uni- or bilateral reconstruction. Self-esteem and satisfaction were compared in these subgroups.

\section{Statistical Analysis}

Data are presented as percentages, medians with ranges, and means. Spearman's correlation coefficient was used to analyze correlation between patient satisfaction and self-esteem. The Mann-Whitney $U$ test was used for the statistical analysis of nonparametric continuous data. The Friedman and Wilcoxon test was used to analyze any significant differences between subgroups. Significance was set at $p<0.05$. Analyses were performed using Statistical Package For Social Sciences (SPSS) for Windows version 15.0 (SPSS Inc., Chicago, IL).

\section{RESULTS}

Study Population

Thirty-eight patients were included with a total of 57 primary breast reconstructions. A total of 31 patients (91\%) completed and returned the questionnaire by mail. The average age at the time of reconstruction was 50.7 years (range, 30-65 years). The mean follow-up was 20.3 months (range, 7-35 months). In 24 women the indication for surgery was breast cancer and in 7 women the indication was BRCA gene mutation. Sixteen patients underwent bilateral reconstruction. In the bilateral reconstruction group, 5 patients underwent "combined bilateral reconstruction." "Combined bilateral reconstruction" refers to a breast reconstruction consisting of a primary reconstruction on one side and a secondary or tertiary reconstruction on the contralateral side, both performed during the same operative procedure. In the five cases mentioned indications for reconstruction of the contralateral breast included prophylactic mastectomy and cancer

Complications occurred in 11 patients (36\%). While no complete flap loss was observed, partia flap loss did occur in three patients (10\%). One patient developed a pulmonary embolism. Three patients developed an abdominal hernia and three patients developed an abdominal hematoma. Four patients required surgical revision of the reconstructed breast because of skin necrosis. Clinical characteristics are shown in Table 1.

\begin{tabular}{ll} 
Table 1. Clinical Patient Characteristics ( $\mathrm{N}=31)$ & \\
\hline \hline Mean age in years (range) & $50.7(30-65)$ \\
Mean follow-up in months (range) & $20.3(7-35)$ \\
Site of immediate breast reconstruction, $\mathrm{n}(\%)$ & \\
$\quad$ Unilateral & $15(46 \%)$ \\
$\quad$ Bilateral & $16(54 \%)$ \\
Condition requiring breast reconstruction, $\mathrm{n}(\%)$ & \\
$\quad \begin{array}{l}\text { Oncological mastectomy } \\
\quad \text { Prophylactic mastectomy }\end{array}$ & $24(77 \%)$ \\
Adjuvant therapy, $\mathrm{n}(\%)$ & $7(23 \%)$ \\
$\quad$ None & \\
$\quad$ Chemo/radiotherapy & $21(68 \%)$ \\
$\quad$ Chemo/hormonal therapy & $3(9 \%)$ \\
\hline \hline & $7(23 \%)$ \\
\hline
\end{tabular}

Aesthetic Satisfaction and Self-Esteem

Aesthetic satisfaction and self-esteem scores of the patients are shown in Table 2. Primary reconstruction yielded a mean satisfaction score of $6.32(0-10)$, whereas patients with previous mastectomy rated their satisfaction with a score of 7.5. The overall patient satisfaction score was 6.55. Patients were most satisfied with the contour and volume of the reconstructed breast and least satisfied with the sensation of the reconstructed breast and the abdominal scars. The Rosenberg selfesteem questionnaire showed a mean score of 32.48 (range, 10-40). A significant correlation was found between patients' self-esteem and aesthetic satisfaction (Spearman's rho, $r=.551, p=.001$ ). Twentyfive women (81\%) were content with their decision to undergo this procedure, and 27 women (87\%) would recommend this operation to a close friend or family member. Table 3 shows the results of the objective aesthetic assessment as carried out by the surgeon and the plastic surgeon. The photographic assessment included 22 patients. A minority of patients were unwilling to participate in the assessment of aesthetic satisfaction, mainly because of long distances 
between their hometown and the hospital. In general, the plastic surgeon was most satisfied with the aesthetic result followed by the surgeon and then the patient. These differences were significant in the majority of items evaluated.

Table. 2 Aesthetic Satisfaction of the Patien

\begin{tabular}{llll}
\hline Patient satisfaction & N & Mean score (0-10) & Median $\mathbf{~ ( 0 - 1 0 )}$ \\
\hline \hline Breast & & & \\
$\quad$ Contour & 39 & 6.00 & 7 \\
$\quad$ Volume & 39 & 6.08 & 7 \\
$\quad$ Sensation & 39 & 4.33 & 5 \\
$\quad$ Symmetry of volume & 31 & 5.58 & 6 \\
$\quad$ Symmetry of contour & 31 & 5.90 & 6 \\
Nipple-areola & & & \\
$\quad$ Symmetry & 20 & 6.68 & 7 \\
$\quad$ Size & 20 & 7.05 & 7 \\
$\quad$ Color & 20 & 7.10 & 7.5 \\
Scars & 31 & & \\
$\quad$ Breast & 31 & 6.00 & 6 \\
$\quad$ Abdominal & 31 & 5.55 & 5 \\
$\quad$ Total score satisfaction & 31 & 6.55 & 7 \\
\hline \hline
\end{tabular}

Table. 3 Aesthetic Satisfaction by Patient-Surgeon-Plastic Surgeon

\begin{tabular}{llllll}
\hline & & \multicolumn{3}{c}{ Mean score (0-10) } & \\
\cline { 4 - 5 } & Patient (P) & Surgeon (S) & Plastic surgeon (PS) & $p$ \\
\hline \hline Breast & & & & & \\
$\quad$ Contour & 27 & 6.00 & 6.70 & 7.63 & .001 \\
$\quad$ Volume & 27 & 6.11 & 7.07 & 7.93 & .004 \\
$\quad$ Symmetry volume & 22 & 5.64 & 7.59 & 7.09 & .006 \\
$\quad \begin{array}{l}\text { Symmetry contour } \\
\text { Nipple-areola }\end{array}$ & 22 & 5.95 & 7.00 & 7.55 & .001 \\
$\quad$ Symmetry & 12 & 7.50 & 7.67 & & \\
$\quad$ Size & 12 & 8.08 & 7.92 & 7.92 & .358 \\
$\quad$ Color & 12 & 8.00 & 7.20 & 8.92 & .004 \\
Scars & & & & 8.08 & .109 \\
$\quad$ Breast & 22 & 5.95 & 7.09 & & .015 \\
$\quad$ Abdominal & 21 & 5.67 & 7.00 & 7.41 & $<.0001$ \\
Total score satisfaction & 22 & 6.68 & 6.73 & 7.81 & $<.0001$ \\
\hline \hline
\end{tabular}

Table. 4 Subgroup Analysis

\section{mastectomy Mastectomy}

Range in the past in the past

$(n=6)$

\begin{tabular}{|c|c|c|c|c|c|c|c|c|c|c|}
\hline & Range & $\begin{array}{l}\text { in the past } \\
(n=6)\end{array}$ & $\begin{array}{l}\text { in the past } \\
(n=25)\end{array}$ & $p$ & $\begin{array}{c}\text { Oncologic } \\
(n=24)\end{array}$ & $\begin{array}{l}\text { Prophylactic } \\
(\mathrm{n}=7)\end{array}$ & $p$ & $\begin{array}{l}\text { Unilateral } \\
(n=15)\end{array}$ & $\begin{array}{l}\text { Bilateral } \\
(n=16)\end{array}$ & $p$ \\
\hline Self-esteem & $10-40$ & 35.33 & 31.80 & .153 & 33.88 & 27.71 & .005 & 33.33 & 31.69 & .275 \\
\hline Total satisfaction & $0-10$ & 7.50 & 6.32 & .049 & 6.58 & 6.43 & 361 & 6.60 & 6.50 & .853 \\
\hline Symmetry contour & $0-10$ & 6.17 & 5.84 & .723 & 6.00 & 5.57 & .582 & 6.33 & 5.50 & .246 \\
\hline Symmetry volume & $0-10$ & 6.00 & 5.48 & .818 & 5.67 & 5.29 & .791 & 5.80 & 5.38 & .614 \\
\hline Scars breast & $0-10$ & 6.50 & 5.88 & .819 & 6.21 & 5.29 & 386 & 6.67 & 5.58 & .058 \\
\hline Scars abdominal & $0-10$ & 6.67 & 5.28 & .121 & 6.00 & 4.00 & .007 & 6.33 & 4.81 & .022 \\
\hline
\end{tabular}

Tests done with Mann-Whitney $\mathrm{U}$ test.

\section{Subgroup Analysis}

The analyzed subgroups comprised women with previous mastectomy, oncological or prophylactic mastectomy, and unilateral or bilateral reconstruction. Table 4 summarizes and compares aesthetic satisfaction and self-esteem data for these subgroups. Women with a previous mastectomy of the contralateral breast showed significantly higher satisfaction scores than women who had no previous mastectomy (primary reconstruction). Abdominal scars were rated significantly lower in the bilatera reconstruction group than in the unilateral reconstruction group. Self-esteem was found to be significantly higher in women who underwent mastectomy for breast cancer than women who underwent prophylactic mastectomy.

\section{DISCUSSION}

The essential role of breasts in female psychosexual development signifies its vast implications in the emotional life of any woman. Indeed the negative effects of mastectomy on body image, sexuality, and patients' feelings of femininity have been described extensively. ${ }^{1-9}$ Similarly, the psychosocial benefits of autologous breast reconstruction have been documented manifold, albeit using different operative techniques and applying different measurement scales. ${ }^{12-18}$ The current analysis contributes to existing literature in several important respects. First, the in and exclusion criteria applied make this patient population a relatively heterogeneous group representative of women undergoing DIEP flap breast reconstruction in the Netherlands. 
Second, we evaluated and compared both patients' and surgeons' satisfaction with the aesthetic result after reconstruction. Most notably, however, we measured self-esteem after breast reconstruction, using the RSES comparing the outcome to previously defined self-esteem levels in the general Dutch female population. The RSES has been applied in several studies involving breast reconstructive surgery. ${ }^{13,15-18}$ These studies evaluated self-esteem outcomes in different therapies, including mastectomy without reconstruction, mastectomy with subsequent reconstruction, correction of breast asymmetry, and breast-conserving therapy (BCT). While the findings in these studies underline the beneficial effect of breast reconstruction, they do show a slight tendency toward higher self-esteem in BCT compared to mastectomy with breast reconstruction. Both breast reconstruction and BCT show significantly higher self-esteem scores than mastectomy alone. The concept of self-esteem, its relation to body image, and psychological well-being remain complex and difficult to comprehend. Self-esteem is the evaluative element of self-concept, known to be an important determinant to psychological well-being. ${ }^{19}$ In fact, low levels of self-esteem as depicted by low scores on the RSES have shown to be correlated to affective disorders such as a depressive episode. ${ }^{20,21}$ The RSES is a valid and reliable scale composed of a continuum of self-worth statements and is widely used to assess feelings of self-worth and self-acceptance. Its uncomplicated language and brevity combined with its relative simplicity and accessibility make it favorable for multilingual translations. ${ }^{22}$ Our patient population scored an average of 32.48 on the RSES, which is comparable to the average score of the Dutch population. ${ }^{22}$ Pursuant to this finding, we found the majority of women $(>80 \%)$ to be content with their decision to undergo this procedure and approximately $90 \%$ would recommend it to a close friend or family member. These figures are highly comparable with recent studies. ${ }^{12,23}$ In assessing patients' satisfaction, we found an overall score of 6.55 on a scale of 1-10. This score is relatively low compared with scores of $8.4^{12}$ and $7.8^{24}$ obtained in other studies. In contrast to our patient population, the two studies mentioned had a population consisting of patients with mostly secondary ${ }^{12}$ and tertiary reconstructions. ${ }^{24}$ Notably, we observed a significantly lower satisfaction score in patients with no previous mastectomy (6.32) compared with patients with previous mastectomy (7.50; $p=.049$; Mann-Whitney $U$ test). Patients with no previous mastectomy composed the majority of our population (80.3\%), which explains the overall satisfaction score of 6.55 . There are conflicting reports regarding patient satisfaction after immediate and delayed reconstruction. Whereas some studies found patient satisfaction to be unaffected by the timing of reconstruction, ${ }^{12,19-27}$ a recent study did report patients with delayed reconstruction to express significantly higher levels of satisfaction with the outcome of reconstruction. ${ }^{26}$
Indeed, a patient having consciously experienced the mutilating effect of mastectomy would predictably have higher appreciation for the outcome of delayed reconstruction than a patient with immediate reconstruction who compares the reconstructive outcome with the natural breast. Not surprisingly, measures of the RSES were found to be significantly correlated to patients' satisfaction (Spearman's rho, $r=$ $.551, p=.001)$. The patients' subjective evaluation of aesthetic result was less positive than the evaluation by both the surgeon and the plastic surgeon. This appears to contradict findings of the previously mentioned studies in which patients expressed more satisfaction with the aesthetic outcome than the surgeon. ${ }^{12,19-27}$ It is plausible that the previous arguments explaining lower patient satisfaction in this study also apply to the discrepancy in patients' and surgeons' satisfaction. The male plastic surgeon was generally more satisfied with the aesthetic result than the female oncologic surgeon. Although this difference may be gender related, it should be taken into account that in judging his own results, assessment by the plastic surgeon may have been subject to bias. It is advisable for future studies to avert potential confounders of this kind by including more medical experts of both genders in the evaluation of aesthetic outcome. Ideally, the judging panel should have no affiliation to the patient or the medical experts involved in treatment. In the current study, women with prophylactic mastectomy and subsequent bilateral reconstruction scored significantly lower on the RSES compared to women with unilateral mastectomy and unilateral reconstruction (33.88 vs. $27.71 ; p=$ .005; Mann-Whitney $U$ test). Several factors may contribute to this discrepancy. First, the more invasive nature of bilateral mastectomy and reconstruction would predictably have a more profound impact on body image and self-esteem. Second, we found postoperative complications to occur more frequently in women who underwent bilateral reconstruction. In accordance with previous studies, we found complications to be negatively correlated to patient satisfaction. ${ }^{25}$ Furthermore, "combined" reconstruction might render both breasts more prone to symmetrical discrepancy. As such, the five cases that underwent "combined" bilateral reconstruction may have been less satisfied with the cosmetic outcome of reconstruction, which in turn might have had a negative impact on the patients' satisfaction score in the bilateral reconstruction group. A concomitant factor that may, in part, explain the lower self-esteem found in the bilateral reconstruction group is a varying magnitude of psychological adaptation to mastectomy between the unilateral and bilateral reconstruction groups. Predictably, psychological adaptation to an upcoming mastectomy would be more prominent in women diagnosed with breast cancer than in women with BRCA gene mutations alone. The diagnosis of breast cancer may cause a shift in thinking of the breasts as a prized possession toward viewing it as a foreign body that threatens life. This may ease acceptance of mastectomy and its consequences. ${ }^{27}$ 
This psychological adaptation is probably less profound in women undergoing prophylactic mastectomy. As such, mastectomy and subsequent physical disfigurement, even though corrected through reconstruction, are more likely to cause negative perceptions of body image and to have a higher impact on self-esteem in patients who undergo bilateral prophylactic mastectomy than in patients who undergo unilateral mastectomy.

The primary aim of our study was to assess patients' self-esteem after breast reconstruction, using the Dutch female population as a reference. As such, our approach to studying self-esteem outcomes did not include an assessment of preoperative baseline patient psychosocial characteristics. This precludes pre- and postoperative comparison, and also precludes detection of potential confounding effects including major life events such as family illness, personal illness, and divorce on patient-reported outcomes of satisfaction and self-esteem

\section{CONCLUSION}

The findings of the current study underline the psychological benefit of DIEP flap breast reconstruction Self-esteem levels after DIEP flap breast reconstruction proved comparable to previously defined self-esteem levels in the general Dutch female population. Furthermore, we found self-esteem to be significantly correlated to the degree of satisfaction with reconstructive outcome. The timing of reconstruction was found to be of significant influence to short-term patient satisfaction. The results of the current study confirm and expand the findings of previous studies, that is, breast reconstruction improves a patient's psychological well-being. The relationship between reconstructive outcome, self-esteem, and psychological well-being, however, remains difficult to comprehend and requires investigation in more detail in future studies.

\section{REFERENCES}

1. Anderson SG, Rodin J, Ariyan S. Treatment considerations in postmastectomy reconstruction: Their relative importance to patient satisfaction. Ann Plast Surg 1994:33:263-70.

2. Bard M, Sutherland AM. Psychological impact of cancer and its treatment: Impact of radical mastectomy Cancer1995;8:656.

3. Bransfield DD. Breast cancer and sexual functioning: A review of the literature and implications for future research. Int J Psychiatry Med 1982;12: 197.

4. Clifford E. The reconstruction experience: The search for restitution. In N. Georgiade (Ed.), Breast reconstruction following mastectomy 1979 pp. 22-34. London: Mosby.

5. Fobair P, Stewart SL, Chang S et al. Body image and sexual problems in young women with breast cancer Psychooncology 2006;15: 579-594.

6. Goldberg P, Stolzman M, Goldberg HM. Psychological considerations in breast reconstruction. Ann Plast Surg 1984;13: 38

7. Magistrato R, DiPaola M, Ruffolo F, et al. Psychological effects of breast reconstruction following radical mastectomy. Minerva Med, 1982;73: 1711.

8. Renneker R, Cutler M. Psychological problems of adjustment to cancer of the breast. JAMA 1952;148: 833

9. Teimourian B, Adham MN. Survey of patient's responses to breast reconstruction. Ann Plast Surg 1982;9: 321

10. Fitts WH, Adams JL, Radford G, et al. The self-concept and self-actualization. Nashville, TN: Counselor Recordings and Tests. 2001

11. Pikler V, Winterowd $C$. Racial and body image differences in coping for women diagnosed with breast cancer. Health Psych 2003;22: 632-637. 
12. Damen TH, Timman R, Kunst EH, et al. High satisfaction rates in women after DIEP flap breast reconstruction. J Plast Reconstr Aesthet Surg 2010;63: 93-100.

13. Markopoulos C, Tsaroucha AK, Kouskos E, et al. Impact of breast cancer surgery on the self-esteem and sexual life of female patients. J Int Med Res 2009;37:182-188.

14. Nano MT, Gill PG, Kollias J, et al. Qualitative assessment of breast reconstruction in a specialist breast unit. ANZ J Surg 2005;75: 445-453.

15. Noyan MA, Sertoz OO, Elbi H, et al. Variables affecting patient satisfaction in breast surgery: A crosssectional sample of Turkish women with breast cancer. Int J Psyc Med 2006;36: 299-313.

16. Rubino C, Figus A, Lorettu L, et al. Postmastectomy reconstruction: A comparative analysis on psychosocial and psychopathological outcomes. J Plast Reconstr Aest Surg 2007:60; 509-518.

17. Sabino Neto M, da Silva AL, Garcia EB, et al. Quality of life and self-esteem after breast asymmetry surgery. Aest Surg J 2007;27: 616-621.

18. Veiga DF, Veiga-Filho J, Ribeiro LM et al. Quality-of-life and self-esteem outcomes after oncoplastic breast-conserving surgery. Plast Rec Surg 2010;125, 811-817.

19. Tarlow EM, Haaga DAF. Negative self-concept: Specificity to depressive symptoms and relation to positive and negative affectivity. J Res Personal 1996; 30: 120-127.

20. Aspinwall LG, Taylor SE. Modeling cognitive adaptation: A longitudinal investigation of the impact of individual differences and coping on college adjustment and performance. J Pers Soc Psychol 1992; 63: 9891003

21. Brown JD, Dutton KA. The thrill of victory, the complexity of defeat: Self-esteem and people's emotional reactions to success and failure. J Pers Soc Psychol 1995;68: 712-722.

22. Schmitt DP, Allik J. Simultaneous administration of the Rosenberg Self-Esteem Scale in 53 nations: Exploring the universal and culture-specific features of global self-esteem. J Pers Soc Psychol, 2005;89: 623642
23. Damen $T H$, Mureau MA, Timman $R$, et al. The pleasing end result after DIEP flap breast reconstruction: a review of additional operations. J Plast Reconstr Aesthet Surg 2009;62:71-76.

24. Visser NJ, Damen TH, Timman R, et al. Surgical results, aesthetic outcome, and patient satisfaction after microsurgical autologous breast reconstruction following failed implant reconstruction. Plast Reconstr Surg 2010;126: 26-36

25. Andrade WN, Baxter N, Semple JL. Clinical determinants of patient satisfaction with breast reconstruction. Plast Reconstr Surg 2001;107: 360-366.

26. Guyomard V, Leinster S, Wilkinson M, et al. A Franco-British patients' and partners' satisfaction audit of breast reconstruction. J Plast Reconstr Aesthet Surg 2009;62:782-789.

27. Bard M, Sutherland AM. Psychological impact of cancer and its treatment. IV. Adaptation to radical mastectomy. Cancer 1955;8:656-672. 
In this thesis innovations in technique and perioperative measures in DIEP flap breast reconstruction (BR) were evaluated. These innovations affect operative outcomes in terms of postoperative complications, cosmetic result and patient satisfaction. In this chapter the findings regarding the objectives as outlined in the general introduction are presented. Also, a review of the latest literature on the specific topics is provided.

\section{RESEARCH QUESTION 1}

Does the incorporation of two venous anastomoses in DIEP flap BR reduce the rate of venous congestion and increase the rate of flap survival?

Anatomic studies showed that drainage of the anterior abdominal wall is preferential through the superficial venous system. ${ }^{1}$ DIEP or TRAM flap harvest interrupts the superficial venous system, and venous outflow is directed from superficial to deep through the venae comitantes of the DIEA perforators. Retrograde flow from the superficial to deep venous system occurs through communicating veins linking the two systems. In some patients, these veins are absent and there exists a continued dependence on the superficial venous system for adequate flap drainage. Such persistent superficial venous system dominance will lead to venous congestion and subsequent total flap failure if not managed adequately. In these cases, augmentation of venous outflow is required by means of a SIEV anastomosed to either a second mammary vein, the cephalic vein, the thoracodorsal vein, or the lateral thoracic vein.

We present our experience with 564 consecutive DIEP flaps. We investigated whether venous augmentation would reduce the overall risk of venous congestion and increase flap survival. We observed a significant reduction of venous congestion in the patients with a second venous outflow route, with the incidence being reduced to zero. However, this had no effect on the rate of flap survival. Other complications were statistically similar between the groups, including complete flap failures (due to either arterial or venous thrombosis), partial flap losses, arterial or venous complications, and overall take-backs. A recent article retrospectively assessed the efficacy of venous augmentation of DIEP flaps in 32 patients, compared to a control group of 47 patients who received a conventional DIEP flap BR. ${ }^{2}$ Complications included partial as well as total flap failure. In the augmented DIEP flap group, total complication rate was significantly lower (3.1\%) than in the conventional DIEP flap group $(10.6 \%, p<0.05)$. However, no significant difference was found in the incidence of total flap necrosis. Another study reported surgical outcomes of 352 DIEP flaps of which 311 (88.4 percent) were augmented by a double venous system anastomosis. ${ }^{3}$ There were no flap failures in either group. In the double venous system group, there was a significantly lower return to the operating room for venous congestion $(0.3 \%)$ compared to the single venous system group $(4.9 \%, p<0.05)$. The authors concluded that a double venous system anastomosis significantly reduces operative take-backs. In contrast to these studies we found no significant effect on any postoperative complication except a reduction in postoperative venous congestion. In our study the main criteria to implement venous augmentation were franc signs of intraoperative venous congestion as well as surgeon's preference based on the caliber of the deep and superficial inferior epigastric veins. This resulted in 291 out of 564 (51.6\%) DIEP flaps being augmented. The criteria to implement venous augmentation applied in other studies were relatively subjective, and therefore prone to inter-observer variability. The criteria used in our study may have been too liberal compared to the previously mentioned studies, meaning that flaps underwent venous augmentation while they were not really at risk for congestion. Therefore differences in postoperative complications between the augmented and the conventional DIEP group may not have become apparent. This may explain the discrepancy in results compared to the two studies discussed above. In another study only 11 cases out of 1201 (0.9\%) DIEP and TRAM flaps showed intra-operative signs of venous congestion and needed venous augmentation. ${ }^{4}$ This discrepancy may be because of the high number of TRAM flaps in this study, as it is known that TRAM flaps are less vulnerable to venous congestion. ${ }^{5}$ So far no studies have been able to show a significant reduction in total flap loss in augmented DIEP flaps compared to conventional DIEP flaps. This is probably because flaps that are at risk of postoperative failure due to venous congestion, already show evident signs of venous congestion intra-operatively and subsequently are likely to undergo venous augmentation by one way or another. Intraoperative flap compromise due to persistent superficial venous system dominance should be identified if there are signs of venous congestion, despite a patent venous anastomosis. In such cases, successful connection of the SIEV as a second venous outflow allows for the reestablishment of adequate drainage. In a pilot study, measurement of pressure in the SIEV was described as a potential predictor for venous congestion. ${ }^{6}$ Within the limited population studied, their results had no clinical implication. The usefulness of intra-operative SIEV pressure monitoring has not been evaluated in larger studies.

Recently, a useful algorithm has been described in managing intra-operative venous congestion. In the presence of frank venous congestion, the authors suggested to incorporate a second DIE concomitant vein. If no improvement occurs, the next step would be to open the ipsilateral SIEV and await the resolution of signs of venous congestion. In case of persistent signs of venous congestion alternative measures include 
additional inclusion of a contralateral DIEV system, inclusion of a lateral row vein, or eventually reduction of flap size by excision of congested areas.

\section{RESEARCH QUESTION 2}

Can one surgical team perform two unilateral DIEP flap BR's in two patients in a single working day without compromising safety and postoperative outcomes?

The meticulous dissection in DIEP flap BR requires lengthy operative times. As a consequence one plastic surgical team can generally perform no more than one DIEP flap BR in the working hours of one day. As the number of mastectomies performed in one day far exceed the number of DIEP flap BR's, the discrepancy leads to an increase in the waiting list of women opting for autologous BR.

We set out to investigate the feasibility of one surgical team performing two DIEP flap BR's in two patients in a single working day. We performed a retrospective study in 101 consecutive patients undergoing delayed unilateral DIEP flap BR. Forty-three patients were treated as full-day cases, and 58 cases were performed with two DIEP flaps booked in on a single day's operating list. Complications, outcomes and techniques used were critically analyzed. Complications did not increase when two DIEP flaps were performed in a single working day.

Preoperative CT angiography contributed to a significant reduction of operative time in our study. The value of CT-angiography has been established in the preoperative work-up of DIEP flap BR. A recent systematic review showed that imaging results in a significant decrease in partial and total flap necrosis rates as well as in a significant reduction of operation duration. ${ }^{8}$ Preoperative CTA in DIEP flap BR has improved the ability of surgeons to devise an optimal strategy before going to the operating theatre and has shown to be beneficial for postoperative outcomes. The main drawbacks of CTA are exposure to ionizing radiation and iodinated contrast medium, which may cause an acute allergic reaction. The incidence of an acute allergic reaction to odine is about $3 \%$. The incidence rate of a reaction to gadolinium, used as a contrast medium in Magnetic Resonance Angiography (MRA), is $0.07 \% .{ }^{9}$ Magnetic resonance angiography has been proposed as an alternative to CTA. MRA is free from ionizing radiation, and the risk of an allergic reaction to gadolinium is fa less $(0.07 \%)$ than lodine contrast. ${ }^{9 ; 10}$ Several studies evaluated the use of MRA in preoperative abdominal wall flap planning and concluded that MRA was less accurate in the evaluation of smaller perforators. ${ }^{11 ; 12}$
However, MRA technique and technology is continuously evolving. A recent study compared 64-slice CTA to 1.5-T MRA in visualization of perforators of the abdomen prior to DIEP flap BR. ${ }^{13}$ The authors concluded that MRA alike CTA is capable of providing accurate visualization of the perforators of the abdomen and should be considered as an alternative to CTA. They mentioned several differences in accuracy between CTA and MRA. While these differences appeared limited, the difference in accuracy between MRA and CTA was not statistically analyzed for any significance. It is likely however, that future improvements in MRA will make it a suitable alternative for CTA in preoperative mapping of DIEA perforators. More studies are required to evaluate the accuracy of MRA as a single preoperative investigation in DIEP flap planning. Based on current evidence, the routine use of CTA prior to DIEP flap BR is recommended.

In our study the use of vascular coupling devices resulted in a statistically significant reduction in anastomotic times. The use of microvascular coupler devices has been explored in free flap head and neck reconstruction as well as lower extremity reconstruction and breast reconstruction, with satisfactory results. ${ }^{14-16}$ Another study described the use of venous coupling devices in 1,000 cases of free flap reconstruction resulting in a significant reduction in anastomotic times. ${ }^{17}$ No other studies were found exploring the feasibility of performing two DIEP flaps a day.

While our study showed that performing two DIEP flaps by one surgical team during the working hours of one day is achievable, we did not analyse the extra effort that is required from the entire surgical team. It is imaginable that performing one additional DIEP flap per day puts a strain on the surgeon and the entire surgical team. Especially if a certain case turns out to be more complicated and takes more time than initially expected, fatigue, stress and the need to rush to meet the strict time schedule are all factors that could have a negative impact on the process of decision making and postoperative outcomes. The number of cases included in this study was limited; as such subtle differences in outcome may not have become apparent. Performing two DIEP flaps a day could be beneficial on a population level by increasing total volume and thereby reducing waiting lists. However, larger prospective studies are required to determine the clinical feasibility and also to determine the financial costs of reserving two operative theatres for the purpose of DIEP flap BR's. Also future studies should include a broader analysis of peri-operative factors that could influence operative outcomes, including psychological and physical factors such as stress and fatigue that concern the surgeon and the surgical team. 


\section{RESEARCH QUESTION 3}

Can DIEP flap BR be performed with a comparable degree of safety and comparable outcomes in both university and community hospital settings?

Only a few years ago, complicated free tissue transfers like a DIEP flap BR were not likely to be performed in community hospitals and patients were often referred to a university hospital. Nowadays, an increasing number of community hospitals in the Netherlands offer DIEP flap BR. This development has led to an increased capacity to help a vast number of women seeking autologous BR. We set out to evaluate and compare different outcome parameters and complications in the two hospital settings. We compared perioperative parameters, and postoperative complications in 77 unilateral DIEP flap BR's of which 49 were performed in a university hospital and 28 in two affiliated nearby community hospitals. There was no specific selection for patients to be operated in the university hospital based on previous medical history or complexity of the reconstruction. All patients were operated by the same two surgeons with extensive experience in microsurgery. The results in the community hospital were comparable in terms of safety and postoperative outcomes compared to BR performed in the university hospital setting. We found two significant differences in outcome parameters. Total operating time was longer in the university hospital than in the community hospitals. Factors that potentially contribute to a longer operative time in the university hospital are training of consultant plastic surgeons who are less experienced. Secondly, a higher number of wound dehiscence was found in the community hospitals compared with the university hospital. This is possibly attributable to more smoking in the community hospital setting.

Limitations of this study include its retrospective nature and a relatively small patient population. In future studies more cases should be included in larger trials and in more community hospitals. Also, documentation was done by different physicians involved in the follow-up of patients, so inter-observer variability cannot be ruled out. In addition, data about flap weight and ischemia time was often incomplete. Nevertheless, it appears that unilateral DIEP flap BR can be performed in a community hospital setting with the same degree of safety as in a university hospital setting.

Since its introduction in the Netherlands, the number of DIEP flap BR's performed in community hospitals has increased. This procedure is currently performed in 35 community hospitals and 8 academic centers in the Netherlands. This increases the availability of DIEP flap BR and consequently could reduce the time patients need to wait for their autologous BR. With increased microsurgical expertise and equipment becoming available in the community hospital, a shift may arise in which a broader array of microsurgical procedures can be performed in the community hospital. This offers potential to augment the volume of microsurgical procedures performed, while reducing the costs per procedure. A possibility that could be examined in the future.

\section{RESEARCH QUESTION 4}

Does acetylsalicylic acid reduce the risk of microvascular thrombosis in autologous BR, and or reduce the risk of flap failure?

Although advances in microsurgery have increased success rates of autologous BR, microvascular thrombosis still remains a major concern as a cause of flap failure. Free flap failure occurs in 1 to $9 \%$ of cases and is generally caused by microvascular thrombosis in the area of the vascular anastomosis or the distal flap microcirculation. ${ }^{18-22}$ While early diagnosis and revision of a thrombosed anastomosis have been shown to salvage free flaps, prevention of microvascular thrombosis remains of primary importance. ${ }^{23} \mathrm{At}$ present, no consensus exists as to the optimal postoperative anticoagulation regimen, if any, following microvascular free tissue transfer surgery. This study investigated the effect of acetylsalicylic acid on the incidence of microvascular complications in patients undergoing autologous BR. We retrospectively evaluated postoperative complications and flap failures in 592 BR's in two groups of patients: one group receiving acetylsalicylic acid perioperatively, while the other group did not. Both groups received Nadroparine according to standard thromboprophylaxis protocol. The combined inhibition of primary and secondary hemostasis by administration of acetylsalicylic acid and Nadroparine did not yield a lower rate of microvascular complications compared to monoprophylaxis by Nadroparine. Several studies have investigated the effects of acetylsalicylic acid on free flap survival. ${ }^{18 ; 20-22 ; 24-26}$ However, all these studies included different patient populations, applied different thromboprophylaxis regimens, and had various limitations in their study design.

Based on a recent literature review, Brinkman et al recommended the use of LMWH monotherapy as this seems to be as effective as acetylsalicylic acid, it has the additional advantage to prevent systemic thromboembolic events, and unlike acetylsalicylic acid does not increase the risk of gastrointestina bleeding. ${ }^{27}$ Results of the most recent study currently available suggest there is an increased risk of general complications and reoperations and no difference in free flap survival or bleeding complications when aspirin is used in free flap reconstructive surgery. ${ }^{28}$ We found a higher hematoma rate leading to reoperation in the acetylsalicylic acid group compared to the control group. Although this difference failed to reach statistical 
significance, this higher hematoma rate could be explained by the addition of acetylsalicylic acid causing a synergistic effect with LMWH. Given the known risks associated with the use of acetylsalicylic acid and the trend for an increased occurrence of hematoma formation in our study, we stopped to routinely administer it after autologous BR. In the absence of evidence in favor of the use of aspirin, and a trend towards more complications, we recommend not to use aspirin in free flap reconstructive surgery.

Our study has some limitations intrinsic to its retrospective design, which limit the level of evidence and mitigate the conclusions that can be drawn. We administered a low dose of acetylsalicylic acid $40 \mathrm{mg}$ per day, which is markedly lower than other studies and as such precludes adequate comparison. ${ }^{22 ; 24}$ Administration of acetylsalicylic acid was initiated late (at the first postoperative day), while aspirin requires one week for its full potential to take effect. Finally, we retrospectively compared two institutions with different regimens, which may have introduced some sort of bias.

Further research is clearly indicated to definitively evaluate the role of postoperative antithrombotic prophylaxis following microvascular free tissue transfer. As free flap failure is multifactorial, future studies should ideally have a randomized controlled design to provide the best level of evidence on the efficacy of different thromboprophylaxis regimens.

\section{RESEARCH QUESTION 5}

How can we identify patients at high risk for symptomatic pulmonary embolism(SPE) after autologous breast reconstruction (ABR)? This research question was subdivided into two other questions.

1- What are risk factors associated with SPE?

2- Can we weigh these risk factors and construct a prediction model that could predict the relative risk of patients at risk for SPE after ABR?

Symptomatic pulmonary embolism constitutes a significant risk following abdominal flap BR. Reported rates vary from 0 to 6 percent. ${ }^{29-38}$ The Davison-Caprini Risk-Assessment Model has been validated in a general plastic surgery population, with the main inclusion criteria being surgery under general anesthesia and postoperative hospital admission. ${ }^{39}$ Patients who received chemical thromboprophylaxis were excluded.
These criteria are too generic in nature, and therefore this risk-assessment model is unlikely to be suitable for accurate prediction of symptomatic pulmonary embolism after abdominal flap BR.

We assessed risk factors associated with SPE and constructed a prediction model to identify high-risk patients. We retrospectively evaluated the incidence of SPE in 430 consecutive patients and searched for significant predictors. SPE occurred in 17 cases (4.0\%). Two independent predictors for SPE were found, body mass index (BMI) higher than 25 , additionally higher than 28 , and the BRCA gene mutation. Operation duration and bilaterality of reconstructions were dependent on the BRCA mutation, and both indirect predictors for SPE. Optimization of sensitivity and specificity resulted in a prediction model.

Using the Nationwide Inpatient Sample (NIS) database in the United States, Masoomi et al. evaluated predictors for venous thromboembolism (VTE) in 35,883 patients who underwent ABR. ${ }^{40}$ Similar to our study, they used multivariate regression analyses by which they were able to identify the following risk factors; immediate reconstruction after mastectomy (adjusted odds ratio [AOR], 5.4), age over 65 years (AOR, 4.2), obesity (AOR, 3.7), history of chemotherapy (AOR, 3.5), and chronic lung disease (AOR, 2.5). In our study two independent predictors for SPE were found, body mass index and BRCA positive gene status. Operation duration and bilaterality of reconstructions were related to a BRCA positive status and both were indirect predictors for SPE. Because the population of Masoomi et al. far exceeded ours in terms of sample size, they had more statistical power to identify risk factors that remained statistically not significant in our study. Masoomi et al. found an overall VTE rate of $0.13 \%$. This is markedly lower than the rate of $4 \%$ SPE found in our study. They did find the highest rate of VTE $(0.26 \%)$ to occur in pedicled TRAM flaps. Our study population consisted of free TRAM and DIEP flap BRs. The cause for the very low VTE rate in their study is not clear, however the authors did point out several limitations to their study. The NIS database is a large administrative database, compiled from discharge abstract data and is limited to in-hospital data without outpatient follow-up data. Any VTE that occurs after discharge would not be captured in this database. As such, their VTE rate is likely to be an underestimation of the true VTE rate. In addition, they did not include asymptomatic VTE patients, which have been reported to be up to $16.7 \%$ in this patient population, and could very well lead to SPE. ${ }^{41}$ Also, no standardized DVT prophylaxis regimens were used, and the authors were unable to identify patients who received chemoprophylaxis, which is an important factor in VTE studies Obesity is a known risk factor for pulmonary embolism. ${ }^{42}$ We found a significantly higher BMI in the SPE group $\left(29.8 \mathrm{~kg} / \mathrm{m}^{2}\right)$ than in the non-SPE group $\left(26.8 \mathrm{~kg} / \mathrm{m}^{2}\right)$. Interesting, however, is the finding that the presence of BRCA mutations was independently correlated to a higher risk for SPE. Cancer cells are known to exert a procoagulant activity in their microenvironment which can extend systemically. ${ }^{43 ; 44}$ As yet we have 
not applied our prediction model in our own clinical practice and therefore cannot present any preliminary data. The data in this study is purely informational and the presented model needs further clinical validation. Future research, with the inclusion of more patients with pulmonary embolism can refine this screener, and can increase the sensitivity and specificity of this instrument. In addition, the role of BRCA gene mutations in systemic coagulopathy is an interesting topic for future investigation.

\section{RESEARCH QUESTION 6}

Is autologous BR by means of the DIEP flap a suitable method for reconstruction of significant partia mastectomy defects?

Breast conservation surgery (BCS) is widely the treatment of choice for early stage breast cancer. Although BCS can preserve an adequate amount of breast tissue to avoid the use of reconstructive techniques, unacceptable disfigurement remains a problem in up to $30 \%$ of patients, many of whom will opt for reconstruction of their partial mastectomy defect (PMD). ${ }^{45 ; 46}$ We evaluated a cohort of 18 patients with significant defects persisting after partial mastectomy, who underwent ABR by means of the DIEP flap. Unsatisfactory results after BCS may occur when the tumor size is large relative to the breast size. ABR after BCS has several advantages compared to reconstruction with implants. Where tissue expansion is needed, the use of expansion can be associated with pain for the patient, and where irradiation has been performed tissue expansion can be problematic and associated with increased pain and inadequate expansion. Implantrelated complications are also of concern, with the risk of infection, capsular contracture, and implant extrusion markedly increased in the presence of irradiated tissue. ${ }^{47 ; 48}$ Given these problems, autologous tissue reconstruction has been described as a preferred option. ${ }^{48 ; 49}$

Reconstructive options after partial mastectomy can be divided into displacement techniques and replacement techniques. Displacement techniques include incorporating a reduction mammaplasty-type procedure during tumor resection, with a similar mammaplasty technique performed on the contralateral breast to match the size and shape of the tumor-affected breast. This approach is particularly useful for a relatively large or ptotic native breast.

Replacement techniques are more useful in case of a large tumor/breast ratio. Depending on the location and the size of the breast defect, different flaps can be used for partial mastectomy reconstruction, including local fasciocutaneous flaps, pedicled flaps and free flaps. ${ }^{50}$ The latissimus dorsi musculocutaneous (LDMC) flap has been widely used to replace tissue defects after BCS, due to its rich vascularity and ease of dissection. ${ }^{51 ; 52}$ However, the LDMC flap has several disadvantages, such as long, conspicuous scars on the back and a high frequency of postoperative seroma formation. ${ }^{53 ; 54}$ The successful use of the free medial circumflex femoral artery perforator flap has been described in the immediate reconstruction of defects after BCS. Given its reliable vascularity and minimal donor-site morbidity, this flap was found to provide a good alternative for the latissimus dorsi flap in partial BR after breast-conserving surgery. ${ }^{55}$

The successful use of DIEP as well as ms-TRAM flaps for reconstruction of defects after BCS has been described, with results similar to our own. ${ }^{56}$ The ultimate choice of flap depends on the size and location of the defect, the patients' wishes and the expertise and experience of the surgeon.

It should be kept in mind that the use of a DIEP flap is a technically more challenging procedure compared to the LDMC flap. The patient is exposed to a longer operative procedure, with potentially a higher risk for postoperative complications. An important consideration is the argument to preserve the abdominal donor site for the case of future need for postmastectomy reconstruction. The LDMC flap is currently the mainstay for correction of partial mastectomy defects, ${ }^{5758}$ while the DIEP flap is the gold standard for postmastectomy breast reconstruction. Reconstruction of partial mastectomy defects by means of a DIEP flap BR would mean that in case of future recurrence and subsequent need of mastectomy the preferred option for postmastectomy reconstruction has already been sacrificed. As such, DIEP flap BR for partial mastectomy defects may seem inappropriate. However, recurrence rates in patients having undergone BCS after breast cancer are low overall, with only 5-8\% requiring salvage mastectomy. ${ }^{47559}$ In these few cases, other satisfactory reconstructive options (both prosthetic and autologous) still remain and thus preservation of this tissue in up to $95 \%$ of cases where it can be effectively used may not be warranted. Case selection is thus highly important in employing this reconstructive option, with clear margins, lack of regional spread, and time to reconstruction all important selection considerations. With no detriment to oncologic outcomes identified in the current series, it is pertinent that postreconstruction oncologic follow-up is essential, with timely administration of adjuvant therapies, ongoing clinical examination and mammography, and consideration of advanced imaging technologies all important. 


\section{RESEARCH QUESTION 7}

How many reoperative procedures are generally required after DIEP flap BR to improve aesthetic results or to correct complications?

Breast reconstruction often requires multiple operations. In addition to potential complications requiring reoperation, additional procedures are frequently essential in order to complete the reconstructive process, with aesthetic outcome and breast symmetry shown to be the most important factors in patient satisfaction. Information regarding the need for additional procedures after DIEP flap surgery is particularly valuable to patients during the preoperative consent process and should play an important role in decision making. In addition, detailed preoperative education will help patients to have realistic expectations.

A review of 370 consecutive ABR's (326 patients) was undertaken. The need for additional procedures for either complications or aesthetic refinement following initial breast reconstruction was assessed. In contrast to previous reports, there was no statistical difference in secondary procedures based on patient age. ${ }^{60-62}$ Previous studies described the appearance of the nipple areola complex (NAC), symmetry of the breasts, and scar appearance on the reconstructed breast as the main factors influencing patient satisfaction. ${ }^{60 ; 63}$ In our series, nipple reconstruction was the most frequently requested procedure (44.8\%), followed by NAC tattooing (37\%), liposuction (36.5\%), and scar revision (25.5\%). Our rate of nipple reconstruction was substantially lower than that of previous reports. ${ }^{60 ; 62}$ While the cause of this is unclear time allocation, a relatively high rate of nipple-sparing mastectomies, and unknown factors relating to our cohort are all possibilities. Overall, there was an average of 1.06 additional interventions for every patient carried out after primary reconstructive surgery. A previous study reported the number of secondary procedures to be higher for autologous tissue transplants than for implants, with TRAM flaps requiring an average of 4.1 additional procedures for unilateral and 6.2 procedures for bilateral breast reconstructions. ${ }^{64}$ These figures far exceeded our own. In our series we found a correlation between bilateral breast reconstruction and a reduction in the number of interventions for aesthetic refinement. This was largely due to the ability to modify the symmetry and shape of both breasts intraoperatively at the primary operation. As such, patients in consultation for breast reconstruction should be advised of the frequent need for secondary operations following primary reconstructive surgery. At least one additional procedure can be expected, with multiple reoperations not uncommon.

\section{RESEARCH QUESTION 8}

What is the impact of DIEP flap BR on a patients' self-esteem and what correlation exists between patient satisfaction and self-esteem?

The objective of study was to assess the impact of DIEP flap BR on self-esteem and to analyze the correlation between aesthetic outcome and self-esteem. We measured self-esteem after BR, using the Rosenberg Self Esteem Scale (RSES) comparing the outcome to previously defined self-esteem levels in the general Dutch female population. Self-esteem levels after DIEP flap BR proved comparable to previously defined selfesteem levels in the general Dutch female population. However, we did not include preoperative baseline data and neither did we include a control group in this observational questionnaire study. Comparing postoperative levels of self-esteem to previously defined self-esteem levels in a larger population allowed observation of a general trend, but did not allow us to draw conclusions about a causal relationship between DIEP flap BR and a high self-esteem. We found self-esteem to be significantly correlated to the degree of satisfaction with reconstructive outcome. The timing of reconstruction was found to be of significant influence to short-term patient satisfaction.

We found the majority of women (80\%) to be content with their decision to undergo this procedure and approximately $90 \%$ would recommend it to a close friend or family member. In assessing patient satisfaction, we found an overall score of 6.6 on a scale of 1-10. This score is relatively low compared to scores of $8.4^{65}$ and $7.8^{66}$ obtained in other studies. In contrast to our patient population, the two studies mentioned had a population consisting of patients with mostly secondary ${ }^{60}$ and tertiary ${ }^{66}$ reconstructions. Notably, we observed a significantly lower satisfaction score in patients with no previous mastectomy (6.3) compared with patients with previous mastectomy (7.5). Patients with no previous mastectomy composed the majority of our population (80.3\%), which explains the overall satisfaction score of 6.6. In accordance with a previous report ${ }^{67}$ we found patients with prophylactic mastectomy $(\mathrm{N}=7)$ to be less satisfied with the aesthetic result, with an overall satisfaction score of 6.6

Not surprisingly, measures of the RSES were found to be significantly correlated to patients' satisfaction. The findings of the current study underline the psychological benefit of DIEP flap BR. A recent study utilized functional magnetic resonance imaging (fMRI) to evaluate "sense of self" following DIEP flap BR. ${ }^{68}$ In patients with a unilateral mastectomy and DIEP flap BR, they found similar activation patterns in brain regions associated with self-recognition during palpation of the reconstructed and or the natural breasts. When palpating the 'not' reconstructed chest wall after mastectomy, these regions were not activated in the 
same way. They concluded that the cognitive process represented by this pattern may be a mechanism by which BR improves self-perception, and thus patient satisfaction following mastectomy.

The results of the current studies confirm and expand the findings of previous studies, that is, breast reconstruction improves a patient's psychological wellbeing. The relationship between reconstructive outcome, self-esteem, and psychological wellbeing is multidimensional with many individual and also environmental variables influencing the sense of psychological wellbeing and satisfaction with the reconstructive result. As such it provides an interesting topic for further investigation .

\section{FUTURE PERSPECTIVES}

With this thesis we aim to contribute to the continuous evolution of DIEP flap breast reconstructive surgery. Some questions could not be answered in part because of the retrospective nature of the studies, with the limitations intrinsic to this design. Some new questions emerged after analyzing the results. However, many of our studies could serve as pilot studies for future prospective trials. In the following chapter the areas and topics that have potential for future research are discussed. Future studies should be prospective in nature and ideally have a randomized controlled design (RCT), whenever feasible, to be able to provide the best level of evidence.

\section{Acetylsalicylic acid in autologous breast reconstruction}

Several experimental and clinical studies investigated the effect of acetylsalicylic acid in prevention of thrombosis after arterial intimal injury. However, currently no consensus has been established on treatment guidelines. We analyzed the value of acetylsalicylic acid in preventing microvascular thrombosis and its complications in a homogeneous patient group undergoing DIEP and free TRAM flap BR. However in ou study, we administered a relatively low dose of acetylsalicylic acid (40mg per day) and we initiated administration one day postoperatively, which may be too late for acetylsalicylic acid to achieve its full protective potential. Therefore, future studies should include a large population, starting administration at least 1 week preoperatively and preferably in a randomized controlled setting. Based on current evidence, however, we recommend not to use acetylsalicylic acid after free flap reconstructive surgery.

\section{Risk assessment model for symptomatic pulmonary embolism}

We undertook a first effort to construct a Risk Assessment Model that predicts the risk of symptomatic pulmonary embolism after DIEP flap breast reconstruction. As yet, we have not applied this prediction model in our own clinical practice and therefore cannot present any preliminary data. The presented model needs further clinical validation.

Although the total sample included a reasonable number of participants, the statistical power was reduced by a limited number of patients with pulmonary embolism. Future research, with the inclusion of more patients with pulmonary embolism, can refine our presented screening tool and can increase the sensitivity and specificity of this instrument. This strategy of preoperative risk assessment can be applied to other aspects of reconstructive surgery, for example by doing multivariate analysis for general postoperative complications such as hematoma, microvascular thrombosis and wound infection, hereby including factors such as age, BMI, hypertension, use of anticoagulants, use of prednisone etc.

\section{$B M I$ and $B R C A$}

Obesity is a known risk factor for pulmonary embolism. Several theories have emerged explaining the link between obesity and the increased risk of pulmonary embolism, including induced blood clotting by leptin, a hormone released by fat cells, a rise in estrogen and progesterone levels, and progressive atherosclerosis. We found a significantly higher body mass index in the symptomatic pulmonary embolism group $29.8 \mathrm{~kg} / \mathrm{m}^{2}$ ) than in the non-symptomatic pulmonary embolism group $\left(26.7 \mathrm{~kg} / \mathrm{m}^{2}\right)$. In contrast, not a single case of symptomatic pulmonary embolism occurred after abdominal flap breast reconstruction in a recent series of 25 women with a body mass index greater than $40 \mathrm{~kg} / \mathrm{m}^{2}$. 99 The correlation of body mass index with symptomatic pulmonary embolism, but also with other postoperative complications is an interesting topic for future research. We found that BRCA gene mutations were independently correlated to a higher risk for symptomatic pulmonary embolism. Cancer cells are known to exert a procoagulant activity in their microenvironment which can extend systemically. ${ }^{43}$ The role of BRCA gene mutations in systemic coagulopathy may also be an interesting topic for future investigation. 


\section{Reduced waiting list for autologous breast reconstruction}

By addressing inefficiencies at each step of the operation, operative time can be reduced significantly and one surgical team should be able to perform two unilateral DIEP flap procedures during the hours of one working day. Being able to do more DIEP flaps in a single working day would mean an increase in the volume of procedures performed in a setting with the microsurgical expertise and equipment already present. We recommend further research into the clinical relevance and cost-effectiveness of performing two DIEP flap breast reconstructions per day. In addition, with increased microsurgical expertise and equipment becoming available in the community hospital a shift may arise in which a broader array of microsurgical procedures can be performed in the community hospital. This offers potential to augment the volume of microsurgical procedures while reducing the costs per procedure. A possibility that should be examined in the future.

\section{OVERALL CONCLUSIONS}

Postmastectomy autologous breast reconstruction can significantly improve patients' quality of life.

Currently, the gold standard for autologous breast reconstruction is the DIEP flap. This thesis reviews a decade of improvements in technique and perioperative measures, and how these improvements affect postoperative outcomes. DIEP flap breast reconstruction is a safe and reliable procedure with good results and high patient satisfaction, with similar outcomes when performed in an academic hospital or in a community hospital. DIEP flap breast reconstruction is also a suitable method for reconstruction of significant partial mastectomy defects. Improvements in preoperative planning, such as better patient selection, accurate identification of patients at risk for complications using a Risk Assessment Model, and more thorough patient information can reduce postoperative complications, improve postoperative results and contribute to higher patient satisfaction. The application of CT-angiography in the preoperative planning stage contributes to better understanding of the individual anatomy of the perforators such as size, location intramuscular and subcutaneous course and thereby significantly affects operative technique and length of operation.

Perioperatively, improvements in surgical technique such as the application of secondary venous outflow routes can reduce the rate of venous congestion in selected patients. By addressing inefficiencies at each step of the operation and by applying technical adjuncts such as coupler devices total operative time can be reduced significantly, thereby potentially reducing risks of postoperative complications and also allowing two DIEP flap reconstructions to be performed in the working hours of one day. This increase in volume of breast reconstructions could eventually reduce the waiting list for patients opting for DIEP flap breast reconstruction.

In the postoperative phase, adequate regimens of anticoagulation and thromboprophylaxis may reduce the risks of microvascular thromboembolic complications as well as deep venous thrombosis and pulmonary embolism. We found no additional value in the preoperative administration of acetylsalicylic acid. After the initial reconstructive procedure an average of 1.06 additional interventions are needed to correct complications and to finish the reconstructive process. 


\section{REFERENCES}

1. Villafane O, Gahankari D, Webster M. Superficial inferior epigastric vein (SIEV) “lifeboat” for DIEP/TRAM flaps. Br J Plast Surg 1999;52:599.

2. Xin $\mathrm{Q}$, Luan J, $\mathrm{Mu} \mathrm{H}$, et al. Augmentation of venous drainage in deep inferior epigastric perforator flap breast reconstruction: efficacy and advancement. J Reconstr Microsurg 2012;28: 313-318.

3. Boutros SG.Double venous system drainage in deep inferior epigastric perforator flap breast reconstruction: a single-surgeon experience. Plast Reconstr Surg 2013;131: 671-676.

4. Sbitany H, Mirzabeigi MN, Kovach SJ. et al.Strategies for recognizing and managing intraoperative venous congestion in abdominally based autologous breast reconstruction Plast Reconstr Surg 2012;129: 809-815.

5. Man LX, Selber JC, Serletti JM. Abdominal wall following free TRAM or DIEP flap reconstruction: a metaanalysis and critical review. Plast Reconstr Surg 2009;124: 752-764.

6. Smit JM, Audolfsson T, Whitaker IS, et al. Measuring the pressure in the superficial inferior epigastric vein to monitor for venous congestion in deep inferior epigastric artery perforator breast reconstructions: a pilot study J Reconstr Microsurg 2010;26: 103-107.

7. Damen TH, Morritt AN, Zhong T. et al. Improving outcomes in microsurgical breast reconstruction: lessons learnt from 406 consecutive DIEP/TRAM flaps performed by a single surgeon J Plast Reconstr Aesthet Surs 2013;66: 1032-1038.

8. Teunis $\mathrm{T}$, van Voss MR, Kon M, et al. CT-angiography prior to diep flap breast reconstruction: a systematic review and meta-analysis. Microsurgery 2013;33: 496-502.

9. Katayama H, Yamaguchi K, Kozuka T, et al. Adverse reactions to ionic and nonionic contrast media. A report from the Japanese Committee on the Safety of Contrast. Med Radiol 1990;175: 621-628.

10. Dillman JR, Ellis JH, Cohan RH, et al. Frequency and severity of acute allergic-like reactions to gadoliniumcontaining i.v. contrast media in children and adults. AJR Am J Roentgenol 2007;189: 1533-1538.

11. Phillips TJ, Stella DL, Rozen WM, et al.Abdominal wall CT angiography: a detailed account of a newly established preoperative imaging technique. Radiology 2008;249: 32-44.
12. Rozen WM, Stella DL, Bowden J, et al. Advances in the pre-operative planning of deep inferior epigastric artery perforator flaps: magnetic resonance angiography. Microsurgery 2009;29: 119-123.

13. Cina A, Barone-Adesi L, Rinaldi P, et al. Planning deep inferior epigastric perforator flaps for breast reconstruction: a comparison between multidetector computed tomography and magnetic resonance angiography. Eur Radiol 2013;23: 2333-2343.

14. Zhang $\mathrm{T}$, Lubek J, Salama A, et al. Venous anastomoses using microvascular coupler in free flap head and neck reconstruction. J Oral Maxillofac Surg 2012;70: 992-996.

15. Ducic I, Brown BJ, Rao SS. Lower extremity free flap reconstruction outcomes using venous coupler. Microsurgery 2011;31: 360-364.

16. Jandali S, Wu LC, Vega SJ, et al. 1000 consecutive venous anastomoses using the microvascular anastomotic coupler in breast reconstruction. Plast Reconstr Surg 2010;125: 792-798.

17. Rozen WM, Whitaker IS, Acosta R. Venous coupler for free-flap anastomosis: outcomes of 1,000 cases. Anticancer Res 2010;30: 1293-1294.

18. Khouri RK, Cooley BC, Kunselman AR, et al. A prospective study of microvascular free-flap surgery and outcome. Plast Reconstr Surg 1998;102: 711-721,

19. Adams WP, Jr, Ansari MS, Hay MT, et al. Patency of different arterial and venous end-to-side microanastomosis techniques in a rat model. Plast Reconstr Surg 2000;105: 156-16.

20. Kroll SS, Schusterman MA, Reece GP, et al. Timing of pedicle thrombosis and flap loss after free-tissue transfer. Plast Reconstr Surg 1996;98: 1230-1233.

21. Lecoq JP, Senard M, Hartstein GM, et al. Thromboprophylaxis in microsurgery Acta Chir Belg. 2006;106: 158-164.

22. Ashjian $P$, Chen $C M$, Pusic $A$, et al. The effect of postoperative anticoagulation on microvascular thrombosis. Ann. Plast. Surg. 2007;59: 36-39.

23. Peter FW, Franken RJ, Wang WZ, et al. Effect of low dose aspirin on thrombus formation at arterial and venous microanastomoses and on the tissue microcirculation. Plast Reconstr Surg 1997;99: 1112-1121.

24. Chien $W$, Varvares MA, Hadlock $T$, et al. Effects of aspirin and low-dose heparin in head and neck reconstruction using microvascular free flaps. Laryngoscope 2005;115: 973-976. 
25. Conrad MH, Adams WP, Jr. Pharmacologic optimization of microsurgery in the new millennium. Plast Reconstr Surg 2001;108: 2088-2096

26. Stephan B, Schenk JF, Nemeh A, et al. The use of antithrombotic agents in microvascular surgery. Clin Hemorheol Microcirc 2009;43: 51-56.

27. Brinkman JN, Derks LH, Klimek M, et al. Perioperative fluid management and use of vasoactive and antithrombotic agents in free flap surgery: a literature review and clinical recommendations. J Reconstr Microsurg 2013;29: 357-366.

28. Lighthall JG, Cain R, Ghanem TA, et al. Effect of postoperative aspirin on outcomes in microvascular free tissue transfer surgery. Otolaryngol Head Neck Surg 2013;148: 40-46.

29. Hofer SO, Damen TH, Mureau MA, et al. A critical review of perioperative complications in 175 free deep inferior epigastric perforator flap breast reconstructions. Ann Plast Surg 2007;59: 137-142.

30. Spear SL, Ducic I, Cuoco F, et al. Effect of obesity on flap and donor-site complications in pedicled TRAM flap breast reconstruction. Plast Reconstr Surg 2007;119: 788-795.

31. Spear SL, Ducic I, Cuoco F, et al. The effect of smoking on flap and donor-site complications in pedicled TRAM breast reconstruction. Plast Reconstr Surg 2005;116: 1873-1880.

32. Mehrara BJ, Santoro TD, Arcilla E, et al. Complications after microvascular breast reconstruction: experience with 1195 flaps. Plast Reconstr Surg 2006;118: 1100-1109.

33. Olsson EH, Tukiainen E. Three-year evaluation of late breast reconstruction with a free transverse rectus abdominis musculocutaneous flap in a county hospital in Sweden: a retrospective study. Scand J Plas Reconstr Surg Hand Surg. 2005;39: 33-38.

34. Wang $\mathrm{HT}$, Hartzell $\mathrm{T}$, Olbrich $\mathrm{KC}$, et al. Delay of transverse rectus abdominis myocutaneous flap reconstruction improves flap reliability in the obese patient. Plast Reconstr Surg 2005;116: 613-618.

35. Gabbay JS, Eby JB, Kulber DA. The midabdominal TRAM flap for breast reconstruction in morbidly obese patients. Plast Reconstr Surg 2005;115: 764-770.

6. Hamdi M, Blondeel P, Van LK, et al. Bilateral autogenous breast reconstruction using perforator free flaps: a single center's experience. Plast Reconstr Surg 2004;114: 83-89.

37. Hartrampf CR, Scheflan M, Black PW. Breast reconstruction with a transverse abdominal island flap. Plast Reconstr Surg 1982;69: 216-225
38. Lemaine V, McCarthy C, Kaplan K, et al. Venous thromboembolism following microsurgical breast reconstruction: an objective analysis in 225 consecutive patients using low-molecular-weight heparin prophylaxis. Plast Reconstr Surg 2011;127: 1399-1406.

39. Pannucci CJ, Bailey SH, Dreszer G, et al. Validation of the Caprini risk assessment model in plastic and reconstructive surgery patients. J Am Coll Surg 2011;212: 105-112.

40. Masoomi H, Paydar KZ, Wirth GA, et al. Predictive risk factors of venous thromboembolism in autologous breast reconstruction surgery. Ann Plast Surg 2014;72: 30-33.

41. Kim EK, Eom JS, Ahn SH, et al. The efficacy of prophylactic low-molecular-weight heparin to prevent pulmonary thromboembolism in immediate breast reconstruction using the TRAM flap. Plast Reconstr Surg 2009;123: 9-12.

42. Kabrhel C, Varraso R, Goldhaber SZ, et al. Prospective study of BMI and the risk of pulmonary embolism in women Obesity. (Silver. Spring) 2009;17: 2040-2046.

43. Lip GY, Chin BS, Blann AD. Cancer and the prothrombotic state. Lancet Oncol. 2002;3: 27-34

44. Agnelli G, Bolis G, Capussotti L, et al. A clinical outcome-based prospective study on venous thromboembolism after cancer surgery: the @RISTOS project. Ann Surg 2006;243: 89-95.

45. Bajaj AK, Kon PS, Oberg KC, et al. Aesthetic outcomes in patients undergoing breast conservation therapy for the treatment of localized breast cancer. Plast Reconstr Surg 2004;114: 1442-1449.

46. Petit JY, Rietjens M, Garusi C, et al. Integration of plastic surgery in the course of breast-conserving surgery for cancer to improve cosmetic results and radicality of tumor excision. Recent Results Cancer Res 1998;152: 202-211.

47. Forman DL, Chiu J, Restifo RJ, et al. Breast reconstruction in previously irradiated patients using tissue expanders and implants: a potentially unfavorable result. Ann Plast Surg 1998; 40: 360-363.

48. Bostwick J, Paletta C, Hartrampf CR. Conservative treatment for breast cancer. Complications requiring reconstructive surgery. Ann Surg 1986;203: 481-490.

49. Hamdi M, Van LK, Monstrey S, et al. Pedicled perforator flaps in breast reconstruction: a new concept. $\mathrm{Br}$ J Plast Surg. 2004;57: 531-539.

50. Clough KB, Kroll SS, Audretsch W. An approach to the repair of partial mastectomy defects. Plast Reconst Surg 1999;104: 409-420 
51. Munhoz AM, Montag E, Fels KW, et al. Outcome analysis of breast-conservation surgery and immediate latissimus dorsi flap reconstruction in patients with T1 to T2 breast cancer. Plas Reconstr Surg 2005;116: 741 752.

52. Noguchi M, Taniya T, Miyazaki I, et al. Immediate transposition of a latissimus dorsi muscle for correcting a postquadrantectomy breast deformity in Japanese patients. Int Surg 1990;75: 166-170.

53. Randolph LC, Barone J, Angelats J, et al. Prediction of postoperative seroma after latissimus dorsi breast reconstruction. Plast. Reconstr. Surg. 2005;116: 1287-1290.

54. Tomita K, Yano K, Masuoka T, et al. Postoperative seroma formation in breast reconstruction with latissimus dorsi flaps: a retrospective study of 174 consecutive cases. Ann Plast Surg 2007;59: 149-151.

55. Izumi K, Fujikawa M, Tashima $\mathrm{H}$, et al. Immediate reconstruction using free medial circumflex femoral artery perforator flaps after breast-conserving surgery. J Plast Reconstr Aesthet Surg 2013;66: 1528-1533.

56. Andree C, Munder BI, Seidenstuecker K, et al. Skin-sparing mastectomy and immediate reconstruction with DIEP flap after breast-conserving therapy. Med Sci Monit 2012;18: 716-720.

57. Munhoz AM, Montag E, Fels KW, et al. Outcome analysis of breast-conservation surgery and immediate latissimus dorsi flap reconstruction in patients with T1 to T2 breast cancer. Plast Reconstr Surg 2005;116: 741-752

58. Noguchi M, Taniya T, Miyazaki I, et al. Immediate transposition of a latissimus dorsi muscle for correcting a postquadrantectomy breast deformity in Japanese patients. Int Surg 1990;75: 166-170.

59. Kroll SS, Evans GR, Reece GP, et al. Comparison of resource costs between implant-based and TRAM flap breast reconstruction. Plast Reconstr Surg 1996;97: 364-372.

60. Damen TH, Mureau MA, Timman R, et al. The pleasing end result after DIEP flap breast reconstruction: a review of additional operations. J Plast Reconstr Aesthet Surg 2009;62: 71-76.

61. Malyon AD, Husein M, Weiler-Mithoff EM. How many procedures to make a breast? Br J Plast Surg 2001;54: 227-231.

62. Schover LR, Yetman RJ, Tuason L, et al. Partial mastectomy and breast reconstruction. A comparison of their effects on psychosocial adjustment, body image, and sexuality. Cancer 1995;75: 54-64.

63. Andrade WN, Semple JL. Patient self-assessment of the cosmetic results of breast reconstruction Plast Reconstr Surg 2006;117: 44-47.
64. Losken A, Carlson GW, Schoemann MB, et al. Factors that influence the completion of breast reconstruction Ann Plast Surg 2004;52: 258-261.

65. Damen TH, Timman R, Kunst EH, et al. High satisfaction rates in women after DIEP flap breast reconstruction. J Plast Reconstr Aesthet Surg 2010;63: 93-100.

66. Visser NJ, Damen TH, Timman R, et al. Surgical results, aesthetic outcome, and patient satisfaction after microsurgical autologous breast reconstruction following failed implant reconstruction. Plast Reconstr Surg 2010;126: 26-36.

67. Gopie JP, Mureau MA, Seynaeve C, et al. Body image issues after bilateral prophylactic mastectomy with breast reconstruction in healthy women at risk for hereditary breast cancer. Fam Cancer 2013;12: 479-487.

68. Caterson SA, Fox SE, Tobias AM, et al. Functional MRI to evaluate "sense of self" following perforator flap breast reconstruction PLoS. One. 7: 2012;7(11)

69. Jandali S, Nelson JA, Sonnad SS, et al. Breast reconstruction with free tissue transfer from the abdomen in the morbidly obese. Plast Reconstr Surg 2011;127:2206-2213. 
Postmastectomy breast reconstruction can significantly improve patient satisfaction, self-esteem and quality of life. Currently, the methods of reconstructive surgery comprise flap reconstruction, implant reconstruction and a combination of these procedures. Autologous breast reconstruction often provides a more pleasing aesthetic outcome than other options for breast reconstruction, because breast volume and shape can be modified based on individual needs, the texture of the reconstructed breast is a closer match to the native breast, and complications such as capsular contracture are avoided. DIEP flap breast reconstruction evolved from TRAM flap breast reconstruction and has currently become the gold standard for autologous reconstruction. This thesis reviews the improvements and innovations in DIEP flap breast reconstruction during the past decade. The studies were all retrospective in nature and the population consisted of patients who had been operated between January 2000 and January 2011 in Uppsala, Sweden as well as in Maastrich and Rotterdam, The Netherlands.

\section{PART I. Optimization of technique and perioperative measures}

In chapter 2 we present our experience with 564 consecutive DIEP flaps. We investigated whether the inclusion of an additional venous drainage route would reduce the overall risk of venous congestion and increase flap survival. We observed a significant reduction of venous congestion to zero in the patients with a second venous outflow route. However, this had no effect on the rate of flap survival. This study demonstrated that a second venous anastomosis significantly improves venous drainage of a free flap, reducing the incidence of venous congestion. The study has also demonstrated that this can be readily achieved, without any demonstrable increase in operative times if planned effectively.

In chapter $\mathbf{3}$ we reviewed the outcome of one surgical team performing two unilateral DIEP flap breastreconstructions in two patients in a single working day. 101 consecutive patients were reviewed for postoperative outcomes and complications. 43 patients were treated as full-day cases, with no other free flap surgery booked in for the senior surgeon. The remaining 58 cases were performed with two DIEP flaps booked in on a single day's operating list. Complications, outcomes and techniques used were critically analysed. Complications did not increase when two DIEP flaps were performed in a single working day. Factors that contributed to a significant reduction in operating time included preoperative CT angiography, the use of vascular closure staple sutures and ring couplers, as well as the use of of two separate theatres for performing two DIEP flaps. The current study demonstrates that, in the adequate setting, two DIEP flaps can safely and routinely be performed within the hours of a single working day. By minimising the overall operative times, these techniques can improve productivity and substantially decrease surgeon fatigue.

In chapter 4 We compared perioperative parameters, and postoperative complications in 77 unilateral DIEP flap BR that were performed in a university hospital and two affiliated nearby community hospitals. All patients were operated on by the same two surgeons with extensive experience in microsurgery. Total operating time of a unilateral DIEP flap procedure was longer in the university hospital than in the community hospitals, explained by the fact that part of the operation was carried out by residents, less experienced in microsurgery. A higher number of wound dehiscence was found in the community hospitals compared with the university hospital. Although no significant differences were found in patient characteristics to which this finding can be attributed, there was a trend towards more smokers or previous smokers in the community hospital setting, which could be an explanation for the difference in complications related to wound healing. No significant difference was found in other postoperative complications or the need for reoperations. In conclusion, DIEP flap BR performed in the community hospital is comparable in terms of safety and postoperative outcomes compared to BR performed the university hospital setting.

In chapter $\mathbf{5}$ we investigated whether administration of Acetylsalicylic Acid reduces the risk of flap failure. We evaluated postoperative complications and flap failures in 592 breast reconstructions in two groups of patients, one group receiving Aspirin perioperatively, while the other group did not. Both groups received Nadroparine according to standard thromboprophylactic protocol. The combined inhibition of primary and secondary hemostasis by administration of acetylsalicylic acid and Nadroparine did not yield a lower rate of microvascular complications compared to monoprophylaxis by Nadroparine. Notably, we found a higher hematoma rate leading to reoperation in the LMWH and acetylsalicylic acid group (9.2\%) compared to the LMWH monotherapy group (4.7\%). Although this difference failed to reach statistical significance, this higher hematoma rate could be explained by the addition of acetylsalicylic acid causing a synergistic effect with IMWH. Given the known risks associated with the use of acetylsalicylic acid and the trend to lead to an increased occurrence of hematoma formation in the present study, we stopped to routinely administer it after autologous breast reconstruction

In chapter $\mathbf{6}$ we present our effort to construct a risk assessment model to identify patients at high risk for symptomatic pulmonary embolism (SPE) after autologous breast reconstruction (ABR).

We retrospectively evaluated the incidence of SPE in 430 consecutive patients and searched for significant predictors. SPE occurred in 17 cases (4.0\%). Two independent predictors for SPE were found, body mass 
index (BMI) higher than 25, additionally higher than 28 , and the BRCA gene mutation. Operation duration and bilaterality of reconstructions were dependent on the BRCA mutation, and both indirect predictors for SPE. Optimalization of sensitivity and specificity resulted in a prediction model. Obesity is a known risk factor for pulmonary embolism and we found a significantly higher BMI in the SPE group $\left(29.8 \mathrm{~kg} / \mathrm{m}^{2}\right)$ than in the non-SPE group $\left(26.8 \mathrm{~kg} / \mathrm{m}^{2}\right)$. Interesting however is the finding that the presence of BRCA mutations is independently correlated to a higher risk for SPE. Fisher's exact test showed a significantly higher risk for SPE in patients with a BRCA gene mutation ( $p=0.01)$, independent from operation duration. We developed a specific model to predict SPE after ABR and determined the optimal specificity and sensitivity at different cut-off scores. Patients at high risk should be explicitly warned about the risk of SPE after ABR. Future research, with the inclusion of more patients with pulmonary embolism can refine this screener, and can increase the sensitivity and specificity of this instrument.

\section{PART II. Optimization of surgical and aesthetic outcomes}

In chapter $\mathbf{7}$ we present a cohort of 18 patients with significant defects persisting after partial mastectomy who underwent DIEP flap breast reconstruction. In our series there were no cases of partial or total flap necrosis, and overall complications were low. There were two cases of wound infection, managed conservatively, and one case of reoperation due to hematoma. There were no cancer recurrences or effect on oncologic management. Cosmetic outcome was rated as high by both patients and surgeon. The results were thus comparable with other reconstructive options. Our results suggest that the DIEP flap may be of considerable value for delayed reconstruction of selected larger partial mastectomy defects.

In chapter 8 we assessed the need for additional procedures for either complications or aesthetic refinement following initial breast reconstruction in 370 consecutive autologous breast reconstructions (326 patients). Overall, there was an average of 1.06 additional interventions for every patient carried out after primary reconstructive surgery. Of 326 patients, 46 underwent early postoperative operations for surgical complications ( 0.17 additional operations per patient as a consequence of complications). Procedures for aesthetic refinement included those performed on the reconstructed breast, contralateral breast, or abdominal donor site. Procedures for aesthetic refinement included nipple reconstruction, nipple-areola complex (NAC) tattooing, dog-ear correction, liposuction, lipofilling, scar revision, mastopexy, and reduction mammaplasty. In our series, nipple reconstruction was the most frequently requested procedure (44.8\%), followed by NAC micropigmentation/tattooing (37\%), liposuction (36.5\%), and scar revision (25.5\%). Patients in consultation for breast reconstruction should be advised of the frequent need for secondary operations following primary reconstructive surgery. At least one additional procedure can be expected, with multiple reoperations not uncommon.

In chapter 9 we investigated the impact of DIEP flap breast reconstruction on a patients' self-esteem and also examined the correlation between patient satisfaction and self-esteem. Global self-esteem was evaluated using the Rosenberg Self-Esteem Scale (RSES) in 31 patients who underwent DIEP flap breast reconstructions. A study-specific questionnaire and photographic evaluation were used by the patient, the plastic surgeon, and the oncological surgeon to measure satisfaction with the aesthetic outcome. Patients' satisfaction and self-esteem were analyzed for any existing correlation. Overall patients' satisfaction had a mean score of 6.55 (range, $0-10$ ) on the Patient Satisfaction Questionnaire. We found the majority of women (80\%) to be content with their decision to undergo this procedure and approximately $90 \%$ would recommend it to a close friend or family member. Notably, we observed a significantly lower satisfaction score in patients with no previous mastectomy (6.32) compared with patients with previous mastectomy (7.50). Patients with no previous mastectomy composed the majority of our population $(80.3 \%)$, which explains the overall satisfaction score of 6.55. Not surprisingly, measures of the RSES were found to be significantly correlated to patients' satisfaction. The findings of the current study underline the psychological benefit of DIEP flap breast reconstruction. Self-esteem levels after DIEP flap breast reconstruction proved comparable to previously defined self-esteem levels in the general Dutch female population. Furthermore, we found self esteem to be significantly correlated to the degree of satisfaction with reconstructive outcome. The timing of reconstruction was found to be of significant influence to short-term patient satisfaction. The results of the current study confirm and expand the findings of previous studies, that is, breast reconstruction improves a patient's psychological wellbeing.

\section{CONCLUSION}

DIEP flap breast reconstruction is a safe and reliable procedure with good results and high patient satisfaction, with similar outcomes when performed in an academic hospital or in a community hospital. DIEP flap breast reconstruction is also a suitable method for reconstruction of significant partial mastectomy defects. Improvements in preoperative planning, such as better patient selection, accurate identification of patients at risk for complications using a Risk Assessment Model, and more thorough patient information can reduce postoperative complications, improve postoperative results and contribute to higher patient 
satisfaction. The application of CT-angiography in the preoperative planning stage contributes to better understanding of the individual anatomy of the perforators such as size, location, intramuscular and subcutaneous course and thereby significantly affects operative technique and length of operation.

Perioperatively, improvements in surgical technique such as the application of secondary venous outflow routes can reduce the rate of venous congestion in selected patients. By addressing inefficiencies at each step of the operation and by applying technical adjuncts such as coupler devices total operative time can be reduced significantly, thereby potentially reducing risks of postoperative complications. In the postoperative phase, adequate regimens of anticoagulation and thromboprophylaxis may reduce the risks of microvascular thromboembolic complications as well as deep venous thrombosis and pulmonary embolism. We found no additional value in the preoperative administration of acetylsalicylic acid. After the initial reconstructive procedure an average of 1.06 additional interventions are needed to correct complications and to finish the reconstructive process. Our studies were all retrospective in nature and therefore coped with limitation intrinsic to this design. Future studies should ideally have a randomized controlled design (RCT) to be able to provide the best level of evidence.

Recommendations for future research include a prospective randomized controlled study of the effect of Aspirin in preventing microvascular thrombosis in autologous breast reconstruction. Also we recommend refinement and the clinical validation of the risk assessment model we constructed to predict symptomatic pulmonary embolism after DIEP flap breast reconstruction. An interesting topic of research is the correlation between a BRCA positive status and the risk of symptomatic pulmonary embolism, or maybe even microvascular thrombo-embolic events. This thesis reviewed a decade of efforts to make improvements in all stages of the DIEP flap breast reconstruction procedure. This work can contribute to the continuous evolution and improvement of this procedure, with these improvements also applicable in other fields of reconstructive microsurgery. 

Een borstamputatie (mastectomie) is een noodzakelijke, doch mutilerende en traumatische ervaring. Een borstreconstructie na een mastectomie dient ertoe om de contouren van de geamputeerde borst te herstellen om dientengevolge het lichaamsbeeld en de kwaliteit van leven van de patiënte te verbeteren. Een reconstructie kan uitgevoerd worden middels het implanteren van prothese materiaal, het toepassen van lichaamseigen weefsel (autologe reconstructie) of een combinatie van de twee. Een autologe reconstructie heeft als voordeel dat het resultaat vaak beter overeenkomt met de natuurlijke borst en zodoende door de patiënt als vertrouwder en cosmetisch meer acceptabel wordt ervaren. Bovendien worden door het toepassen van lichaamseigen weefsel complicaties vermeden die inherent zijn aan het toepassen van prothesemateriaal, te noemen een kapselcontractuur of wondinfectie met betrokkenheid van het prothesemateriaal. Tegenwoordig wordt de DIEP (Deep Inferior Epigastric Perforator) lap beschouwd als de gouden standaard voor autologe borstreconstructies. De techniek is relatief nieuw en vloeit voort uit de TRAM (Transverse Rectus Abdominus Muscle) lap. Sinds zijn eerste toepassing heeft deze techniek een gestage evolutie doorgemaakt, waarbij het zich heeft bewezen als een betrouwbare methode met goede resultaten. In dit proefschrift worden perioperatieve innovaties en verbeteringen die de DIEP lap borst reconstructie in het laatste decennium heeft doorgemaakt beschreven en worden aanbevelingen gedaan voor toekomstige verbeteringen. De studies in dit proefschrift zijn retrospectief van aard en de patiëntenpopulatie betreft patiënten die tussen januari 2000 en januari 2011 geopereerd zijn in het Academisch Ziekenhuis Uppsala, Zweden, het Academisch Ziekenhuis Maastricht en het Erasmus Medisch Centrum te Rotterdam, Nederland.

\section{Deel I: Optimaliseren van techniek en perioperatieve benadering}

$\mathrm{Na}$ een borstreconstructie middels een DIEP lap kan veneuze stuwing optreden ten gevolge van inadequate veneuze afvloed. Dit kan leiden tot verminderde doorbloeding en weefselversterf met uiteindelijk het afsterven van de lap (lapfalen) tot gevolg.

In hoofdstuk 2 werd in 564 opeenvolgende DIEP lap borstreconstructies onderzocht of het 'uitbreiden' van de veneuze afvloed van de DIEP lap door incorporatie van een tweede vene in de vascularisatie zou leiden to een reductie van veneuze stuwing, met dientengevolge mogelijk een afname van het percentage lapfalen. Weliswaar werd een significante reductie van veneuze stuwing waargenomen, echter ging dit niet gepaard met een significante reductie in lapfalen.
In hoofdstuk $\mathbf{3}$ is gekeken naar de veiligheid en praktische haalbaarheid van het verrichten van twee DIEP lap borstreconstructies binnen de werkuren van één dag, beide operaties verricht door één chirurg. De postoperatieve resultaten van 101 patiënten werden geëvalueerd. 43 patiënten werden behandeld volgens het standaard protocol van één borstreconstructie per dag. 58 patiënten werden behandeld volgens het schema van twee opeenvolgende borstreconstructies op dezelfde dag. Complicaties verschilden niet tussen beide groepen. De operatieduur kon significant gereduceerd worden door het toepassen van CT-angiografie, het toepassen van vaatkoppelaars, alsmede het opereren in twee separate operatiekamers. Dit onderzoek heeft aangetoond dat door efficiënte implementatie de operatieduur aanzienlijk gereduceerd kan worden en dat het verrichten van twee DIEP lap borstreconstructies binnen de werkuren van één dag mogelijk is zonder concessies te doen aan veiligheid en resultaat.

In hoofdstuk 4 zijn perioperative parameters en postoperatieve complicaties vergeleken bij 77 unilaterale DIEP lap borstreconstructies die verricht waren in het Academisch Ziekenhuis Maastricht en twee geaffilieerde perifere ziekenhuizen in de omgeving, waarbij specifiek gekeken is naar eventuele verschillen in postoperatieve complicaties tussen de academische en perifere setting. Alle patiënten werden geopereerd door dezelfde twee chirurgen met aanzienlijke microchirurgische ervaring. Totale operatieduur van een unilaterale DIEP lap borstreconstructie was langer in het academisch ziekenhuis vergeleken met het perifere ziekenhuis. De verklaring hiervoor is dat in het academisch ziekenhuis de operaties mede door plastische chirurgen in opleiding werden verricht. In de perifere ziekenhuizen werd een hoger percentage wonddehiscenties waargenomen. Dit werd mogelijk veroorzaakt door een hoger percentage patiënten die roken. Er werden geen significante verschillen waargenomen in de overige complicaties of het totaal aantal reoperaties. Dit onderzoek concludeert dat het verrichten van een DIEP lap borstreconstructie in de academische of in de perifere setting vergelijkbare resultaten oplevert.

In hoofdstuk $\mathbf{5}$ is onderzocht of het toedienen van aspirine leidt tot een reductie in lapfalen. We evalueerden postoperatieve complicaties in 592 DIEP lap borstreconstructies in twee groepen patiënten. De ene groep ontving aspirine vanaf de eerste dag postoperatief, terwijl de andere groep geen aspirine kreeg. Beide groepen kregen Nadroparine toegediend volgens het standaard thromboprophylaxe protocol. De gecombineerde inhibitie van de primaire en secundaire hemostase door het toedienen van aspirine en Nadroparine resulteerde niet in een lager percentage van microvasculaire complicaties vergeleken met monoprophylaxe middels Nadroparine. In de groep met aspirine + Nadroparine werd een hoger percentage hematomen waargenomen waarvoor een reoperatie noodzakelijk was $(9.2 \%)$, in vergelijking met de

Nadroparine monotherapie groep (4.7\%). Dit verschil was echter niet significant. Gezien de mogelijke risico's 
die gepaard gaan met het toedienen van aspirine en de trend naar een hogere percentage hematomen hebben we besloten om aspirine niet meer toe te dienen na een autologe borstreconstructie.

In hoofdstuk $\mathbf{6}$ is een risico-predictie model beschreven. Dit model heeft als doel het voorspellen van het risico op symptomatische longembolieën (SLE) na een autologe borstreconstructie. De incidentie van SLE na een DIEP lap borstreconstructie werd geëvalueerd in 430 patiënten, waarbij middels multivariate analyse potentiële predictoren werden geïdentificeerd. SLE trad op bij 17 patiënten (4.0\%). Twee onafhankelijke predictoren voor SLE werden gevonden, zijnde body mass index (BMI) boven de $25 \mathrm{~kg} / \mathrm{m}^{2}$ en in sterkere mat boven de $28 \mathrm{~kg} / \mathrm{m}^{2}$, alsmede een BRCA positieve genmutatie. Operatieduur en een bilaterale reconstructie waren gerelateerd aan een BRCA positieve status en vormden indirecte predictoren voor SLE. Optimalisatie van sensitiviteit en specificiteit resulteerde in een predictiemodel. Obesitas is een bekend risicofactor voo SLE. We vonden dan ook een significant hogere BMI in de SLE groep $\left(29.8 \mathrm{~kg} / \mathrm{m}^{2}\right)$ dan in de groep waarin geen SLE voorkwam $\left(26.8 \mathrm{~kg} / \mathrm{m}^{2}\right)$. Een interessante bevinding is dat de aanwezigheid van BRCA gen mutaties onafhankelijk gecorreleerd was aan een hoger risico voor SLE. Deze correlatie bleek significant $(p=0.01)$ en onafhankelijk van de operatieduur. Dit model is vooralsnog niet klinisch gevalideerd. In de toekomst kan verder onderzoek, met inclusie van meer patienten met SLE de nauwkeurigheid van dit predictiemodel verbeteren.

\section{Optimalisatie van chirurgische en esthetische resultaten}

In hoofdstuk 7 presenteren we een cohort van 18 patiënten met significante contourdefecten na een borstsparende operatie. Gezien de grote omvang van de defecten bij een relatief kleine borstomvang, is besloten tot borstreconstructie middels een DIEP lap. De resultaten werden geanalyseerd met nadruk op cosmetisch resultaat, postoperatieve complicaties en oncologische recidieven. In deze serie waren geen gevallen van partiële of totale lapfalen. Overige complicaties waren beperkt. Één reoperatie was noodzakelijk ivm een hematoom. In geen van de patiënten was er sprake van een recidief maligniteit. Het cosmetisch resultaat werd door zowel de patiënt als door de chirurg als goed beoordeeld. De resultaten van deze studie geven aan dat de DIEP lap beschouwd mag worden als een goede optie voor de secundaire reconstructie van grotere contourdefecten die persisteren na een borstsparende operatie.

In hoofdstuk 8 hebben we, in een groep van 326 patiënten, gekeken naar alle aanvullende operaties die nodig zijn na de initiële borstreconstructie. De aanvullende operaties hadden als doel het corrigeren van postoperatieve complicaties en/of het verbeteren van het esthetisch resultaat ter completering van het reconstructieve proces. Gemiddeld waren per patiënt 1.06 aanvullende ingrepen vereist na de initiële reconstructie. Van de 326 patiënten ondergingen 46 patiënten aanvullende ingrepen in de vroege postoperatieve fase ter correctie van postoperatieve complicaties ( 0.17 aanvullende operaties per patient tgv complicaties). Procedures voor verbetering van het esthetisch resultaat werden verricht op de gereconstrueerde borst, de contralaterale borst en de abdominale donorsite. Deze procedures waren tepelreconstructie, tepeltatoeëring, dog-ear correctie, liposuctie, lipofilling, littekenrevisie, mastopexy en mammareductie. In onze serie was tepelreconstructie de meest toegepaste procedure (44.8\%), gevolgd door tepeltatoeëring (37\%), liposuctie (36.5\%) en littekenrevisie (25.5\%).

Patiënten dienen in het preoperatieve consult ingelicht te worden dat na de initiële reconstructie, ten minste één aanvullende ingreep noodzakelijk is ter completering van het reconstructieve proces, waarbij niet zelden meer aanvullende operaties nodig zijn ter correctie van postoperatieve complicaties.

In hoofdstuk 9 werd onderzocht wat het effect van een DIEP lap borstreconstructie is op het gevoel van zelfvertrouwen bij de patiënt. Tevens werd onderzocht of er een correlatie bestaat tussen zelfvertrouwen en patiënttevredenheid. De mate van zelfvertrouwen werd gekwantificeerd middels het Rosenberg Self-Esteem Scale (RSES) bij 31 patiënten. Het postoperatieve esthetische resultaat werd op basis van foto's beoordeeld door de patiënt, de plastische chirurg en de oncologische chirurg. Patiënttevredenheid en zelfvertrouwen werden onderzocht op een potentiële correlatie. De patiënttevredenheid had een gemiddelde score van 6.55 (range, 0-10). De meerderheid van de vrouwen (80\%) was tevreden met hun besluit om deze procedure te ondergaan. Patiënten met een primaire reconstructie waren over het algemeen minder tevreden met het resultaat (score 6.32) dan patiënten met een secundaire reconstructie (score 7.50). Aangezien vrouwen met een primaire reconstructie de meerderheid van de populatie betroffen (80.3\%), was de gemiddelde patiënttevredenheid relatief laag (6.55). Uitkomsten van de RSES bleken significant gecorreleerd te zijn aan de mate van patiënttevredenheid. De timing van de reconstructie bleek een belangrijke factor te zijn voor de patiënttevredenheid op de korte termijn. De bevindingen van deze studie onderstrepen het positieve effect van een DIEP lap borstreconstructie op het psychische welzijn van de patiënte na een borstamputatie en tonen tevens een correlatie tussen patiënttevredenheid en zelfvertrouwen. 
De DIEP lap borstreconstructie heeft zich bewezen als een betrouwbare en veilige procedure met goede resultaten en goede patiënttevredenheid. De ingreep kan zowel in een academisch ziekenhuis als in een perifeer ziekenhuis worden uitgevoerd zonder concessies te doen aan postoperatieve resultaten of de veiligheid. De methode zou ook kunnen dienen voor reconstructie van significante contourdefecten na een borstsparende operatie. Verbeteringen in de preoperatieve planning, te weten betere patiëntselectie, betere risico-inventarisatie en betere patiëntvoorlichting kunnen allemaal bijdragen aan betere postoperatieve resultaten en betere patiënttevredenheid. CT-angiografie in de preoperatieve fase kan bijdragen aan een beter begrip van de individuele vasculaire anatomie van de buikwand. Een goede voorbereiding maakt het mogelijk preoperatief een juiste benadering van de abdominale perforatoren te kiezen, waarmee de operatieduur aanzienlijk verkort kan worden. Het peroperatief toepassen van een secundaire veneuze afvloedroute kan in bepaalde patiënten bijdragen aan een afname van het risico op veneuze stuwing. Door inefficiënties in verschillende fases van de operatie zo veel mogelijk te elimineren kan de operatieduur aanzienlijk verkort worden, waarbij het risico op postoperatieve complicaties gereduceerd kan worden. In de postoperatieve fase kan een adequate antistollingsregime en tromboprofylaxe het risico op microvasculaire trombose, alsmede veneuze trombo-embolische complicaties en longembolieën reduceren. Echter is vooralsnog geen gunstig effect van ascal bewezen. Na de initiële reconstructie dient de patiënt gemiddeld nog één operatie te ondergaan ter behandeling van complicaties of ter afronding van het reconstructieve proces.

De studies in dit proefschrift waren retrospectief van aard. Toekomstige studies dienen idealiter een gerandomiseerde opzet te hebben om de bewijskracht te optimaliseren. Een onderwerp die in de toekomst uitgebreider onderzocht dient te worden is het effect van ascal in de preventie van microvasculaire trombosering. Tevens verdient het aanbeveling om het risico-predictiemodel zoals opgesteld in dit proefschrift nader te onderzoeken, waarbij het model in een grotere patiëntenpopulatie dient te worden toegepast ter validatie en 'finetuning'. Een ander interessant onderzoeksonderwerp is de correlatie tussen BRCA positieve genmutaties en het risico op veneuze tromboembolische of microvasculaire

tromboembolische complicaties. 


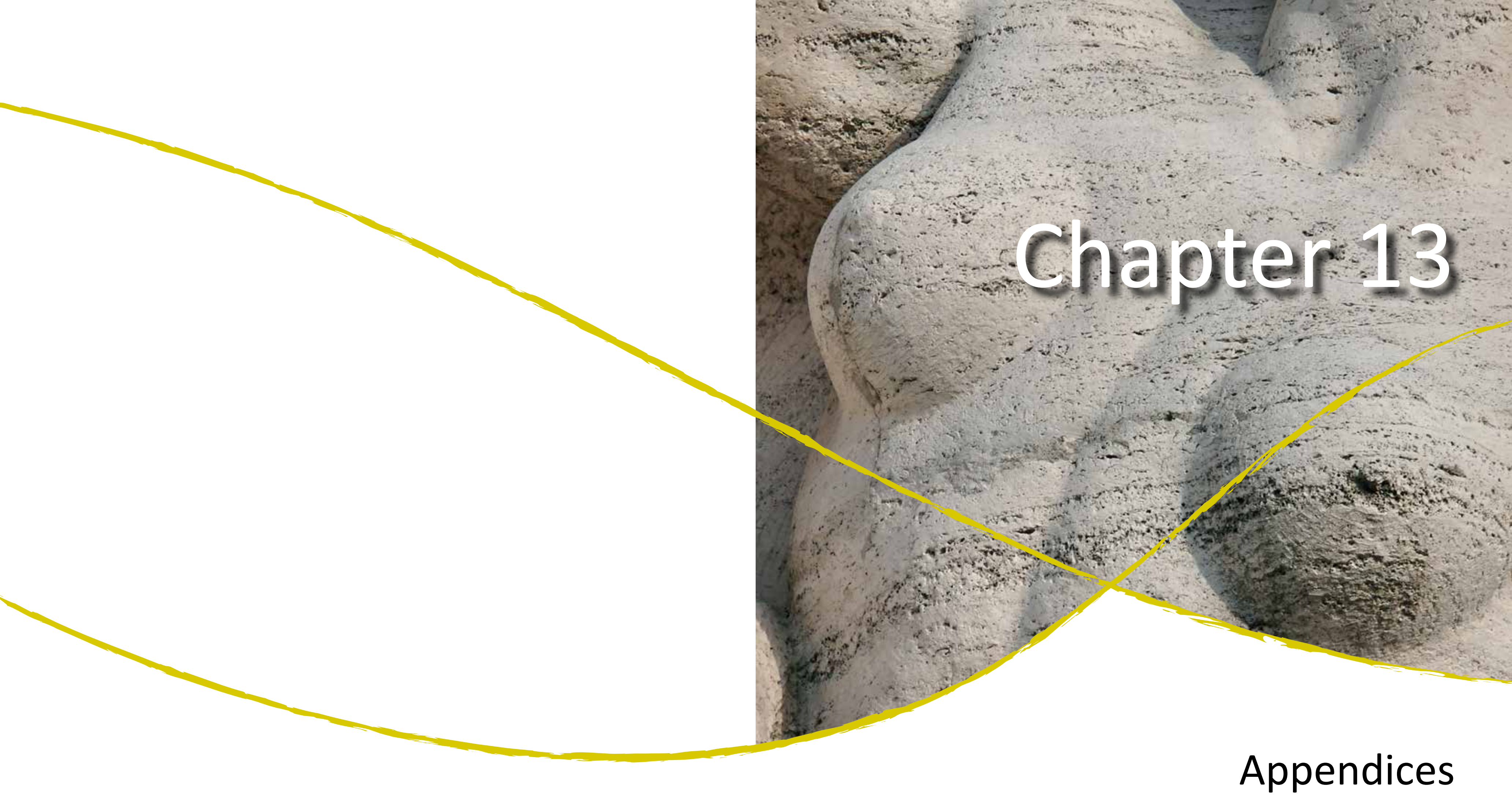

Acknowledgements List of publications 


\section{Acknowledgements}

Dit proefschrift draagt weliswaar mijn naam, maar zou niet tot stand zijn gekomen zonder de inbreng van velen. Mijn dank aan iedereen die direct of indirect een bijdrage heeft geleverd aan dit proefschrift.

Allereerst mijn dank aan alle patiënten die hun bereidheid hebben getoond deel te nemen aan de onderzoeken die dit proefschrift mogelijk hebben gemaakt.

Prof. R.R.W.J van der Hulst, promotor. Beste Rene, als enthousiaste, maar nog onwetende student kwam ik je kantoor binnengelopen met de mededeling dat ik onderzoek wilde doen via het MUMC. Je zag een mogelijkheid om mijn wetenschappelijke output te combineren in een promotietraject en dat vormde de basis voor dit proefschrift. Je hebt mij op belangrijke momenten in mijn carriere een stap vooruit geholpen zowel in de wetenschap als in de kliniek. Ik waardeer je oprechtheid. Bedankt voor je begeleiding en vertrouwen

Dr. M.A.M. Mureau, co-promotor. Beste Marc, ik ben altijd geïnspireerd geweest door je passie voor de plastische chirurgie, zowel de kliniek als de wetenschap, bewonderenswaardig! Je wetenschappelijke inzichten en je continue feedback hebben me een eind op weg geholpen. Je hebt mij geholpen het niveau van mijn wetenschappelijke werk te verbeteren. Dank voor je begeleiding en sturing. Zonder jouw input had dit boekje er niet gelegen

Geachte leden van de promotiecommissie, hartelijk dank voor jullie bereidheid om mijn proefschrift te beoordelen en zitting te nemen in de promotiecommissie.

Dr. J. Sawor. Beste John, in de korte tijd dat ik bij je heb gewerkt als ANIOS plastische chirurgie heb ik je leren kennen als een toegewijde en vaardige plastische chirurg met een warm hart voor het vak, maar ook een goed mens, oprecht begaan met het lot van je patiënten en collega's. Je was een zeer goede leermeester die mij de beginselen van het vak plastische chirurgie heeft geleerd, zowel de snijdende als de sociale kant. Dat ik zo ver ben gekomen heb ik direct aan jou te danken, waarvoor mijn dank! Ik kan alleen maar hopen dat ik ooit zo goed in mijn vak mag worden als jij dat bent.

Dr. Rafael Acosta, Your dedication to your work and to your patients is admirable. Your skills and experience in reconstructive surgery have always been an example to me. Thank you for your hospitality, and your commitment to training generations of young plastic surgeons.
Reinier Timman, bedankt voor je ondersteuning in de statistiek. Mede door jouw expertise is de juiste wetenschappelijke diepgang in dit proefschrift tot stand gekomen.

Jeroen Smit. Mede door jouw bemiddeling kwam ik terecht in Uppsala, waar ik een zeer vruchtbare onderzoekstijd heb gehad. Je hebt je ervaringen met me gedeeld en jouw eerste begeleiding en introductie in de wereld van de plastische chirurgie vormden een vruchtbare bodem om op voort te bouwen. Dank voor je hulp.

Warren Rozen. You've been a good research colleague in Uppsala. Your work ethics and your never ending enthousiasm have been a source of inspiration.

Hossein Ghaeminia, paranimf. Beste Hos, door de jaren heen hebben we samen veel meegemaakt, onze vriendschap is nog steeds puur en oprecht. Het was een eer om als getuige op je bruiloft aanwezig te mogen zijn. Je gedrevenheid en passie in het leven, voor alles wat je doet, zijn voor mij een inspiratiebron en een groot voorbeeld. Ook al ben je als kaakchirurg in wording bezig met een andere tak van sport, ik ben dankbaar en vereerd dat jij mijn paranimf wilt zijn.

Victor Boldewijn, paranimf. Beste Victor, het is een eer dat je mijn paranimf bent. Al kennen we elkaar nog niet zo lang, we hebben mooie momenten beleefd en ik kijk uit naar alle vrijgezellenfeesten die nog moeten komen.

Beste familie en vrienden, Jullie liefde en vriendschap is een bron van nodige ontspanning geweest tussen het data-crunchen door

Beste stafleden en collega's van de afdeling chirurgie van het Rode Kruis Ziekenhuis, Beverwijk. Ik denk nog regelmatig met plezier terug aan de goede sfeer tussen bazen en assistenten, de korte lijntjes en de onvergetelijke skiweekenden. Onze zandsculptuur van Conchita Wurst en het winnen van de chirurgencup 2014 vormden een prachtige afsluiting van mijn vooropleiding .... Een mooie tijd!

Vahid Samadi, my dear uncle, your unconditional support means a lot to me. Your advise has helped me through many times. I'm blessed with such caring family.

Grandmother, You are the source of love that binds the members of our family. You have lived a life, but we all hope you'll be around for a very long time to come. Thank you for your unconditional love and support. 
Lindsey van der Sluis, lieve Lindsey, met je warme karakter haal je het beste in mij naar boven en geef je mijn leven meer smaak. Ik ben gezegend met jouw liefde en kijk uit naar alle mooie momenten die we nog samen te beleven hebben.

\section{List of publications}

1-Effect of acetylsalicylic Acid on microvascular thrombosis in autologous breast reconstruction

Enajat M, Aziz Mohammadi M, Debeij J, van der Hulst RR, Mureau MA. J Reconstr Microsurg. 2014 Jan;30(1):65-70.

2- Pulmonary embolism after abdominal flap breast reconstruction: prediction and prevention.

Enajat M, Damen TH, Geenen A, Timman R, van der Hulst RR, Mureau MA. Plast Reconstr Surg. 2013 Jun;131(6):1213-22.

3- Autologous dermal grafts for rectus sheath reconstruction and application in closure of ventral myofascial defects.

Rozen WM, Kapila S, Enajat M, Tan MJ, Whitaker IS, Acosta R. Updates Surg. 2012 Sep;64(3):203-10.

4- The unilateral deep inferior epigastric perforator flap: comparing university to community hospital.

de Wildt RP, Enajat M, Sawor JH, Fresow RN, Nanhekhan LV, van der Hulst RR. J Plast Surg Hand Surg. 2012 Sep;46(3-4):159-62.

5- Self-esteem and patients' satisfaction after deep inferior epigastric perforator flap breast reconstruction.

Haekens CM, Enajat M, Keymeulen K, Van der Hulst RR. Plast Surg Nurs. 2011 Oct-Dec;31(4):160-6.

6- One-year cholesterol lowering treatment reduces medial temporal lobe atrophy and memory decline in stroke-free elderly with atrial fibrillation: evidence from a parallel group randomized trial.

Tendolkar I, Enajat M, Zwiers MP, van Wingen G, de Leeuw FE, van Kuilenburg J, Bouwels L, Pop G, PopPurceleanu M. Int J Geriatr Psychiatry. 2012 Jan;27(1):49-58.

7- The deep inferior epigastric artery perforator flap for autologous reconstruction of large partial mastectomy defects.

Enajat M, Rozen WM, Whitaker IS, Smit JM, Van Der Hulst RR, Acosta R. Microsurgery. 2011 Jan;31(1):12-7.

8- A clinical review of 9 years of free perforator flap breast reconstructions: an analysis of 675 flaps and the influence of new techniques on clinical practice. 
Acosta R, Smit JM, Audolfsson T, Darcy CM, Enajat M, Kildal M, Liss AG. J Reconstr Microsurg. 2011 Feb;27(2):91-8.

9- Introduction of the implantable Doppler system did not lead to an increased salvage rate of compromised flaps: a multivariate analysis.

Smit JM, Werker PM, Liss AG, Enajat M, de Bock GH, Audolfsson T, Acosta R. Plast Reconstr Surg. 2010 Jun;125(6):1710-7.

10- Aesthetic refinements and reoperative procedures following 370 consecutive DIEP and SIEA flap breast reconstructions: important considerations for patient consent.

Enajat M, Smit JM, Rozen WM, Hartman EH, Liss A, Kildal M, Audolfsson T, Acosta R. Aesthetic Plast Surg. 2010 Jun;34(3):306-12.

11- Postoperative monitoring of lower limb free flaps with the Cook-Swartz implantable Doppler probe: A clinical trial.

Rozen WM, Enajat M, Whitaker IS, Lindkvist U, Audolfsson T, Acosta R. Microsurgery. 2010 Jul:30(5):354-60.

12- A single center comparison of one versus two venous anastomoses in 564 consecutive DIEP flaps: investigating the effect on venous congestion and flap survival.

Enajat M, Rozen WM, Whitaker IS, Smit JM, Acosta R. Microsurgery. 2010;30(3):185-91.

13- Safety of the combination of intensive cholesterol-lowering therapy with oral anticoagulation medication in elderly patients with atrial fibrillation: a randomized, double-blind, placebo-controlled study.

Enajat M, Teerenstra S, van Kuilenburg JT, van Sorge-Greve AH, Albers-Akkers MT, Verheugt FW, Pop GA

Drugs Aging. 2009;26(7):585-93.

14- A dislocation of the carpal-metacarpal joints of the index, middle and ring finger.

Enajat M, de Boer L, Smit JM. Am J Emerg Med. 2009 Jun;27(5):630.e1-2.
15- How long are fasciocutaneous flaps dependant on their vascular pedicle: a unique case of SIEA flap survival.

Enajat M, Rozen WM, Whitaker IS, Audolfsson T, Acosta R. J Plast Reconstr Aesthet Surg. 2010 Apr;63(4):e347-50.

16- Perineal and posterior vaginal wall reconstruction with superior and inferior gluteal artery perforator flaps.

Wagstaff MJ, Rozen WM, Whitaker IS, Enajat M, Audolfsson T, Acosta R. Microsurgery. 2009;29(8):626-9.

17- Performing two DIEP flaps in a working day: an achievable and reproducible practice.

Acosta R, Enajat M, Rozen WM, Smit JM, Wagstaff MJ, Whitaker IS, Audolfsson T. J Plast Reconstr Aesthet Surg. 2010 Apr;63(4):648-54.

18- Thermal injuries in the insensate deep inferior epigastric artery perforator flap: case series and literature review on mechanisms of injury.

Enajat M, Rozen WM, Audolfsson T, Acosta R. Microsurgery. 2009;29(3):214-7.

\section{Upcoming publications}

19- Thromboprophylaxis and antithrombotic therapy in reconstructive microsurgery.

Chapter in upcoming book: Breast Reconstruction: Art, Science, And New Clinical Techniques. (Shiffman, MA) Enajat M, van der Hulst RR, Mureau MA.

20- Deep venous thrombosis and pulmonary embolism after breast reconstruction.

Chapter in upcoming book: Breast Reconstruction: Art, Science, And New Clinical Techniques. (Shiffman, MA) Enajat M, Mureau MA, van der Hulst RR. 
